\title{
COMMUNICATION LINKING TEAM MENTAL MODELS AND TEAM SITUATION AWARENESS IN THE OPERATING ROOM
}

\author{
A thesis submitted to \\ the Faculty of Graduate Studies and Research \\ in Partial Fulfillment of the requirements for the degree \\ Masters of Arts \\ by
}

Chelsea Kramer

Department of Psychology

Carleton University

September, 2009

(C)2009 Chelsea Kramer 


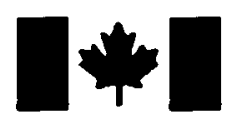

\section{Library and Archives}

Canada

Published Heritage

Branch

395 Wellington Street

Ottawa ON K1A ON4

Canada
Bibliothèque et

Archives Canada

Direction du

Patrimoine de l'édition

395, rue Wellington

Ottawa ON K1A ON4

Canada
Your file Votre refférence
ISBN: $978-0-494-58449-1$
Our file Notre référence
ISBN: $978-0-494-58449-1$
NOTICE:

The author has granted a nonexclusive license allowing Library and Archives Canada to reproduce, publish, archive, preserve, conserve, communicate to the public by telecommunication or on the Internet, loan, distribute and sell theses worldwide, for commercial or noncommercial purposes, in microform, paper, electronic and/or any other formats.

The author retains copyright ownership and moral rights in this thesis. Neither the thesis nor substantial extracts from it may be printed or otherwise reproduced without the author's permission.
AVIS:

L'auteur a accordé une licence non exclusive permettant à la Bibliothèque et Archives Canada de reproduire, publier, archiver, sauvegarder, conserver, transmettre au public par télécommunication ou par l'Internet, prêter, distribuer et vendre des thèses partout dans le monde, à des fins commerciales ou autres, sur support microforme, papier, électronique et/ou autres formats.

L'auteur conserve la propriété du droit d'auteur et des droits moraux qui protège cette thèse. $\mathrm{Ni}$ la thèse ni des extraits substantiels de celle-ci ne doivent être imprimés ou autrement reproduits sans son autorisation.
In compliance with the Canadian Privacy Act some supporting forms may have been removed from this thesis.

While these forms may be included in the document page count, their removal does not represent any loss of content from the thesis.
Conformément à la loi canadienne sur la protection de la vie privée, quelques formulaires secondaires ont été enlevés de cette thèse.

Bien que ces formulaires aient inclus dans la pagination, il n'y aura aucun contenu manquant.

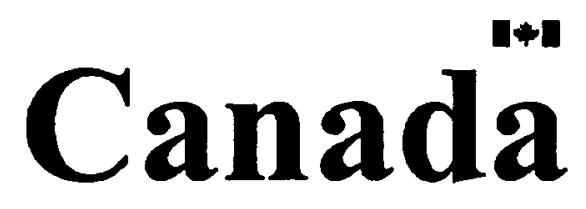




\begin{abstract}
Effective teamwork in the operating room requires congruent team mental models (TMM) and real-time team situation awareness (TSA). Effective communication is a critical process teams use to coordinate actions, adjust possible mental model gaps, and build and maintain TSA. The objective of this study was to explore whether gaps in TMM, due to differences among individual mental models, could be linked with communication patterns of team information sharing or confusion. The communication analysis revealed two major types of TSA indicators: building and maintaining TSA, and TSA breakdown. Maintained TSA was linked with shared TMMs, whereas TSA breakdown was primarily linked with gaps in the TMM (71\% of links), but also with shared TMM (29\% of links). The links identified between TMM similarities and gaps and TSA maintenance and breakdown reflect basic teamwork processes: interdependence, coordination, and communication effectiveness. Practical implications for OR teamwork, technology, and future research are discussed.
\end{abstract}




\section{Acknowledgements}

I would like to thank my supervisor, Dr. Avi Parush, for his continuous guidance and support. Under his supervision I have gained invaluable research and life experience, and I look forward to applying this knowledge throughout my upcoming career. I would also like to thank Seneca Brandigampola for his hard work and dedication during early morning data collection, and Tara Foster-Hunt for her earlier work in cardiac that helped guide this project. Furthermore, I would like to acknowledge the support of the OGSST scholarship and the generous support of The Ottawa Hospital, particularly Dr. Jim Worthington. I would also like to thank Dr. Kathryn Momtahan, Joanna Schubert, Bonnie Dove, and the whole thoracic team, as their dedication and interest in research made this entire study possible. Thank you to Dr. Gitte Lingaard and Dr. Alex Ramirez for serving on my committee and providing insightful and encouraging feedback. I especially would like to thank our graduate advisor Etelle Bourassa for always helping me with all of the important details needed to complete this process. Finally, I would like to thank my family and friends, who have been there for me throughout this journey, and whom I could not have done this without. 


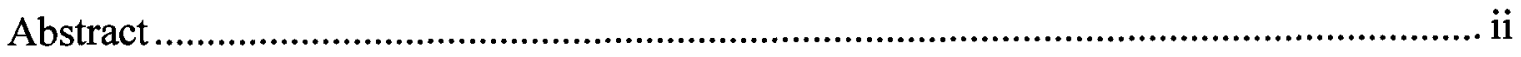

Acknowledgements ................................................................................................. ii

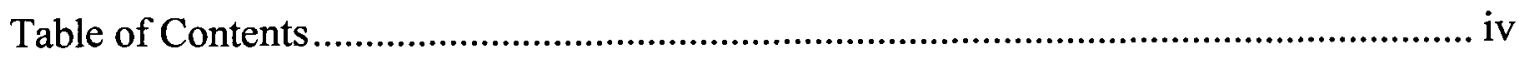

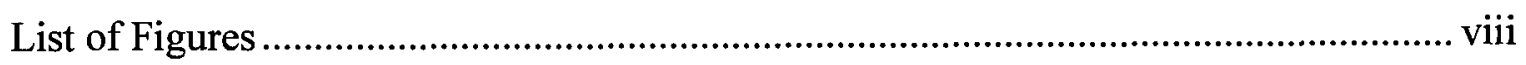

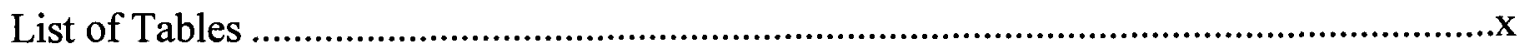

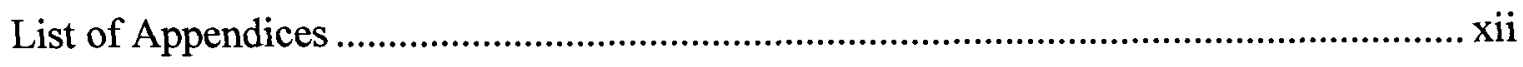

Understanding the Need ....................................................................................

Research Motivation ........................................................................................

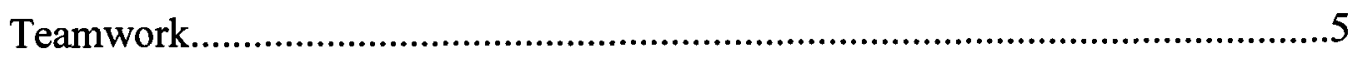

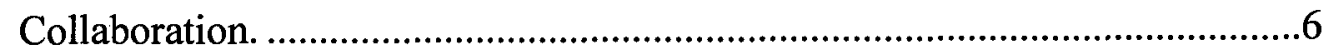

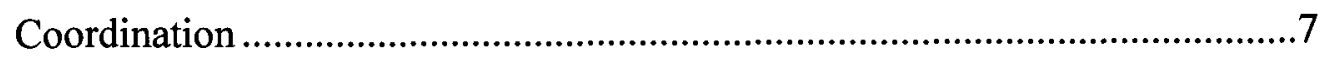

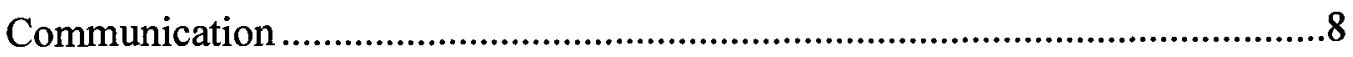

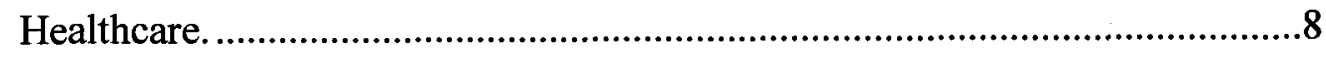

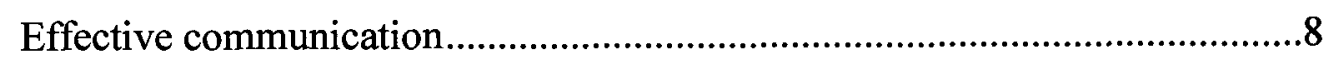

Breakdowns in communication .....................................................................10

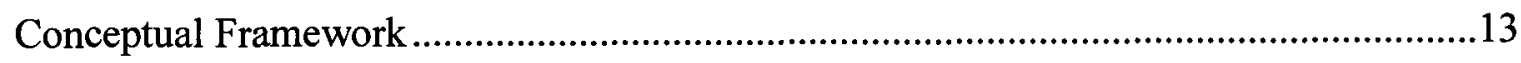

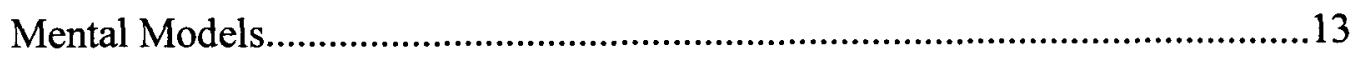

Shared Mental Models ...................................................................................14

Mental Models and Performance …………………........................................18

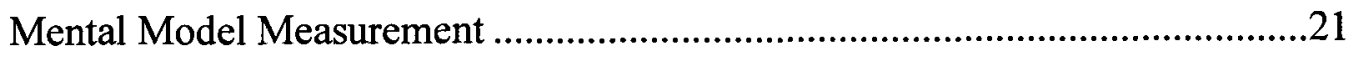

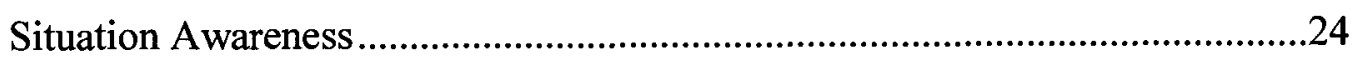

Mental Models as Basis for Situation Awareness ...............................................26 


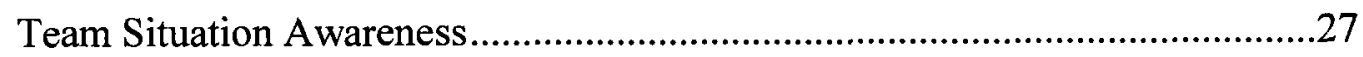

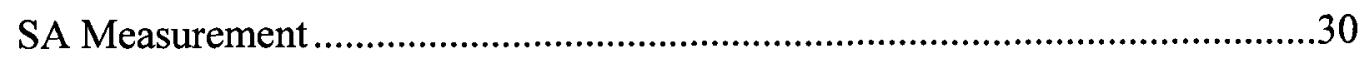

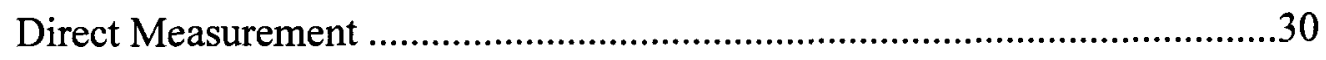

Inferred Measurement.....................................................................................

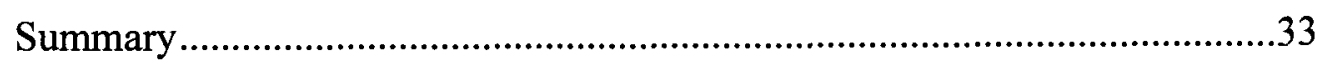

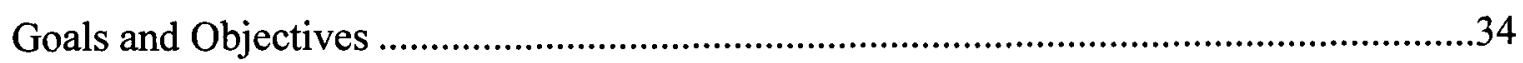

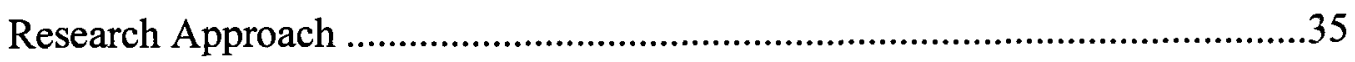

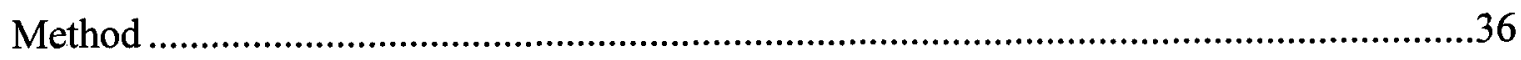

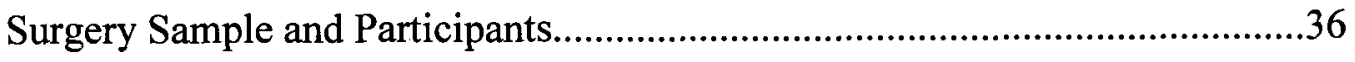

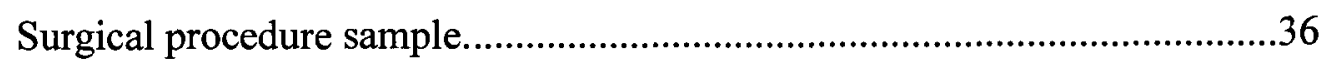

Healthcare workers sample..........................................................................

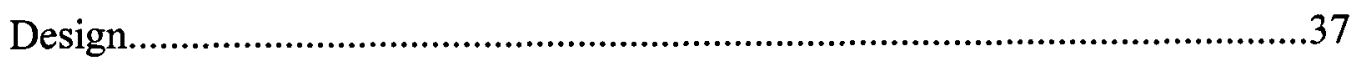

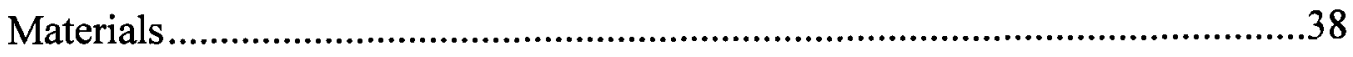

Fujitsu Lifebook USeries U820 ...................................................................38

Operating Room Management Attitudes Questionnaire. ..................................38

Procedure

Phase I: Preliminary Interviews .....................................................................

Phase II: Observations.......................................................................................4

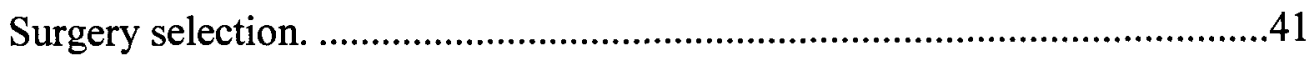

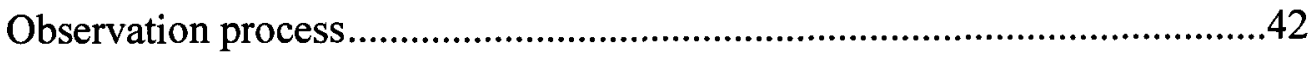

Phase III: Post-Observation Interviews.............................................................43

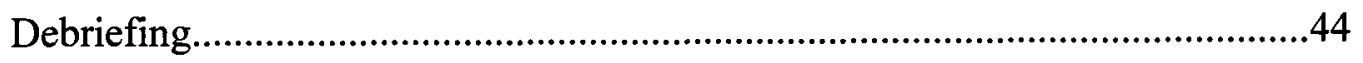

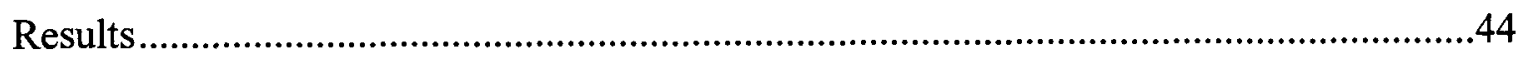




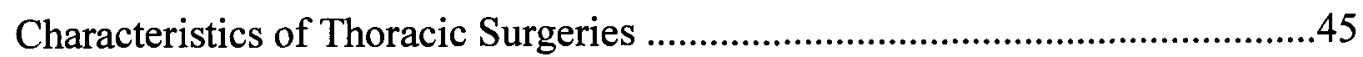

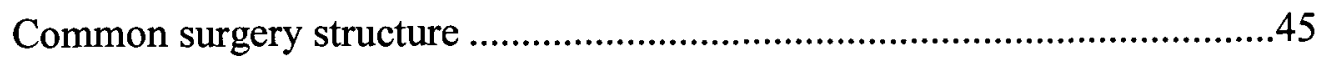

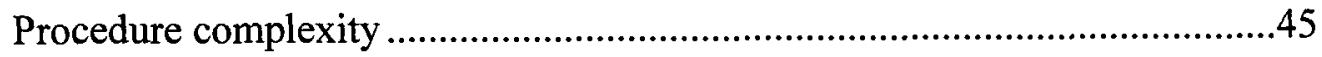

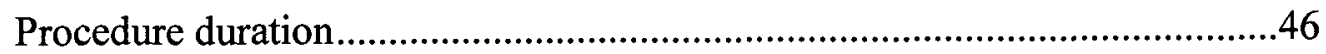

Characteristics of Communication ....................................................................47

Communication and procedure duration. .......................................................48

Communication distribution by phase. .........................................................48

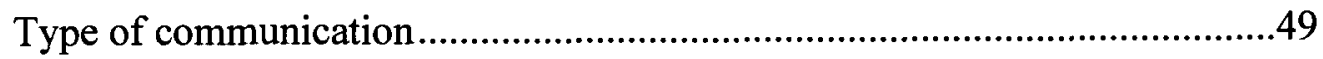

Content of communication. .........................................................................54

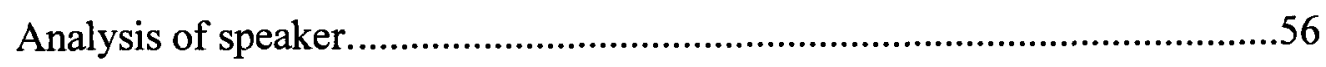

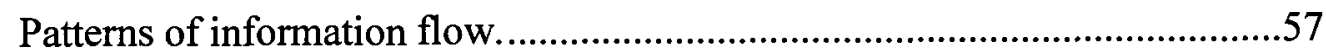

Interim summary of key findings. ................................................................59

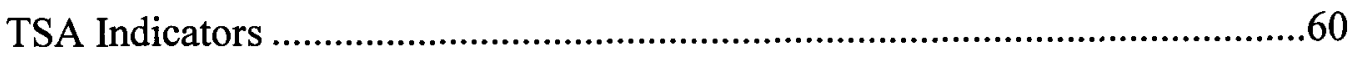

Information flow within TSA breakdowns......................................................64

Surgery-specific TSA categories. ..............................................................66

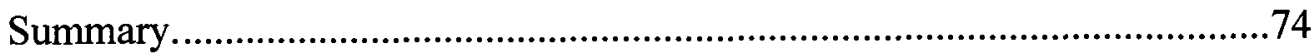

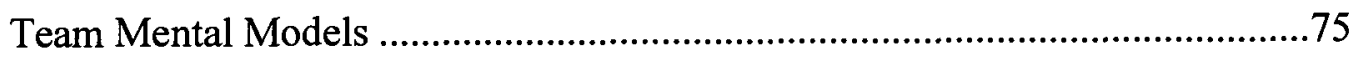

Gaps/similarities in team mental models ..........................................................78

Linking Mental Models to TSA ………………………...................................79

Problems with the pause ..............................................................................88

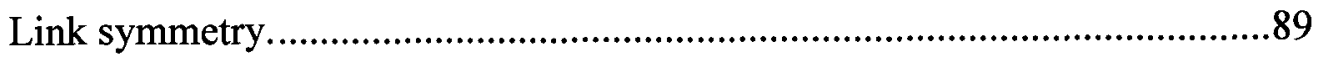

TMM-TSA links by content categories.........................................................90

Attitudes and perceptions of teamwork ............................................................91 
Summary of findings.

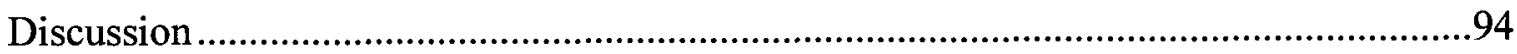

Overview of findings........................................................................................94

Distribution of communication...................................................................94

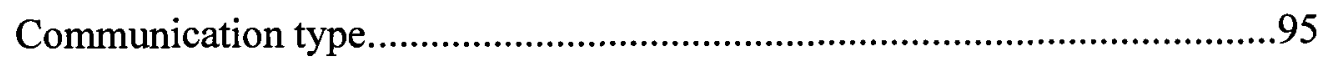

Communication content...............................................................................95

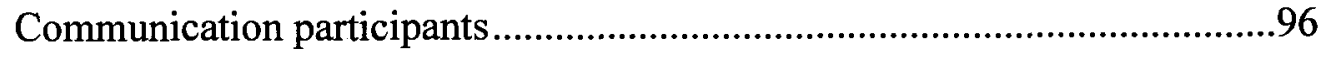

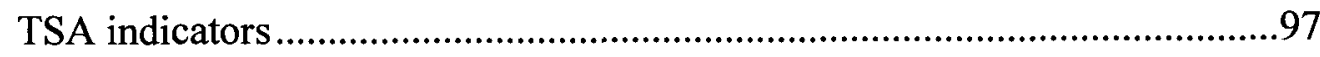

TSA content categories ...............................................................................98

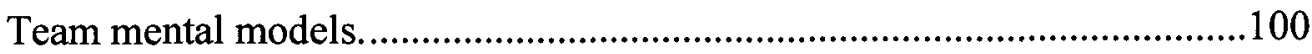

Linking TSA and TMM...........................................................................102

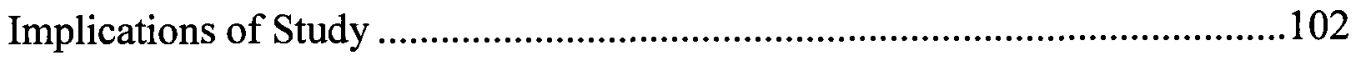

Theoretical implications. ...............................................................................102

Implications to Patient Safety......................................................................104

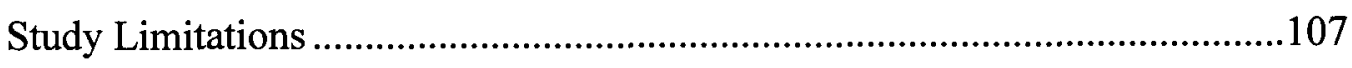

Implications for Future Research …………………………..............................109

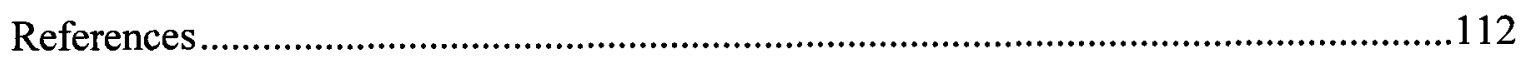

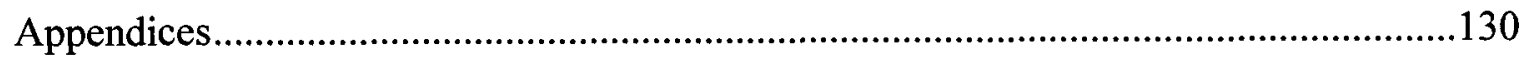




\section{List of Figures}

Figure 1. A schematic representation of the study phases. ........................................ 40

Figure 2. Complexity ratings of all the observed surgeries grouped into high and low

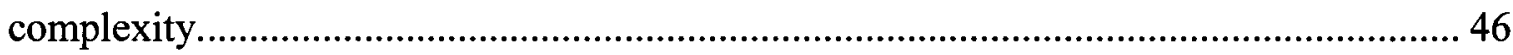

Figure 3. Mean durations of high and low complexity procedures. ............................. 47

Figure 4. Relationship between procedure duration and number of utterances............... 48

Figure 5. Proportion of communication utterances as function of phase for high and low complexity procedures.

Figure 6. Distribution of high level communication categories for high and low complexity procedures.

Figure 7. Proportion of communication types by sub-categories for high and low complexity procedures.

Figure 8. Distribution of communication by content category, for high and low complexity procedures. 55

Figure 9. Proportion of communication utterance as a function of speaker for high and low complexity procedures.

Figure 10. Sequential analysis diagram showing probabilities of information paths; left diagram - high complexity, right diagram - low complexity.

Figure 11. Proportion of total communication reflecting TSA maintenance and breakdowns within high and low complexity groups. 62 Figure 12. Proportion of utterances within total communication per phase for each type of TSA indicator, as a function of phase and case complexity. 63 
Figure 13. Communication type as a function of overall utterances within each type category

Figure 14. Link diagram illustrating probability of information flow involved in TSA indicators between members; left - TSA breakdowns, right - maintained TSA............... 66

Figure 15. Links as a function of Symmetry and TSA Indicator ...................................... 89

Figure 16. Number of identified links as a function of symmetry, content and TSA

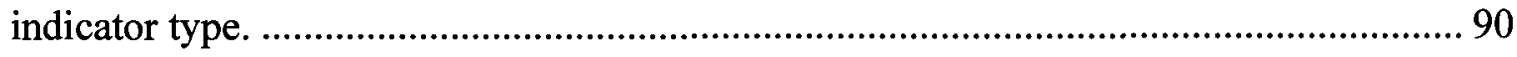

Figure 17. Mean ORMAQ scores for each category...................................................... 92 


\section{List of Tables}

Table 1: Communication Categories, Definitions, and Examples.......................50

Table 2: Content Categories and Examples of Coded Utterances........................54

Table 3: TSA Indicator Showing the Building and Maintaining of TSA..................61

Table 4: TSA Indicator Showing Breakdown in TSA .............................................61

Table 5: A General Template for Team Mental Model Matrix.......................................75

Table 6: TMM of Each TSA Content Category by Team and Task

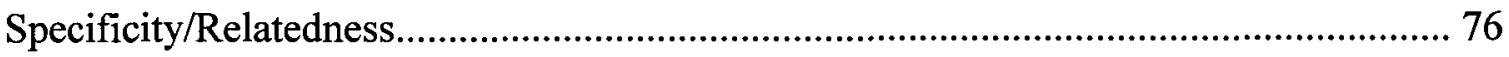

Table 7: Gap/Similarity Identification in TMM Concerning the Pause. ........................ 79

Table 8: Link Between TMM Gap and TSA Breakdown Regarding Lungs.....................80

Table 9: Link between TMM agreement and TSA maintenance regarding Lungs...........81

Table 10: Link Between TMM Agreement and TSA Breakdown Regarding Patient

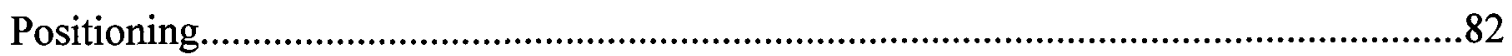

Table 11: Link Between TMM Agreement and TSA Built and Maintained Regarding

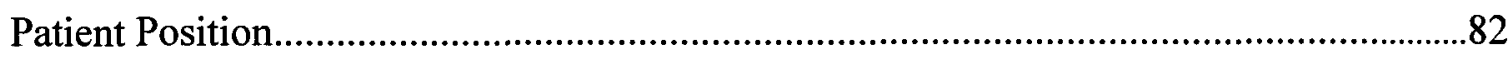

Table 12: Link Between TMM Gap and TSA Breakdown Regarding the Procedure.......83

Table 13: Link Between TMM Agreement and TSA Building and Maintaining Regarding

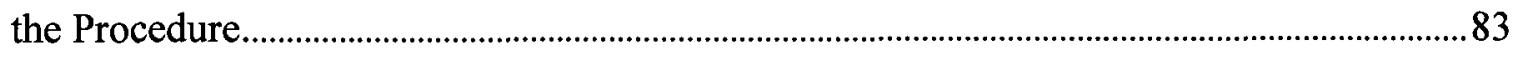

Table 14: Link Between TMM Gap and TSA Breakdown Regarding Scheduling...........84

Table 15: Link Between TMM Agreement and TSA Building and Maintaining Regarding

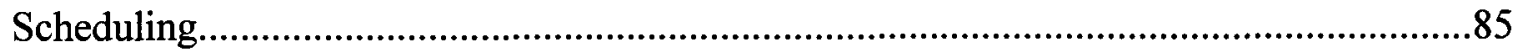

Table 16: Link Between TMM Gap and TSA Breakdown Regarding Equipment............86

Table 17: Link Between TMM Agreement and TSA Maintained Regarding Equipment.86 
Table 18: Link Between TMM Gap and TSAB breakdown Regarding the Pause.............87

Table 19: Link Between TMM Agreement and TSA Maintained Regarding the Pause...88 


\section{List of Appendices}

Appendix A: Questionnaire and Demographics ...................................130

Appendix B: Observed Thoracic Procedures …....................................136

Appendix C: Distribution of Communication Content as a Function of Phase ..........139

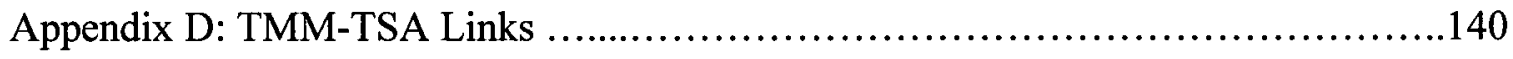

Appendix E: Participant Consent Form ….....................................155 
OR Team Communication, Mental Models, and Situation Awareness 1

Communication Linking Team Mental Models and Team Situation Awareness in the Operating Room

\section{Understanding the Need}

Patient safety is a global concern and a current nationwide challenge. From January 1995 to June 2009, the Joint Commission (2009) reported 4334 deaths, and 579 losses of function as a result of unexpected occurrences involving death or serious physical/psychological injury, known as adverse events (Reason, 1995). The landmark report, To Err Is Human: Building a Safer Health System, states that errors cause between 44,000 and 98,000 deaths, and over one million injuries every year in American hospitals (Kohn, Corrigan \&, Donaldson, 2000). The first national study in Canada to examine adverse events projected that hospitals experience up to 185,000 adverse events annually, including 70,000 instances of preventable error (Baker, Norton, Flintoft, et al, 2004). Preventable medical errors cost employers of those who experience adverse events as much as $\$ 1.5$ billion annually (Encinosa \& Hellinger, 2008). Nonetheless, adverse events are difficult to dissect because "even apparently single events or errors are due most often to the convergence of multiple contributing factors" (Kohn, Corrigan \&, Donaldson, 2000, p.49).

The spotlight on error and adverse events has helped recruit a broad array of stake-holders to advance research in patient safety (Leape \& Berwick, 2005). In 2001, the U.S. Congress allocated $\$ 50$ million annually for patient safety research to the Agency for Healthcare Research and Quality (AHRQ), the lead federal agency for health care safety (Stelfox, Palmisani, Scurlock, Orav, \& Bates, 2006). In 2002, the Canadian government budgeted $\$ 50$ million for the creation of the Canadian Patient Safety Institute 
(CPSI - Safer Healthcare Now, 2008). Initiatives resulting from this funding have supported hospitals and other healthcare facilities in developing standardized guidelines and procedures targeting patient safety.

A key initiative influencing this thesis is from the World Health Organization's (WHO) Safe Surgery Saves Lives, which advocates the effective minimization of unnecessary loss of life and serious complications. The guideline of primary interest to this thesis is how "the team will effectively communicate and exchange critical patient information for the safe conduct of the operation" (WHO -Safe surgery saves lives, 2008). Complex interactions and exchanges are couched in teamwork, making "linguistic communication...the choreography of team performance" (Weil, et al., n.d., p.2). However, communication issues are a frequent cause of inadvertent patient harm (Leonard, Graham, \& Bonacum, 2004), and are estimated to cause $70 \%$ of the adverse events cited by the Joint Commission (The Joint Commission - Sentinel Events, 2008b). The target of the following literature review and the main focus of this thesis are team communication and its implications for patient safety.

\section{Research Motivation}

Communication is considered a critical factor in various healthcare contexts, particularly in surgery contexts. Surgery involves an interdisciplinary group of healthcare professionals who use a variety of tools to complete the surgical procedure. In the operating room, poor communication among the surgeons, anesthesiologists, and nurses may lead to adverse events that can compromise patient safety (Awad et al., 2005). Communication is paramount to team performance, and teamwork in surgery is essential 
OR Team Communication, Mental Models, and Situation Awareness 3

to overall quality of care (e.g., Ellingson, 2002; Frankel, Gardner, Maynard, \& Kelly, 2007).

The significance of surgical communication to patient safety is demonstrated in a variety of studies. For example, over a series of 50 urology procedures, Undre, Sevdalis, Healey, Darzi, and Vincent (2007) found gaps in teamwork communication in surgical, anesthesia, and nursing sub-teams. Anesthetists and nurses obtained their lowest scores on communication and surgeons' teamwork behaviours appeared to deteriorate as the procedures were finishing. Similarly, in a review of 444 surgical malpractice claims, Greenberg et al. (2007) identified 60 cases involving 81communication breakdowns resulting in harm to patients. The majority of breakdowns was verbal communications (92\%) involving one transmitter and one receiver (64\%), and occurred in the preoperative (38\%), intraoperative (30\%), and postoperative periods $(32 \%)$.

The focus during surgery may be on a single patient, but each team member has individual activities, motivations, and concerns (Reddy, Dourish, \& Pratt, 2001). Contrasting stances within the surgical procedure is characterized in the literature as differences in mental models, and may contribute to communication breakdown. A certain level of mutual knowledge and common expectations, known as shared mental models, allow for more efficient collaboration (e.g., Rouse \& Morris, 1986). For example, the finely tuned mental models of Formula 1 pit stop teams allow for the seamless coordination in changing four tires and refuel in less than seven seconds (Catchpole et al., 2007). In general, research on mental models suggests that team members who hold common knowledge and expectations of a task should outperform teams who do not. 
OR Team Communication, Mental Models, and Situation Awareness 4

Part of the reason for collaborating and information sharing during surgery is to build and maintain current knowledge of the situation. Knowing what is going on in the environment in relation to the interdependencies within a team is known as Team Situation Awareness (TSA; e.g., Endsley, 1995, 2000). Individuals in the OR team need to share a common vision of the procedure, but no person can do the others' jobs. Individual's activities are largely interdependent, so the appropriate information must be shared at the right time to actively construct a shared and accurate picture of the situation. Research suggests that a team's ability to build and maintain TSA is related to effective team performance.

Shared mental models and TSA are presented here as important theoretical constructs of teamwork and safety. Due to their relatively intangible nature, this research attempts to infer these constructs by exploring communication as an inherent part of the process of interaction during teamwork. Taken together, there appears to be a link between shared mental models, team communication and team situation awareness. However, as will be shown in the following detailed literature review, there is not enough conclusive evidence on the nature and impact of that link.

The main purpose of this thesis is to study patterns of communication associated with teamwork processes in the operating room. The aim is to gain insight into the underlying relationship between team shared mental models and team situation awareness. While current knowledge can be updated moment by moment, mental models are relatively stable knowledge constructs that are built within individuals over time. Thus, at some point during the process of building TSA, teams will have to compensate for knowledge that is not implicitly shared, defined here as gaps within the team shared 
OR Team Communication, Mental Models, and Situation Awareness 5

mental model. The intent of this paper is to explore whether gaps, due to differences

among individual mental models, are associated with the sharing and seeking of

information among team members. In other words, communication may bridge the gap between mental models and the process of building TSA. This constant alignment of perceptions and expectation enables the team's goals to remain mutually understood and achievable.

\section{Background}

\section{Teamwork}

Teamwork is a necessary, yet often underappreciated skill needed in all domains of healthcare (Paris, Salas, \& Cannon-Bowers, 2000; West \& Field, 1995). Some might argue that little leadership or overt communication should be expected in routine procedures, however, adequate communication and leadership behaviours are certainly needed during a crisis (Undre, Sevdalis, Healey, Darzi, \& Vincent, 2006; 2007). Teamwork is not a natural product of working together (Undre et al., 2007); teamwork must be learned and practiced (Wallin, Meurling, Hedman, Hedegard, \& Felländer-Tsai, 2007). Although numerous processes are involved in teamwork, this section addresses a few that are within the scope of this thesis.

Teams are characterized largely by the need for interdependence; no one member can perform the team's tasks alone (Jentsch \& Bowers, 2005). Teams are most often defined as "a distinguishable set of two or more people who interact dynamically, interdependently, and adaptively toward a common and valued goal/object/mission, who have each been assigned specific roles or functions to perform, and who have a limited life span of membership" (Salas, Dickinson, Converse, \& Tannenbaum, 1992). This 
OR Team Communication, Mental Models, and Situation Awareness 6

division of labour enables teams to assume tasks too complex for any single individual. Nevertheless, complex tasks require substantial information exchange, making communication a distinguishing factor of effective teams (Mickan \& Rodger, 2005).

A summary of the literature suggests that collaboration and coordination are essential teamwork processes (e.g., Reddy \& Spence, 2008). Although the focus is on one patient, each team member has distinct roles, responsibilities and incentives that drive their respective actions and attentions (Reddy, Dourish, \& Pratt, 2001). Information exchange facilitates teamwork by enabling coordination of unique perspectives on the same information through interaction (Gorman, Cooke, \& Winner, 2006).

Collaboration. Collaboration is often used inconsistently or improperly in the literature and at times confused with cooperation or compromise (Henneman, Lee, \& Cohen, 1995). For the purpose of this thesis, collaboration can be viewed as the "joint communicating and decision-making process with the expressed goal of satisfying the patient's wellness and illness needs while respecting the unique qualities and abilities of each professional" (Coluccio \& Maguire 1983 as cited in Henneman, Lee, \& Cohen, 1995, p. 104).

Some level of collaboration between healthcare providers is necessary in any healthcare setting. No single discipline or specialty can meet all of a patient's needs (Ellingson, 2002). Collaboration involves coordination of individual actions, cooperation in planning and working together, and sharing of goals, planning, problem-solving, and decision-making (Baggs \& Schmitt, 1988). A hospitalized patient, for example, may need a physician to provide a diagnosis and treatment plan, nurses to administer medications, a dietitian to monitor food intake, a physical therapist to aid in muscle 
OR Team Communication, Mental Models, and Situation Awareness 7

strengthening and flexibility, and a social worker to coordinate home care following release (Ellingson, 2002). Distributed responsibilities allow the team to process massive amounts of patient information, thus reducing the cognitive load on individuals (Patel, Cytryn, Shortliffe, \& Safran, 2000). But without communication among all of these professionals, comprehensive and efficient treatment of the patient can be severely degraded.

Coordination. Coordination can be viewed as "the management of interdependencies among activities in terms of actors, goals, time, space, quality of products" (Bardam, 2000, p. 158). In other words, teams coordinate to ensure that the right things happen at the right time. A team's pattern of communication serves as a coordination device because it "enables... the sequencing of actions to accomplish tasks required by the work" (Hazlehurst, McMullen, \& Gorman, 2007). For example, the surgeon cannot operate until the patient is sedated; the anesthetist needs to administer a sedative and inform the surgeon when the patient is ready. Each member relies on knowledge of each other's activities, yet, surgical teams are often formed from a collection of individuals who do not regularly work together (Henderson, Mills, Hobbs Bleakely, Boyden, \& Walsh, 2007, p. 260). Prior to conducting a surgical procedure the team does not usually engage in any pre-briefing activity, often meeting for the first time 'over the body' (Henderson et al., 2007, p.260). Therefore, there is a need to exchange information among team members.

To summarize, the literature on teamwork emphasizes collaboration and coordination as key behaviours affecting team performance and patient outcome. When expectations differ and the situation becomes unclear, communication is certainly vital 
OR Team Communication, Mental Models, and Situation Awareness 8

for establishing teamwork. As such, it is important to understand more about what is meant by communication itself. The following sections deals with the specifics of communication which can be a reflection of the quality of teamwork and overall quality of care.

\section{Communication}

Healthcare. Communication in the healthcare context refers to the quality and the quantity of the information exchanged among members of the team (Undre et al., 2007). In healthcare, the word 'communication' covers a wide range of interactions, including interpersonal communication, communication technology, medical education, health policy, and mass communication (Lewis, 2002). It takes many forms, from a brief informal talk between colleagues to formalized written documents between professionals. The essence of verbal and written communication is the sharing of information. This paper acknowledges the existence and importance of all types of communication in healthcare, but for the purpose of this study, the scope is limited to verbal communication as a primary form of information sharing in healthcare (e.g., Beyea, 2004; Moss \& Xiao, 2004). Within this limited scope, the following section deals with aspects and implications of communication effectiveness.

Effective communication. Models of communication most commonly address dialogue between individuals (e.g. Clark \& Brennan, 1991) or team-based communications. Fitting with this paper's focus on OR teams, Blakar (1985) proposes five pre-conditions for effective team communication: a) Team members must have shared social reality within which the exchange of messages can take place, including a shared language base and perception; b) Team members must be able to "de-centre", that 
OR Team Communication, Mental Models, and Situation Awareness 9

is, to take the perspective of others into account in relation to both their affective and cognitive position; c) Team members must be motivated to communicate; d) There must be "negotiated and endorsed contracts of behaviour" (i.e., agreement among team members about how interactions take place); and finally e) the team must attribute communication difficulties appropriately, so if one of the other preconditions is not being met, the team is able to correctly identify the problem and develop a solution.

Blakar's communication model captures the two main themes of this thesis: shared mental models and Team Situation Awareness (TSA). Blakar proposes that effective communication requires a shared social reality - including shared language base and perception - which includes some cognitive factors associated with mental models. Furthermore, being able to de-centre and take the perspective of others along with familiarity with other team members' roles are crucial for constructing TSA. Consequently, by identifying problems and developing solutions, the team is building a current awareness of the situation and taking actions to maintain it.

In addition to the prerequisites needed for communication, it is also important to consider what is said. Schramm's (1954) simple model of communication describes the initiation of effective communication when the sender encodes a message for transmission, which then requires decoding by the receiver before reception is complete. An effective closed-loop communication is said to occur when a) sender initiates message, $b$ ) receiver accepts message and provides feedback that it was received, and c) sender double checks to ensure that message was received as intended. On the contrary, open-loops are communications that lack feedback about messages received or comprehended, such as an unanswered question. 
OR Team Communication, Mental Models, and Situation Awareness 10

Based on Schramm's (1954) model, effective communication in the OR can be viewed as the complete transfer of information from one team member to another (Parush, Momtahan, Foster-Hunt, Kramer, Holm, Nathan, 2008). In a study of 16 minute-by-minute surgery observations, Parush et al. (2008) characterized the spectrum of communication quality in the operating room using four parameters: a) closure type (closed vs. open), b) closure timing (immediate vs. delayed) of the communication loop, c) number of participating agents (two-agent vs. multi-agent), and d) directedness of the loop (directed towards a specific agent vs. not directed towards anyone in particular or a broadcast). The most effective communications are therefore closed, immediate, involve two-agents, and are directed towards a specific person. For the purpose of this thesis, effective communication will use the categories described by Parush et al. (2008).

To summarize, effective communication involves both physical and cognitive processes. It can mitigate interruptions and act as a buffer against failures by facilitating a common awareness of intentions and actions of others, which in turn enables collaboration of coordinated actions (Orasanu, 1994). In contrast to effective communication, communication errors are the most common cause of adverse events and wrong-site operations in the United States (Makary, et al., 2006). When the requirements of effective communication are not met, communication breakdown increases susceptibility to errors within teamwork.

Breakdowns in communication. In critical care, the complexity of performing even routine tasks is increased by the constraints of time, insufficient or unavailable information, stress, and by frequent and unpredictable interruptions (Alvarez \& Coiera, 2005). As surgical environments are characterized by contingencies and evolving 
OR Team Communication, Mental Models, and Situation Awareness 11 circumstances (Ash, Berg, \& Coiera, 2004), accurate information transfer among people and technology is essential to effectively coordinate separate but interdependent activities as part of the teamwork process (Reddy, Pratt, Dourish \& Shabot, 2003).

Although interruptions are important to update awareness of the continuously changing work environment, inappropriate management of interruptions can be detrimental to performance. A physician whose attention is constantly shifting and who needs to mentally integrate data from disparate displays as well as other members of the operating team may not be able to formulate a complete and coherent picture of the current state of systems. As a result, information shared among team members may be incomplete -or worse, inaccurate- and consequently lead to degradation in teamwork and quality of care.

Communication breakdowns are demonstrated in a range of studies. During a series of observations in operating rooms, Helmreich and Davies (1996) observed breakdowns in communication that resulted in loss of awareness of the patient's condition, distractions that resulted in failure to note adverse changes in patient status, and disputes between members of anesthesia and surgical teams. In another study of OR observations, Lingard, Espin, Whyte, et al. (2004) classified roughly $30 \%$ of the overall 421 communication events as failures. Failures were defined as communication events flawed in at least one of the following dimensions: content, audience, purpose, or occasion of communication exchange. Communication failures exhibited a common set of problems: timing is too late to be effective, content is not consistently complete and accurate, key individuals are excluded, and issues are left unresolved until the point of urgency. 
OR Team Communication, Mental Models, and Situation Awareness 12

In a related study, Parush et al. (2008) noted 158 instances of communication breakdowns over a series of ten cardiac surgeries. Analysis of 461 human face-to-face information exchanges revealed that $34.3 \%$ were problematic, or open looped communications, where the receiver did not acknowledge the message sent. Within the open loops, $30 \%$ of messages were directed to a specific individual who did not respond, and $4 \%$ of the time the message was simply broadcast to the room with no response. Unacknowledged messages are a chance for information loss or misunderstanding. Communication itself has been investigated as a potential distraction in the OR. Sevdalis, Healey, and Vincent (2007) found that irrelevant comments and queries (i.e., 'small-talk') accounted for half of the observed Case-Irrelevant Communications (CICs). Suggestive of hierarchical team structures, the CICs addressed to surgeons introduced significantly less distraction to the operating theatre than those addressed to anesthetists and nurses. While it seems logical that irrelevant communication is distracting, standard surgical practices can also be disruptive. Over the course of 10 complex general surgery cases, Christian et al. (2006) identified recurring factors that either contributed to or mitigated the overall effect on the patient's outcome. Ironically, the counting protocol - a mandatory safety procedure in which all tools and materials are manually counted before and after surgery- was found to significantly compromise case progression and patient safety.

Taken together, the literature on ineffective information flow indicates that communication breakdowns are not uncommon occurrences in the OR. Breakdowns can occur for a variety of reasons, notably by interruptions, which can lead to incomplete information transfer as in open-loops where, for example, a query is not answered and 
information is potentially lost. Breakdowns are also susceptible to the manner in which an intended message is delivered. Finally, effective communication includes cognitive factors associated with mental models such as common language, perceptions and expectations. In view of this connection, mental models are an important part of the conceptual framework for this thesis when studying shared mental models and team situation awareness.

\section{Conceptual Framework}

\section{Mental Models}

The concept of mental models suggests in general that similar mental models can facilitate effective communication and teamwork (e.g., O`Conner \& Johnson, 2006) because verbal communication is more meaningful when the words used have a known and common context or framework (Lewis, 2002). Thus, mental models can provide a contextual framework to guide the proposed communication exploration. Accordingly, the research question is whether the quality and type of communication exchanged in teams can be a reflection of similarities in shared mental models. In order to better address this question, the following section reviews mental models as a theoretical construct.

When people interact with systems, simple as well as complex, they develop a subjective internal representation of the system and of their role in the environment in which they operate (Rouse \& Morris, 1986; Sarter, Nadine \& Woods, 1991; Sasse, 1991; Sinreich, Gopher, Ben-Barak, Marmor, \& Lahat, 2005). A mental model is a combination of the individual's subjective perceptions, concepts, ideas and perceived system status (Sinreich, et al., 2005). Rouse and Morris (1986) describe mental models as 
organized knowledge structures that allow individuals to interact with their environment. They allow people to predict and explain the behavior of the world around them, to recognize and remember relationships among components of the environment, and to construct expectations for what is likely to occur next (Rasmussen, 1979; Rouse \& Morris, 1986).

\section{Shared Mental Models}

People can have unique mental models about information that is specific to them, or shared mental models of common situations that include others. A shared mental model is naturally constructed through team cognitive processes, and can be understood as individual mental models amalgamated through team interactions (Gutwin \& Greenberg, 2004). This interaction results in shared knowledge that is represented as a shared mental model (SMM; Rentsch \& Hall, 1994). Shared mental models allow individuals to work together (Stout, Cannon-Bowers, \& Salas, 1996). Just as two people performing a duet on the piano, team members in the operating room ...cannot even begin to coordinate... without assuming a vast amount of shared information or common ground- that is, mutual knowledge, mutual beliefs, and mutual assumptions. And to coordinate on process, they need to update their common ground moment by moment. All collective actions are built on common ground and its accumulation (Clark \& Brennan, 1991, p.127).

The shared mental model in teams is thought to provide team members with valuable information during team processes that further allows for performance predictability and adaptability (Cannon-Bowers \& Salas, 2001). Teams that have a shared mental model can work more smoothly to respond and adapt to the needs of the team. 
OR Team Communication, Mental Models, and Situation Awareness 15

Shared mental models help team members coordinate multiple perspectives for the effective solutions to given problems. However, not all knowledge possessed by each team member needs to be shared with the other members in order to improve team performance (Cannon-Bowers, Tannenbaum, Salas \& Volpe, 1995).

While the term shared is not standardized, a review of the literature (e.g. CannonBowers \& Salas, 2001; Cannon-Bowers et al, 1993; Langan-Fox, Anglim \& Wilson, 2004; Lim \& Klein, 2006) suggests that there is probably not a single mental model that must be shared among team members, but that there are most likely multiple mental models co-existing among team members at a given point in time, especially when carrying out complex tasks. Trends in recent research suggest that mental models can be similar, overlapping, or compatible:

1. Similar mental models refer to common, if not identical, knowledge between members. This level of commonality applies most directly to mutual attitudes and beliefs in order to draw common interpretations. Edwards and Wilson (2004) describe a team with similar mental models as a 'Kung-Fu army', in which skills are well known, understood and recognized as interchangeable, such as in manufacturing product line teams. Too much similarity between mental models, however, can lead to 'group think' (Janis, 1972) in which the desire to maintain team cohesion is awarded priority over the decision-making process and the evaluation of divergent view-points becomes neglected (Cannon-Bowers et al., 1993).

2. Overlapping mental models refer to some common knowledge between members, but this does not mean that members need fully redundant knowledge. Edwards and Wilson (2004) would attribute overlapping mental models to a 'Total Football' team, 
OR Team Communication, Mental Models, and Situation Awareness 16

where members have their own roles and positions, but can interchange at times. A physician and a nurse, for example, have different roles, but each could administer a needle to a patient if needed.

3. Compatible mental models may not need to have shared or similar knowledge, but the knowledge must lead members to draw similar expectations for performance. Not to say that shared or similar knowledge will not lead to similar expectations, but only that it may not be necessary. Teams with specialized roles- compatible but different knowledge, may be what is crucial to task performance. This team concept is described by Edwards and Wilson (2004) as 'Guns of Navarone' and skills are rarely interchangeable. A multidisciplinary healthcare team (e.g., doctors, psychologists and physiotherapists) has members with distinct knowledge but are treating the same patient to achieve overall health. In any given team, such as a surgical one, some knowledge will have to be shared, other knowledge similar, and yet other knowledge compatible. The combinations of all individual mental models interact synergistically to form the team mental model.

The view that effective teams have shared knowledge within shared mental models in the sense of common or similar knowledge may be overly simplistic. There may be some overlap in knowledge required among team members, but compatible rolespecific knowledge is also required. This is known in the literature as team heterogeneity, in which different team members are assigned different roles (e.g., a multidisciplinary healthcare team), and is a well-accepted definition of teams. In contrast, team homogeneity describes teams where every member has the same knowledge, same roles and same responsibilities (e.g., a team of cardiac surgeons). Heterogeneous teams and 
homogeneous team differ in the degree of sharedness that is needed among members, that is, the amount and type of mutually known information.

Within the span of knowledge held by individuals within a team, two primary shared mental models are crucial to team performance: the team-related shared mental model (Team-SMM) and the task related shared mental model (Task-SMM; Mathieu et al., 2000). The Team-SMM includes an understanding of team interactions, and teammates' knowledge skills, abilities, beliefs, preferences, and tendencies; the TaskSMM includes knowledge of typical task strategies, procedures and team-environment (Cannon-Bowers, Tannenbaum, Salas, \& Volpe, 1995; Mathieu et al., 2000). Extending Task- and Team-SMM, Cannon-Bowers and Salas (2001) account for differing levels of sharedness in team and task knowledge by parsing mental models into physical and procedural aspects of the work environment, as well as aspects related specifically to the team members:

1. Task-specific knowledge allows team members to take action in a coordinated manner without need to communicate overtly. Members act on knowledge that each hold without the need to discuss it, leading members to have compatible expectations for performance. The nature of knowledge is highly task-specific, involving specific procedure, sequences, actions and strategies necessary to perform a task and can only be generalized to other instances of similar tasks.

2. Task-related knowledge is common knowledge that is relevant to a variety of tasks but not necessarily to a single task. For example, during surgery, the common understanding not to interrupt the surgeon while operating can transfer to any surgery. 
3. Team-specific knowledge relates to members' knowledge of each other (e.g., transactive memory; Wegner, 1986) team members need to understand each other; preferences, strengths, weaknesses, tendencies. For example, a team member may not know a piece of information, but is aware of who knows it and thus can easily acquire this information. Knowledge in this case holds primarily when the team membership remains constant.

4. Team-related knowledge is information about a team's structure in general, and can be generalized across teams. For example, knowledge that cardiac surgery is usually composed of surgeons, anesthetists, perfusionists and nurses, and this could apply to any cardiac surgery team.

Team shared mental models consist of varying degrees of overlapping team and tasks based knowledge possessed by each person. Of primary interest to the study is the hypothesized relation between shared mental models and team performance - that performance can be better understood and predicted by measuring and understanding shared mental models (Evans, Harper \& Jentsch, 2004; Rentsh \& Klimoski, 2001).

\section{Mental Models and Performance}

Teams that must adapt quickly to changing task demands might be drawing on shared mental models (Cannon-Bowers, Salas, \& Converse, 1993). In contrast, widely different mental models suggest that team members work toward different objectives and predict different future system states, and therefore have difficulty coordinating their efforts. Highly shared mental models suggest that team members work towards common objectives and have a shared vision of how their team will function (Kraiger \& Wenzel, 1997). 
Taken together, the mental model literature suggests several potential implications of the Shared Mental Model Construct. As synthesized by Langan-Fox et al (2004), SMM are said to make communication and coordination more efficient by requiring less communication between individuals for the same result (i.e., by using a common language; Langan-Fox, Code, \& Langfield-Smith, 2000; Langan-Fox, 2001). For instance, in a flight simulator study, both shared team and task-based mental models related positively to subsequent team process and performance (Mathieu, Heffner, Goodwin, Salas, \& Cannon-Bowers, 2000). Team processes (e.g., communication, leadership, conflict etc.) fully mediated the relationship between mental model convergence and team effectiveness, meaning team communication was an overriding factor in terms mental model similarity and performance.

SMMs speed up mutual team member learning and improve allocation of tasks and decision control through awareness of team member strengths and weaknesses (Langan-Fox, 2001) For example, SMM had a positive effect on team coordination and prior familiarity with the same software parts and reduced project development time (Espinosa, Kraut, Slaughter, Lerch, Herbsleb, Mockus, 2002). Finally, SMMs assist in the efficient use of time and planning for action by enabling team members to better predict what will be required and how they should interact with the team (Klimoski \& Mohammed, 1994; Langan-Fox, 2003; Mohrman, 1993). In a field study of military action teams, Lim and Klein (2006) found that similarity in mental models of task and teamwork as well as model accuracy predicted team performance.

While it may seem plausible that those who think alike should work better together, other mixed results are less supportive of this. Mathieu, Heffner, Goodwin, 
Cannon-Bowers, Salas and Eduardo (2004) failed to find evidence that shared team mental models improved team performance. Team processes (e.g., communication) partially mediated the relationship between task mental model sharedness and team performance in flight simulations. However, mental model sharedness did not exhibit a significant linear relationship with team processes or performance. Team processes and performance were better among teams sharing higher-quality (i.e., more accurate) team mental models than among teams evidencing less sharedness or who had lower-quality models.

A possible explanation for these inconclusive findings might be that under conditions that allow team members to freely communicate and strategize, shared mental models will not be very important (Stout, Cannon-Bowers, \& Salas, 1996). This is because the team can discuss its next move without having to rely on existing knowledge. However, in conditions where communication is difficult - due to excessive workload, time pressure, or other environmental features, teams are not able to engage in necessary strategizing (Stout et al., 1996). In such contexts, having an SMM becomes crucial to team functioning because it allows members to predict the information and resource requirements of their teammates.

From a human factors perspective, mental models are simulations that are run to produce qualitative and quantitative inferences, underpin our understanding of a system, and allow us to describe, predict, and explain behavior of a system (Langan-Fox, Anglim, \& Wilson, 2004). The mental model is usually a simplification of reality, which is achieved by decomposing the system in terms of an abstraction of hierarchies that facilitate different levels of reasoning (Rasmussen 1986; Moray 1990). They are 
OR Team Communication, Mental Models, and Situation Awareness 21

instantiated each time they are required and therefore vary over time both in terms of memory degradation and refinement through learning. However, the "eminently reasonable even seductive notion" of a mental model does present us with measurement challenges. These challenges have to do with how to represent a phenomenon that is often characterized as having an incomplete, multiple, and inconsistent structure (Langan-Fox et al., 2004, p.334). The next section addresses this challenging issue of measuring mental models.

\section{Mental Model Measurement}

There is confusion over how to measure cognitive structures such as SMM at the group level. Similarity ratings, Likert scale questionnaires, and concept mapping (e.g., Pathfinder) are reportedly the most popular methods of measurement (Mohammed \& Dumville, 2001). However, there appears to be no one preferred technique; researchers must justify their choice of measurement after carefully considering the research question and team context (Mohammed et al., 2000). As such, multiple measures are necessary for a thorough assessment, emphasizing the need to clearly articulate the particular content domain being considered and the sharing perspective hypothesized (Kraiger \& Wenzel, 1997).

Measurement is further complicated by the difficulty in analyzing mental model similarity and overlap at the team level (Klimoski \& Mohammed, 1994). While a number of techniques have been developed to measure mental model similarity between two people, the development of techniques to elicit and represent team SMM has been slow (Converse et al., 1991). The challenge is how to measure these mental models in a way that comparisons could be made to other team members and then to other teams (Lee, 
OR Team Communication, Mental Models, and Situation Awareness 22

2007). Since mental models cannot be observed directly, indirect methods have been developed to elicit and capture them (Cooke, Kiekel, Salas, Stout, Bowers, \& CannonBowers, 2003).

Two primary approaches to measure team knowledge can be found in the literature. The collective approach to measuring team knowledge involves a collection or sum of individual knowledge. On the other hand, holistic approach incorporates the interactions among members in addition to individual knowledge (Klimoski \& Mohammed, 1994). The holistic approach focuses on team knowledge that results from the application of team processes, such as communication, situation assessment and coordination. Among the many available methods, this thesis focuses on holistic knowledge elicitation as a way to infer mental models. Cooke, Salas, Cannon-Bowers and Stout (2000), and Klimoski and Mohammed (1994) provide a thorough review on mental models measurements, but here is a brief summary of knowledge measurement approaches described in those reviews.

Interviews and surveys are a common approach to measure team knowledge due to their independence of task performance (Cooke, Kiekel, \& Helm, 2001). They are used for gaining a general understanding of the situation and generating hypotheses (Cooke et al., 2000). Interviews can be structured or free form. Structured interviews take more time to prepare and may be more rigid but may be easier and quicker to administer. Unstructured interviews are free-form where content and sequencing are not specified. Another approach to elicit team knowledge is called process tracing, which involves collecting data at the same time as individuals are performing the task or retrospectively (i.e., tracing the process; Cooke, et al., 2000). Post-analysis of the data 
allows the researcher to make inferences about team knowledge and task performance. A popular form of process tracing involves verbal reports, where the participant "thinks aloud" during performance. Within process tracing, protocol analysis is the method used to summarize and interpret the data collected. Protocol analysis involves transcribing recorded data, such as speech, developing a coding scheme which captures the critical content, applying the coding scheme to each indentified unit in the protocol, and exploring the frequencies, patterns and sequential dependencies in the results (Cooke et al., 2000).

Upon completion of process tracing, conceptual methods can be used to produce representations of domain concepts and their relations. In general, the methods take pairwise estimates of relatedness for a set of concepts and generate a spatial or graphical representation of the concepts and their relation. Langan-Fox ,Code, and Langfield-Smith (2000) list the following eight common conceptual method techniques: Cognitive Interviewing Techniques, Verbal Protocol Analysis, Content Analysis, Visual Card Sorting Techniques, Repertory Grid Technique, Causal Mapping, Pair-wise Rating Methods, and Ordered Tree Technique. One limitation of such techniques is in comparing more than two mental models at once, or where more than two mental models can be compared, make assumptions about uniformity or normality which might otherwise be considered inappropriate.

Thus far, this paper has discussed communication in the OR as a critical element for teamwork, patient safety and quality of care. SMM facilitate effective teamwork by aligning mutual expectations, perceptions and goals. The benefits of effective communication in mitigating interruptions were highlighted, as well as the potential 
OR Team Communication, Mental Models, and Situation Awareness 24

dangers of poor communication, such as information loss. The following section will illustrate how communication serves as a tool to build and maintain awareness of environment and particularly Team Situation Awareness (TSA).

\section{Situation Awareness}

Situation Awareness (SA) is a concept first recognized in aviation and later became popular in social sciences during the 1980's (Endsley, 1988; 2000, p. 2). Despite SAs rising popularity, its use is most often based on an intuitive, not necessarily appropriate, understanding (Salmon, Stanton, Jenkins et al., 2007; Sarter \& Woods, 1991). SA is parsed by situation and awareness, although the concept of the situation itself is often overlooked in the literature. The situation can be viewed as. "...a set of environmental conditions and system states with which the participant is interacting that can be characterized uniquely by a set of information, knowledge and response options" (Pew, 2000, p.34). Pew (2000) proposes that SA should integrate five aspects of the situation: a) the surrounding environment, b) the mission's goals, c) the system, d) the physical and human resources, and e) the crew. Awareness of these five aspects of the situation is what can be considered to lead to the concept of SA.

While the most straight forward explanation of SA is "knowing what is going on around you", a recurrently cited definition is "the perception of the elements in the environment, within a volume of time and space, the comprehension of their meaning and the projection of their status in the near future" (Endsley, 1988; 1995a; 1995b). Another definition describes SA as a process of "combining of new information with existing knowledge in working memory and the development of a composite picture of the situation along with projections of future status and subsequent decisions as to 
appropriate course of action to take" (Fracker, 1991). Although Endsley's SA seems ubiquitous in the literature, the latter definition better incorporates the concept of mental models as a prerequisite to achieving SA.

Endlsey (2000) states that although the specific elements of SA may differ among occupations, the way in which these elements are extracted from the environment can be generalized across a wide variety of domains. Research adopting Endley's definition needs to operationally define information requirements used for specific needs and goals. For example, Endsley and Bolstad (1994) note that a tremendous amount of emphasis is placed on the necessity for aircrew members to have high SA, however, the pilot does not need to know every piece of information about the environment (e.g., the co-pilot's children's names), but does need to know an array of details concerned with the actual flying and safety of the plane (Endlsey, 2000, p.2). In dynamic environments such as the flight deck, minor deviations or failures that are not critical in themselves may evolve or interact over time to become a major threat. It is therefore essential for the pilot to observe, integrate, and remember these events (Sarter \& Woods, 1991). This continuous awareness requires the diagnosis of problems that are caused or influenced by precursors in the past, as well as the prognosis and prevention of potential future problems based on the analysis of currently available data.

SA is primarily concerned with the information needs of individuals in order for them to make accurate predictions and decisions (Smith \& Hancock, 1995). However, situation awareness may not always be consistent among group members in a shared environment. For example, Guerlain et al. (2005) identified considerable variation in situational awareness by participants in an operative case. The study observed that only a 
few members of the operating team, typically the attending surgeon, held key information. For instance, given the question of whether an ultrasound was indicated for the patient in a case, respondents noted that this was "a surgical, not an anesthesia problem" or that they "would have to ask surgeon." The authors suggest that these gaps in SA are an underappreciated source of operative adverse events. This problem is complicated by the very nature of the dynamic operative environment, where shift changes and circulating roles permits students, nurses, and sometimes even residents, to be present during only portions of an operative case.

Mental Models as Basis for Situation Awareness

Given these descriptions, the distinction between situation awareness and the concept of mental models seems blurred. Mogford (1997) calls attention to the possible lack of distinction by comparing Endley's perception, comprehension and projection model of SA to the mental models proposed earlier by Rouse and Morris (1986, p. 360) as mechanisms that allow humans to "describe, explain, and predict behavior". Even within Endley's (1988; 1994) definition, mental models and SA are interwoven to a point of near inseparability by the introduction of "SA, a person's mental model of the world" (Endsley \& Bolstad, 1994).

It might be useful to constrain the concept of SA to that which is implied in the term (i.e., the contents of awareness about a situation at any given moment). These contents might be data, meanings, or predictions, but they are not the same as the mechanisms that help generate this information. In Air Traffic Control, for example, the mental model is the underlying knowledge that is the basis for SA, or the picture. The 
controller's picture is defined by the mental model and, in turn, supplies information to build and modify it (Sarter \& Woods, 1991).

Sarter and Woods (1991) propose that the first difference between situation awareness and mental models lies in their point of reference. Mental models refer to systems or devices that can be represented by "a finite number of elements and algorithms", whereas situation awareness is about a "continuously changing open system involving a large variety of unpredictable and interacting agents and devices" (Sarter \& Woods, 1991). Mental models may be seen as a basis for adequate situation assessments which, in turn, result in related knowledge that may eventually become part of the situation awareness. In other words, adequate mental models are one of the prerequisites for achieving situation awareness.

If mental models are the basis for SA, and SA can in turn influence the construction of the mental models, what happens when multiple people must be considered? The concern of other individuals in addition to each person's perceptions of the environment is a defining factor of teams and teamwork processes, particularly in the OR.

\section{Team Situation Awareness}

In the OR, work consists of both individual and team activities. Thus, it is necessary to consider the SA of not just individual team members, but also the SA of the team as a whole. When considering SA in multiple individuals, a further layer of complexity is added with teams (Kaber \& Endsley, 1998). People need to act reciprocally with both other team members and the shared environment (Stanton, Stewart, Harris et al., 2006). TSA is more than the sum of individual SAs. TSA is beyond the scope of 
OR Team Communication, Mental Models, and Situation Awareness 28

adding up the operator's private awareness, and is predicated on interaction (Garbis \& Artman, 2004). For instance, when backing out of a parking garage it is convenient when the passenger notices that the driver is unknowingly approaching a large cement pole, but only to the extent the passenger communicates this fact (Gutwin \& Greenberg, 1996). Effective TSA does not depend on all operators being individually aware, nor does it make sense for everybody to be aware of the same thing at the same time (Garbis \& Artman, 2004). Above all, the right information needs get to right person at right time, and this involves team coordination (Harris, Treanor, \& Salisbury, 2006).

Similar to the concept of SMM, Endsley and Jones (2001) describe a model of TSA as a means of conceptualizing how teams develop high levels of shared SA across members. Four factors - requirements, devices, mechanisms and processes - act to help build team and shared SA.

1. Team SA Requirements: the degree to which the team members know which information needs to be shared, including their higher level assessments and projections (which are usually not otherwise available to fellow team members), and information on team members' task status and current capabilities.

2. Team SA Devices: the devices available for sharing this information, which can include direct communication (both verbal and non-verbal), shared displays (e.g., visual or audio displays, or tactile devices), or a shared environment.

3. Team SA Mechanisms - the degree to which team members possess mechanisms, such as shared mental models, which support their ability to interpret information in the same way and make accurate projections regarding each other's 
OR Team Communication, Mental Models, and Situation Awareness 29

actions. The possession of shared mental models can greatly facilitate communication and coordination in team settings.

4. Team SA Processes - the degree to which team members engage in effective processes for sharing SA information which may include a group norm of questioning assumptions, checking each other for conflicting information or perceptions, setting up coordination and prioritization of tasks, and establishing contingency planning among others.

In view of the components of TSA, perhaps a more appropriate definition is "two or more individuals who share the common environment, up-to-the moment understanding of situation of the environment, and another person's interaction with the cooperative task" (Furuta \& Shu, 2004). Mutual familiarity (described here as shared knowledge) with other team members enables interpretation of each other's actions in order to coordinate and provide context for individual activities (Shu \& Furuta, 2002). This definition of TSA incorporates the previously discussed individual SA as well as awareness of other team members as a unique layer. Many incident-related processes are interwoven- even though each member might have his own area of expertise and responsibility, it is only through their mutual understanding (i.e., shared mental model) that they can coordinate their resources and actions to accomplish the task (Hazlehurst, McMullen, Gorman, 2007).

TSA is the successful integration of mutual understanding and coordination of resources throughout the team. From Endsley \& Jones's (2001) model, a main focus of this thesis will be to investigate the communication processes that team use as a means to 
OR Team Communication, Mental Models, and Situation Awareness 30

build and maintain their TSA. Therefore, to study TSA processes, it is important to establish methods of measurement.

\section{SA Measurement}

Two general techniques exist for measuring SA. Direct (i.e., product-oriented) measures define SA as the outcome of SA assessment (e.g., objective real-time probes or subjective questionnaires assessing perceived SA). Inferred (i.e., process-oriented) measures assess SA by measuring the underlying processes or mechanisms required to achieve SA (e.g., methods that infer SA based on operator behavior or performance; Graham \& Matthews, 2000). The following are a few examples ${ }^{1}$ of direct and inferred measurement techniques of SA, and their applicability to TSA.

Direct Measurement. Direct SA measurement can be ${ }^{1}$ objective or subjective. Objective measures directly assess SA by comparing an individual's perceptions of the situation or environment to what is actually happening. SAGAT (Situation Awareness Global Assessment Technique, Endsley, 1995a) is a commonly used measurement of SA where the participant answers questions about SA requirements during an interruption in task performance. However, the interruption-based format of SAGAT is often criticized because SA related questions are thought to shift participants' attention to SA requirements, thus influencing subsequent SA scores (McGowan \& Banbury, 2004). In comparison, subjective measures of SA involve individuals rating their own, or the observed SA of individuals on an anchored scale (e.g., Situation Awareness Rating Technique the (SART) - Taylor, 1989). While the relative straightforward and simple

\footnotetext{
${ }^{1}$ This paper acknowledges the existence of other SA measures, such as behavioural-, performance-, and physiological-based measures, but for the purpose of this thesis, the scope is limited to
} 
OR Team Communication, Mental Models, and Situation Awareness 31

administration of subjective measures is appealing, individuals are often unaware of information they do not know (Luft \& Ingram, 1955).

Methods for studying TSA from these types of measurements involve an aggregate sum, or average of each individual's SA scores (Endsley, 1995; Endlsey and Jones, 2001). However, some authors argue that extrapolating individual SA to the team level is overly simplistic (e.g., Garbis \& Artman, 2004). The current trend suggests that TSA is much more complex because multiple people working together add numerous complex layers of SA that is beyond Endsley's three levels of SA. As such, inferred methods of TSA may be a more appropriate way to assess TSA via team interactions.

Inferred Measurement. Process indices examine how individuals process information in their environment, such as by analyzing communication patterns between team members, and infer TSA based on this process. Team communication (particularly verbal communication) supports the knowledge building and information processing that leads to SA construction (Endsley \& Jones, 1997). CAST (Coordinated Awareness of Situations by Teams; Gorman, Cooke, Pederson, Connor, \& DeJoode, 2005) is one type of inferred process technique in which the research interjects 'roadblock', such as communication glitches between team members, and then observes the processes used to recover from the roadblock and complete a mission. Accordingly, this thesis will adapt an inferred, process measurement of TSA, discussed later in the method.

In line with process methods, Shu and Furuta (2005) propose that both verbal and non-verbal communications are the means to achieving the underlying mechanism of TSA. The underlying TSA mechanism reflects team cognitive processes that are consistent with cooperative activity and mutual understanding, but its maintenance and 
OR Team Communication, Mental Models, and Situation Awareness 32

momentary loss is likely a result of the communicative practice between team members (Hazlehurst, McMullen, Gorman 2007). TSA is achieved in part through explicit communication (e.g., direct face to face verbal exchange) and part is inferred through observed external actions of another without explicit verbal exchange (e.g., non-verbal actions). Shu and Furuta (2005) showed that even if the team cannot observe each other, they can still obtain good TSA via communication. When teams could only observe each other, but not communicate, their TSA scores were significantly lower than the first condition.

Similarly, Garbis and Artman (2004) suggest that TSA can be understood through the communicative and coordinative practices used within teams. TSA requires articulation of each individual's activity so that every team member can synchronize their actions with those of the others to reach a collectively shared goal (Garbis \& Artman, 2004). Hazlehurst, McMullen and Gorman (2007) identified six types of verbal exchanges between surgeons and perfusionists that facilitated TSA in cardiac surgery by making the current situation clear and mutually understood, and by making goals and envisioned future situations clear and thereby anticipated. Their communication analysis focused on the type of verbal exchange that served to enable coordination and collaboration among team members, resulting in six categories: a) Direction commands an action that seeks to transition the activity system to a new state; b) Goal Sharing creates a common expectation about series of desired future states; c) Status creates a shared understanding about the current state. Also, status updates can be indirect commands, implying that a given action ought to happen; d) Alert conveys abnormal or surprising info about a current state; e) Explanation creates a rationale for the current 
OR Team Communication, Mental Models, and Situation Awareness 33

state by creating a shared understanding of the situation as well as reasons for taking certain actions; f) Problem solving states facts that highlight uncertainty about system state, which are in conflict with held assumptions in order to explain facts, create coherent understanding and reduce uncertainty.

The Hazelhurst, McMullen and Gorman (2007) study focused on cardioplegia (i.e., induced paralysis of the heart muscle), a time-dependent task based on the interaction of two people, and found that different patterns in communication enabled various teamwork processes. This thesis aims to uncover similar types of communication patterns within OR teams, by focusing on interactions that may be unique to the type of surgery observed. The Hazelhurst study will guide, but not limit our definition of categories as to the types of information exchanges we can expect.

Summary. While consistent and standardized definitions of mental models and situation awareness in teams are yet to be established, both constructs are recognized as critical to team performance. Research focused on mental models and SA has developed more or less in parallel thrusts although both should be two constructs of the same overarching theory because of their mutual impact on teamwork. Regardless of how much SMM and TSA are linked, communication is a prevalent factor in both. Exhaustive research exists on the study of communication, and some research has indeed emphasized the importance of communication to building TSA in general. However, there is a lack of studies that specifically explore the details of how communication may link mental models and TSA. In addition to its potential theoretical contribution, addressing this question can help in team building in healthcare along with the development of procedures and technologies that can facilitate teamwork and increase patient safety. 
OR Team Communication, Mental Models, and Situation Awareness 34

The literature review characterized effective teamwork by shared mental models and team situation awareness along with their essential process of communication. The emerging question is if patterns of communications used to establish and maintain TSA are actually reflections of shared mental models. In other words, are increased communications to build and maintain TSA reflective of possible gaps in shared mental models within the team? Therefore, there is a need to study communication in surgical teams as a reflection of 1) team shared mental models, and 2) team situation awareness. This paper approaches communication as an indirect measure of SMM, as well as a direct measure of the processes used to build TSA. The study of communication patterns as a primary unit of analysis was used to understand the relationship between TSA and SMM as it supports the multifaceted team level needs in the OR.

\section{Goals and Objectives}

The long term goal of this research is to contribute to improved patient safety and overall quality of care. The focus on verbal communication in thoracic surgery explored whether the processes used by teams to build and maintain TSA is reflective of the degree of similarity in mental models (i.e., of team and task knowledge). Through the exploration of links between TMM and TSA, the aim was to use this understanding to derive implications for healthcare and human factors.

The objectives of the study were to: 
OR Team Communication, Mental Models, and Situation Awareness 35

1. Capture communication patterns in OR teamwork;

2. Deduce OR team members' mental models and subjective perceptions of teamwork;

3. Assess potential gaps and similarities in mental models in order to link them to communication patterns exhibited during teamwork communication;

4. Explore possible explanations and implications of these links.

Addressing the above objectives facilitated answering the main research question of whether there is a link between mental models of OR healthcare workers and OR TSA as represented by a) communication patterns reflecting TSA processes, and b) subjective perceptions of teamwork?

\section{Research Approach}

Cognitive Ethnography shaped the research approach to study the mental processes associated with the work carried out within the OR setting (Ball \& Ormerod, 2000; Hammersly \& Atkinson, 1995; Hollan, Hutchins, \& Kirsh, 2000; Patel, Zhang, Yoskowitz, Green, \& Sayan, 2008). Cognitive Ethnography differs from other qualitative styles (e.g., grounded theory), in which the researcher observes and records as much information as possible from the population of interest and allows patterns to emerge from the data (Creswell, 2007, p. 64). While this research acknowledged the emergence of patterns and themes, the primary approach involved a) having specific research goals and theoretical interests, b) specifying data collection, and c) using purposive techniques and triangulating data gathering methods (Ball \& Ormerod, 2000; Patel et al., 2008). 
OR Team Communication, Mental Models, and Situation Awareness 36

Method

\section{Surgery Sample and Participants}

This research was qualitative in nature, where it was necessary to "select" participants from pre-existing groups, without the ability to "completely control the what, when, where, and how" of participants and their activities" (McBurney, 2001, p. 335). Variability (e.g., case complexity, duration, and number of team members involved) within and across cases was influenced by the needs of the patient and OR scheduling, and not by experimental design. However, the focus of this thesis was the verbal exchanges produced by teams involved in a given surgery and not the individual healthcare workers themselves. Consequently, the details of the surgery observations are described first, followed by the details of the human participants involved in those observations.

Surgical procedure sample. Thoracic surgery treats diseases (largely cancerrelated) of organs within the thorax (i.e., chest cavity) such as the lungs, chest wall and diaphragm (Hood, 1985). A defining feature of thoracic surgery is the use of videoassisted thoracoscopic surgery (VATS), which uses a small video camera that is introduced into the patient's chest through the esophagus with a long flexible scope (Shields, 2004). The scope enables the surgeon to view the patient's anatomy and their

own surgical manoeuvres. The surgeries observed consisted of three Esophagoscopies, two Bronchoscopies, two Mediastinoscopies, three Lobectomy/Thoracotomies, one Esophagectomy, three Bullectomy/Pleurectomies, and one Chest Lavage (i.e., rarely performed procedure and considered an outlier). Appendix B contains a detailed description of each procedure. 
Healthcare workers sample. Twenty-five thoracic OR healthcare workers from a large hospital in eastern Ontario were observed in 15 surgeries. As was explained above, they were not selected, recruited, or randomly assigned by the researcher. The sample included four staff surgeons, six staff anesthesiologists, two surgical fellows, three anesthesia residents, six circulating nurses, and four scrub nurses. Depending on the surgery, individual healthcare workers may have been observed repeatedly. Department leaders from all three professions (surgery, anesthesia, and nursing) were contacted and met with individually to acquire their verbal consent regarding their respective department. Based on these meeting, information about the research was conveyed to all members of the three disciplines. Consent was considered granted unless specifically declined by any particular individual (i.e., passive consent).

The 12 ( 3 females, 9 males) healthcare worker participants interviewed postobservations included four surgical, five anesthesia, and three nursing team members. Age ranged from 30 to $50+$ years. Participation was voluntary and participants did not receive remuneration. While no single individual actively refused to be interviewed, the other 13 observed participants did not respond to the contact information request (a limitation that is covered in the discussion).

\section{Design}

The research comprised a field study examining communication and perceptions of teamwork processes in operating rooms during thoracic surgery. In order to address the research questions there were two main variables of interest, TSA and TMM. To study these two constructs, there were three phases using ethnographic methods of data collection: 1) background education and pre-observation interviews with senior surgical 
OR Team Communication, Mental Models, and Situation Awareness 38 staff formed the researcher's foundation of knowledge for thoracic procedures; 2) realtime observations and field notes of thoracic procedures to capture team communication used to build TSA; and 3) post-observation interviews and questionnaires with observed healthcare workers to capture their knowledge assumed to represent TMMs. The analysis of components involved in TSA focused on the teamwork communication in order find links with knowledge within TMMs.

\section{Materials}

Fujitsu Lifebook USeries U820. A fellow graduate student collected observational data using a hand-held computer tablet (Fujitsu Lifebook USeries, U820) installed with Remote Analysis of Team Environments (RATE, Guerlain et al., 2005). RATE facilitates the capture of communication descriptors using customized lists of the people and actions/events that re-occur in the OR. Here, RATE recorded the speaker, responder, type of event, content of communication, and free-form comments made by the researcher. Each data entry was time-stamped and then imported to Excel for analysis.

Operating Room Management Attitudes Questionnaire. The researcher collected subjective perceptions of teamwork and demographic information (i.e., age, experience, ethnicity etc) during interviews using structured questionnaires (see Appendix A). Items extracted from the Operating Room Management Attitudes Questionnaire (ORMAQ, Sexton, Helmriech, Glenn, Wilheim \& Merritt, 2000) assessed perceptions of teamwork. The ORMAQ is inspired by Crew Resource Management (CRM, Helmreich \& Davies, 1996) and uses Likert scales to tap into teamwork, communication, stress recognition, and safety concerns in healthcare. An example item is "[regarding last case], communication between Anesthesia and Surgical teams was established and maintained". 
OR Team Communication, Mental Models, and Situation Awareness 39

The ORMAQ has been used in a variety of teamwork in teamwork studies (e.g., Flin, Yule, McKenzie, Paterson-Brown, \& Maran, 2006). Many of the questions address stress and error which are important, but the scope of this research was limited to aspects of teamwork (see Sexton et al., 2000 for the full version).

\section{Procedure}

To compare communication patterns in the $\mathrm{OR}$ to mental models of information flow, the study used a multi-phase approach (see Figure 1) in which results from a given phase inform subsequent phases (Espinosa, 2002). The first three phases involved data collection and analysis, while the fourth phase was the main analysis to answer the research question:

1. Phase I: Interview senior surgeon and senior anesthesiologist to guide the subsequent observations;

2. Phase II: Observe and document OR team communication; Assess procedure structure, interactions, and communications patterns in order to identify TSA related communication;

3. Phase III: Interview observed OR team members to infer Team Mental Models, and assess differences and similarities of knowledge;

4. Phase IV: Compare TSA related communication to knowledge within Team Mental Models. 
OR Team Communication, Mental Models, and Situation Awareness 40

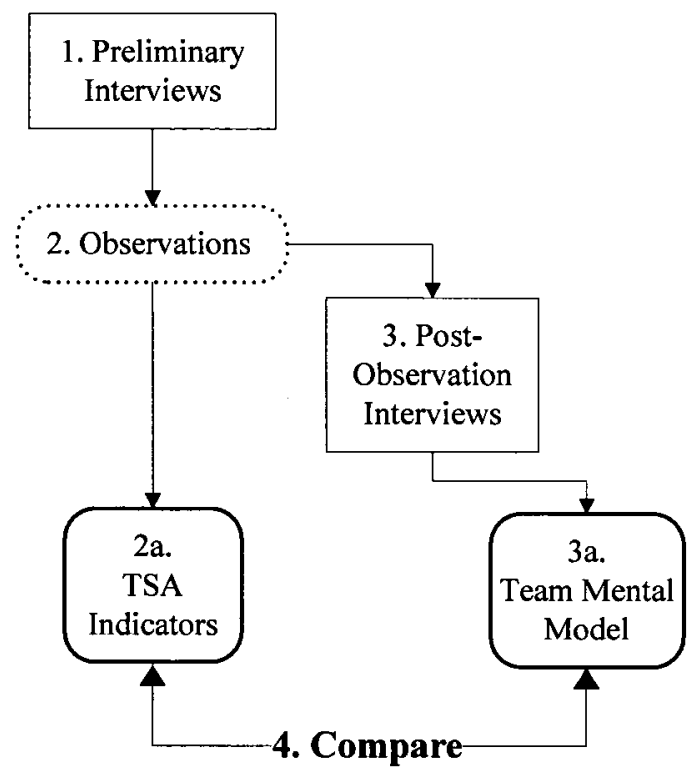

Figure 1. A schematic representation of the study phases.

Phase I: Preliminary Interviews

The primary purpose of the preliminary interviews was to gain familiarity with the surgical context and teamwork processes, to prepare for the observations, and eventually answer the research questions (Espinosa, 2002). After reviewing background information on thoracic surgery (Hood, 1985), the researcher met and interviewed a senior surgeon and senior anesthesiologist from a large hospital in eastern Ontario as the representative Subject Matter Experts (SME). The SMEs had 24 years of combined experience between them, and have each worked at that specific campus for approximately 7 years. Due to their demanding schedules, the entire interview process lasted no longer than one hour each. It should be noted that the SMEs were also part of the observed sample of team staff, and their demographics are included in the participants section of the method.

The interviews addressed the main components of thoracic surgery and the interactions of individual healthcare workers. Interviews began open-ended, to allow 
each SME to become comfortable with the researcher and familiar with the interview expectations (Langan-Fox et al., 2000). Each SME described the main tasks of a typical thoracic procedure, and then relevant subtasks needed to execute the relevant main task. For example, if an epidural was considered a main task, the respective subtasks included the entire anesthesia teamwork - someone must support the patient's shoulders from the front, someone must assemble the correct drug mixture, and someone must administer the epidural syringe. For each step in the surgery, interviewees also described the healthcare workers' involvement in terms of: a) who is directly involved in each task; b) who needs to know about each task indirectly to be able to coordinate their activities; and c) the path of information flow needed for the completion of each task. Answers to these questions allowed the researcher to infer mental models associated with interdependent tasks and team interactions for the subsequent coding analysis. At those preliminary interviews, the SMEs were given the demographic questionnaire and ORMAQ. Both were completed and obtained within a week of each interview.

\section{Phase II: Observations}

The purpose of the observations was to capture teamwork processes in the form of verbal communication among team members. These communications are assumed in this study as essential, yet not exclusive, to building and maintenance of TSA. The communication data was later categorized into specific types of TSA indicators to be used for the subsequent analyses.

Surgery selection. Due to the qualitative nature of the study, the surgical cases and respective OR teams were not randomly assigned by the researcher. The surgical coordinator determined regular shift assignments, and team composition varied for each 
OR Team Communication, Mental Models, and Situation Awareness 42

case. The choice of surgery varied daily, based on availability of cases and time constraints of the researchers. Depending on the estimated duration of the procedures scheduled for any given day, the researchers ensured that procedures could be observed from start to finish.

Observation process. The observation of nineteen thoracic procedures transpired over the course of 14 non-consecutive days between February and April of 2009. Patient consent was obtained two hours prior to each case. The researchers piloted the first four surgeries to facilitate and practice data capture, and therefore retained 15 of the 19 observations for analysis. The unit of measurement for teamwork was verbal information exchange between team members in the OR. Non-verbal communication was documented when it was relevant to other verbal communication. For example, researchers noted that a question was asked, and acknowledged with an action (e.g., a head nod). However, it should be emphasized that there may have been other non-verbal communication, such as body language, that was beyond the scope of this study. Also noted were various events throughout the observation, such as the activities of different team members, or events. For example, when the patient was anesthetized and when the initial skin incision was made. These events added contextual cues to the conversation data.

The researcher recorded communication during surgery observations using handwritten notes, while another graduate student used the RATE program installed on a hand held computer tablet. At the end of each observation, the data from RATE was uploaded into an Excel spreadsheet in order to merge the transcribed dialogue and any other information from the hand notes into the appropriate place holder created by the 
RATE program. For example, using RATE, if the surgeon asked the nurse a question about drugs at 11:03am, the researcher would add the corresponding dialogue from the hand notes. Identifiers were removed from the data to ensure patient and OR team's anonymity. Each researcher maintained the same form of data collection throughout the entire observation process to increase proficiency and data consistency respectively. The merging of hand notes and RATE data facilitated a more detailed and reliable level of final observation notes.

\section{Phase III: Post-Observation Interviews}

All healthcare workers were contacted via email requesting to be interviewed for 30-45 minutes by the researcher. Interviews were conducted on site at the hospital campus, and took place in a variety of locations including offices, coffee shops and park benches, depending on the availability of the participant. All interviews were recorded by the researcher using hand notes which were then transcribed into Excel.

The interviews followed the same procedure as was described in preliminary interviews. As the goal was to elicit mental model knowledge and not test memory, the questions were from a general perspective and not directed at any particular surgery in which the participant was observed. The main difference between the pre- and postinterview tasks analyses was that through the experience of the nineteen thoracic observations, the researcher was better able to focus and expand on certain topics of interest. In addition, the process of interviewing itself allowed the researcher to continually evolve and improve the format of information acquisition. These descriptions were key components of the mental model of teamwork processes. Following each 
interview, participants completed the demographics questionnaire and the ORMAQ, which took approximately 10 to 15 minutes.

Debriefing

Given that the same SME or team member may have re-participated on different observations throughout the course of the study, debriefing during the study may have influenced behavior and reduce the validity of the data collected. In lieu of debriefing after each observation or interview, the researcher scheduled a presentation at the hospital detailing the nature of the study, the objectives, research questions, findings and implications. The investigator contact information was made available to all members of the units.

\section{Results}

The iterative nature of qualitative data coding shaped the choice of data organization and presentation in order to draw conclusions and implications. Consequently, data coding, operational definitions, and general results for each of the variables of interest within TSA and mental models are presented first. Detailed relationships amongst the variables follow the general results. With the exception of few non-parametric tests, most of the numerical data and relationships could not undergo a statistical analysis. Small sample sizes and the inability to assign participants to surgeries either randomly or in a counter-balanced fashion meant that some observed participants produced verbal data over repeated procedures, thus violating independence of cases assumption. Therefore, most of the reported results are descriptive and exploratory. 
OR Team Communication, Mental Models, and Situation Awareness 45

Characteristics of Thoracic Surgeries

In order to analyze OR communication as a function of transferable contextual categories and not as a function of diverse individual procedures and cases, the following categories and groupings were defined: 1) Common surgery structure; 2) Procedure complexity; and 3) Procedure duration.

Common surgery structure. The common surgery structure provided chronological context and facilitated comparison of communication among diverse procedures. The five generic chronological phases typical of thoracic surgeries were: 1 ) the insertion of intravenous lines and patient intubation (Lines); 2) the scoping and patient positioning (Scope); 3) the surgical prep (Prep); 4) the surgical procedure (Surgery); and 5) the surgical close (Close). The content of each category was reviewed and validated by an SME to ensure accuracy, and is described in detail in Appendix B.

Procedure complexity. Complexity rating defined the subjective perception of case difficulty relative to the other cases observed. Complexity was derived from ratings of 11 OR team members during post-observation interviews (i.e., scale of $1-5$, with 1 being the least complex and 5 being the most complex). As shown in Figure 2, mean ratings appeared to fit into two complexity groups: ratings above three for high complexity $(M=3.96, M d n=4.00)$ and below three for low complexity $(M=1.70, M d n$ $=1.33$ ). Procedures were thus classified as either high complexity (i.e., lobectomy/thoracotomy, esophagectomy, and bullectomy/pleurectomy), or low complexity (i.e.,esophagoscopy, broncoscopy and mediastinoscopy). Due to the small sample size, non-parametric analysis assessed the difference between complexity ratings of high and low groups. Significant results from the Friedman's Test $\left(X^{2}=56.8, d f=6, p\right.$ 
$=.000)$, Wilcoxon's signed ranks $(z=-2.95, p=.003)$ and the sign test $(p=.001)$, suggest that high complexity cases had significantly higher ratings than low complexity cases. The outlier surgery was not analyzed unless specified.

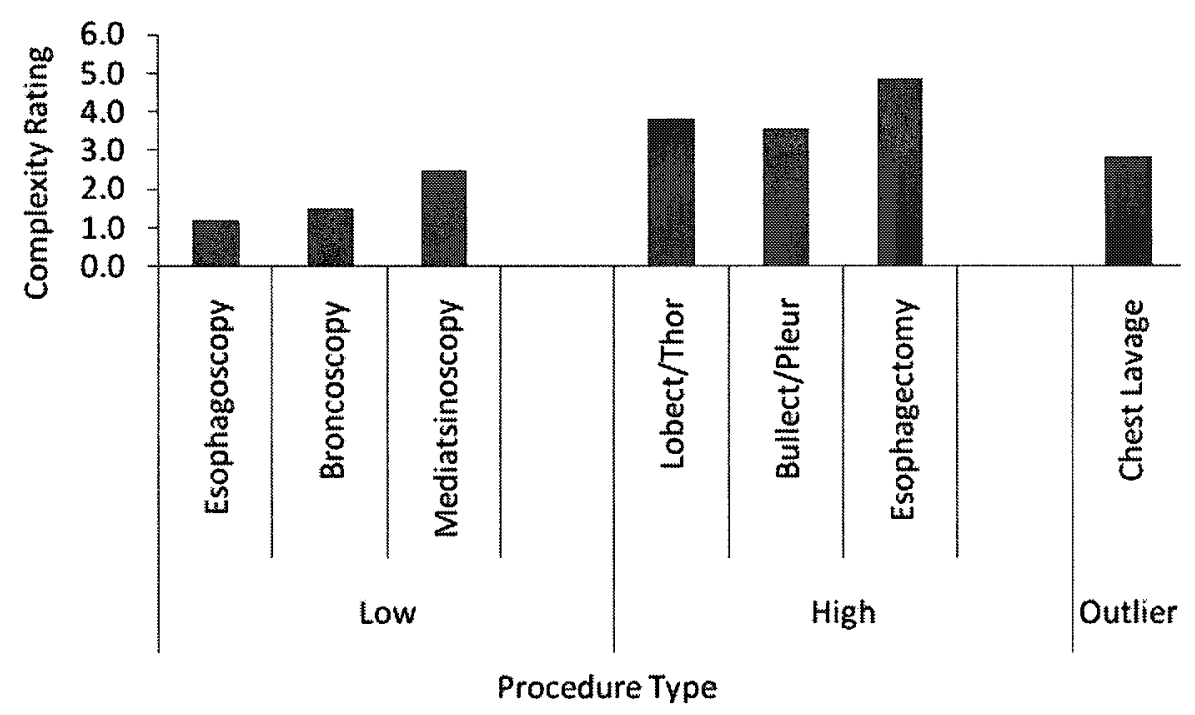

Figure 2. Complexity ratings of all the observed surgeries grouped into high and low complexity.

Procedure duration. Procedure durations were based on the patient's noted entry and departure from the OR. Excluding the outlier, researchers observed a total of 1407.17 minutes ( 23.45 hours) of thoracic procedures. Procedure durations ranged from approximately 29 to 241 minutes ( $M=103$ minutes; $M d n=79$ minutes). Times are approximate due to rounding of seconds when taking into account noted RATE and wall clock time.

High complexity cases tended to be longer than low complexity cases (see Figure 3). The Mann-Whitney Test was significant, $z=-3.0, p=.000$, suggesting that longer procedures are associated with more complex ratings. High complexity cases ranged from 
68.08 to 240.71 minutes ( $M d n=147.74$ minutes), while the duration range for the low complexity procedures was 28.03 to 45.98 minutes ( $M d n=29.26$ minutes).

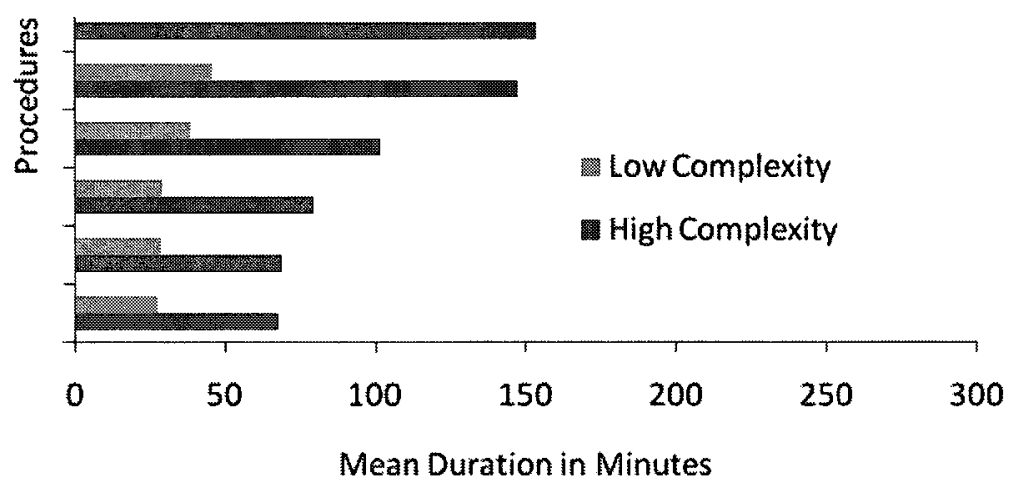

Figure 3. Mean durations of high and low complexity procedures.

\section{Characteristics of Communication}

Conversation analysis (e.g., Pomerantz \& Fehr, 1997) guided the mapping and description of patterns of TSA communication. The full protocols of human verbal communication in the OR were segmented into utterances produced from participants taking turns in the verbal interaction. The unit of analysis was each utterance produced by an OR member. The sequence of utterances shown here contains two surgeon (S) utterances and one anesthesiologist (A) utterance.

S to A: Okay time to go.

$\mathrm{S}$ to A: Art[erial] line?

A to S: Ya, then good to.

Utterances could also be from one person to the team where the response is implied by the action. The following is an example of a one-sided communication sequence.

S to Team: "Let's get scrubbed" 
Utterances were chosen as the unit of analysis because they best reflected the volume of communication. In total, 1633 utterances were documented over the course of the 15 surgery observations. Excluding the outlier procedure, 1506 utterances were analyzed $(\operatorname{Min}=20 ; \operatorname{Max}=189 ; M=108.97, M d n=101.5) .1270$ utterances were part of high complexity cases, and 236 communications were from low complexity cases. Verbal utterances were then analyzed as a function of 1) procedure duration, 2) distribution by phase, 3) type, 4) content, 5) speaker, and 6) direction of communication.

Communication and procedure duration. The number of utterances was positively correlated with the total duration of surgery, Pearson's $r=.91, p<.01$, that is, longer procedures were associated with more utterances (see Figure 4). Since duration was also associated with surgery complexity, it can be inferred that high complexity cases were associated with more utterances than low complexity.

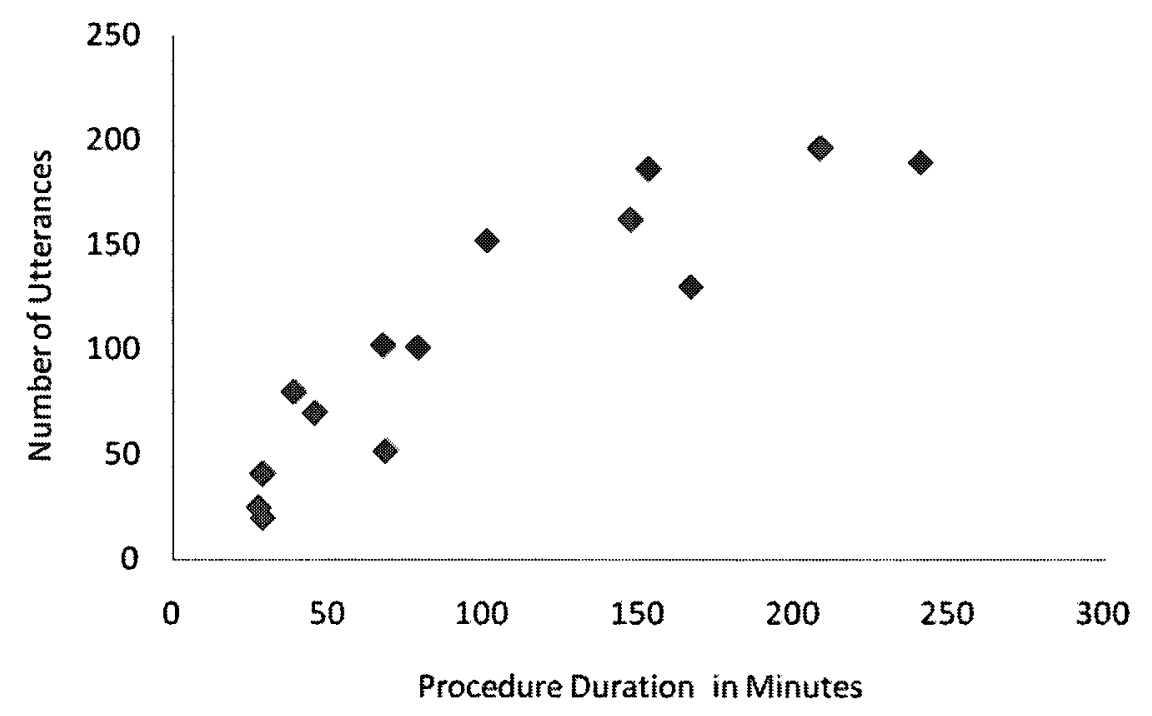

Figure 4. Relationship between procedure duration and number of utterances.

Communication distribution by phase. The frequency of utterances was analyzed as a function of phase within each complexity group. The purpose was to uncover 
possible trends related to specific timeframes of the procedure. Utterances were counted within each of the five procedure phases, and the proportion within each phase was calculated relative to the total number of utterances. Figure 5 shows that communication was primarily concentrated within the surgery phase. Surgery contained almost half of all utterances in both high complexity (45.3\%) and low complexity $(50.4 \%)$ procedures. Lines and intubation, scoping and patient positioning, and surgical close ranged from $13 \%-20 \%$ of total utterances across both groups. The exception was for the low complexity surgeries where patient prep phases were either extremely brief (i.e., during a mediastinoscopy where surgery is minimal) or did not exist for non-surgical procedures.

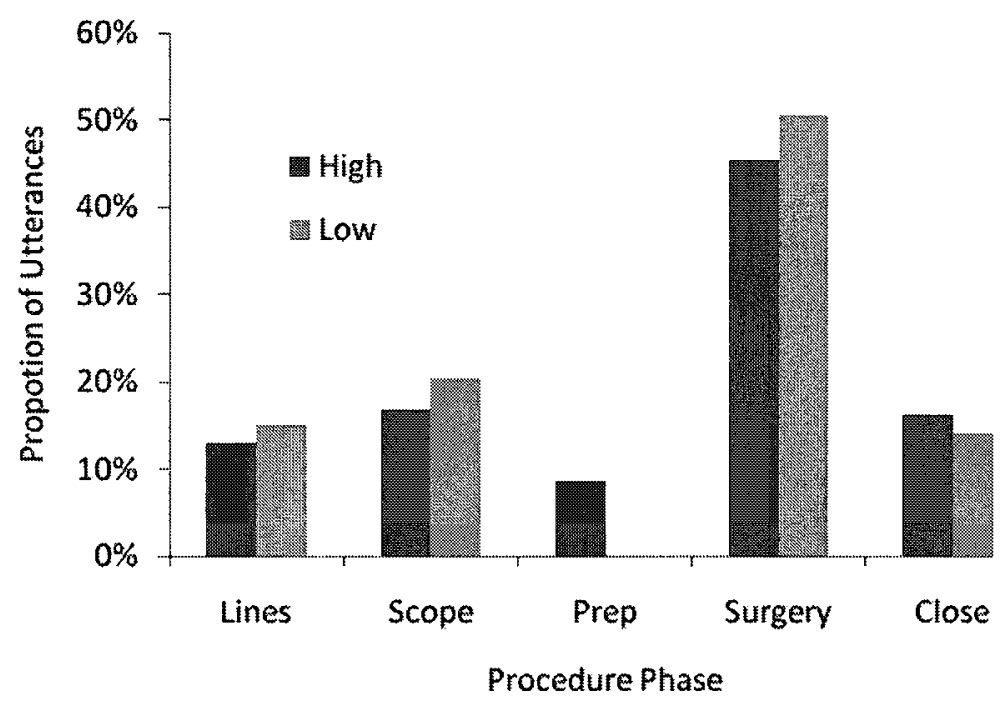

Figure 5. Proportion of communication utterances as function of phase for high and low complexity procedures.

Type of communication. Categories describing the type (i.e., purpose) of communication were based on conversation analysis adapted from Parush et al. (2008), combined with categories that emerged through data coding. This method produced seven 
high-level categories: seeking information, responsive information, proactive information, requesting information, educating, comments, and irrelevant information.

Each high-level category contained several sub-categories (17 sub-categories in total).

Table 1 summarizes all of the high level and respective sub-categories of communication types, each illustrated by an example.

Table 1

Communication Categories, Definitions, and Examples

High Level Category Sub-Category Example

\section{Seeking Information}

One person requires information from another.

\section{Question:}

Requesting information known (or assumed to be known) by another person, such as a numerical value or current state of affairs

Clarify:

Asking for further information to elucidate a previously provided response

\section{Anticipate:}

Asking a question in which the answer is already expected, desired, or implied

\section{Responsive Information}

Providing information in response to another type of communication

\section{Reply:}

Providing previously unknown information needed by the requester

Confirm: Acknowledging that a request was made and indicating the manner that it will be acted upon

Read-back : Repeating verbatim the words of the requester

\section{Offering Information}

Announce:

"We're going to need an endostapler."

-"Blue or green?"

"Ready to turn?"

"Is the suction on here?"

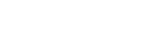

"What time did he get his first dose of antibiotics?"

-“10. Sorry, 9:30."

"Let's put the patient on their side."

-"Okay."

"This biopsy will be 4."

-“4."

“There's no need for 
Information offered without having been requested or sought by another

\section{Requesting/Commanding}

Expressing a need, a want, or an order for something other than information
Offering information to other members about the current state of affairs without being asked

Plan:

Similar to announcements, but indicative of future events

Concern-Raising:

Alerting the team to current or possible problems

Brief :

Bringing someone "up to speed" antibiotics."

"The next patient is heavy-set; we'll need help lifting her."

"I think there is something wrong with the stent."

"This patient has a history of airway issues, has a latex allergy and was consented for epidural."

\section{For objects:}

“More saline please."

Asking for a tool or a piece of equipment

For actions:

Directing another to do something

\section{Educating}

Instructing, guiding, or quizzing

Coach/Teach:

Assisting during a situation where that person was not yet proficient
"Push it more towards the lung, yes that's it."

\section{Commenting}

Extending a previous

communication without providing new information to the situation
Discuss/Explain:

Case relevant communication used to elaborate on a previously mentioned topic

Other:

Case relevant information, but not new or needed

\section{Irrelevant}

Content and intent had nothing to do with the current case or other patients
Joke

Non-serious, or sarcastic nature, light-hearted, laughable conversation
"Also since this one doesn't work with our OR, we can't use it..."

"I should be wearing gloves."
Socialize

Case-irrelevant conversation
"You scrubbed for 7 minutes, that's a new record."

-"Oh no, you're timing me!?"

"Did you have a good weekend?" 
Communication coded by type was analyzed as a function of phase in order to identify any trends in the purpose of communication for high and low complexity procedures. Figure 6 shows similar distributions of communication types within high and low complexity procedures. The most likely reasons to communicate were to seek, respond to or offer information (accounting for approximately $80 \%$ of all utterances). Seeking information was the highest proportion (21\%) of communications in high complexity surgeries, while proactively offering information was the highest $(26 \%)$ proportion of communications in the low complexity surgeries. The least likely reasons to communicate were for education, making comments, or irrelevant communication. These results suggest that a large part of team communication revolves around information sharing and receiving.

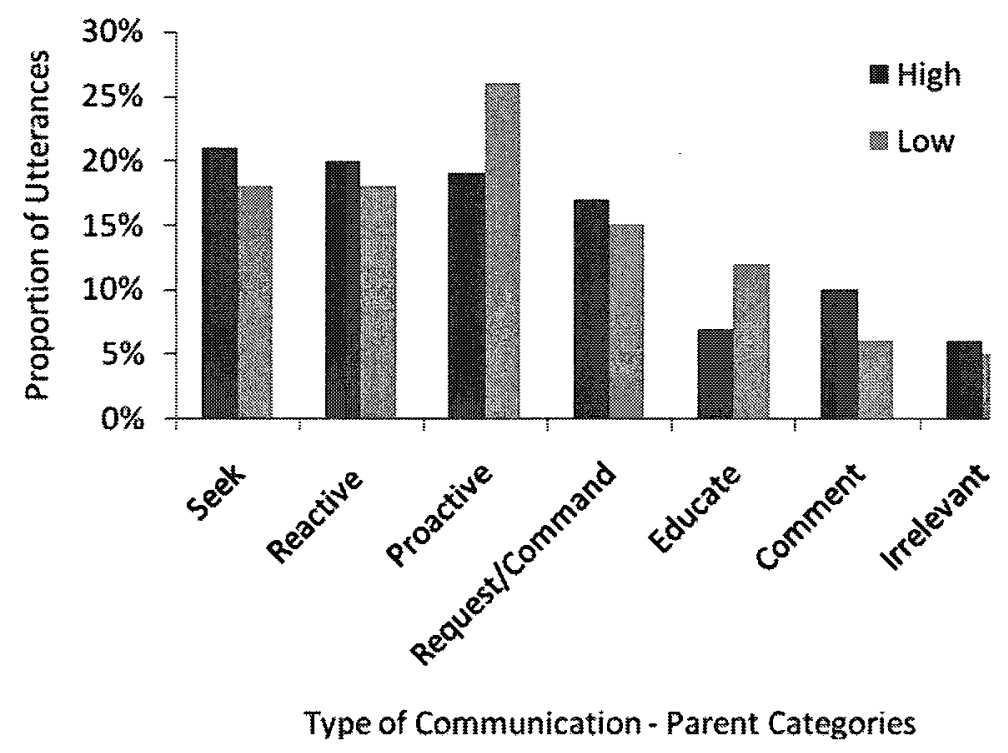

Figure 6. Distribution of high level communication categories for high and low complexity procedures. 
Further analysis of proportions of communication sub-categories implies that communication was not structured or standardized. One way to define a lack of structured communication is through Schramm's (1954) open-loops, where communications lack feedback about messages received or comprehended. Open-loops can be implied here by the uneven ratio of requests to confirmations. Requests represented $17 \%$ of high complexity communications, and $15 \%$ of low complexity communications (refer to Figure 7). However, confirmations and read-backs combined only make a total of $6 \%$ and $2 \%$ for high and low respectively. Even considering clarifications as an indirect acknowledgement, which account for about 4 and 5\% in each case, $10 \%$ and $7 \%$ for high and low are still not equal to the amount of requests recorded.

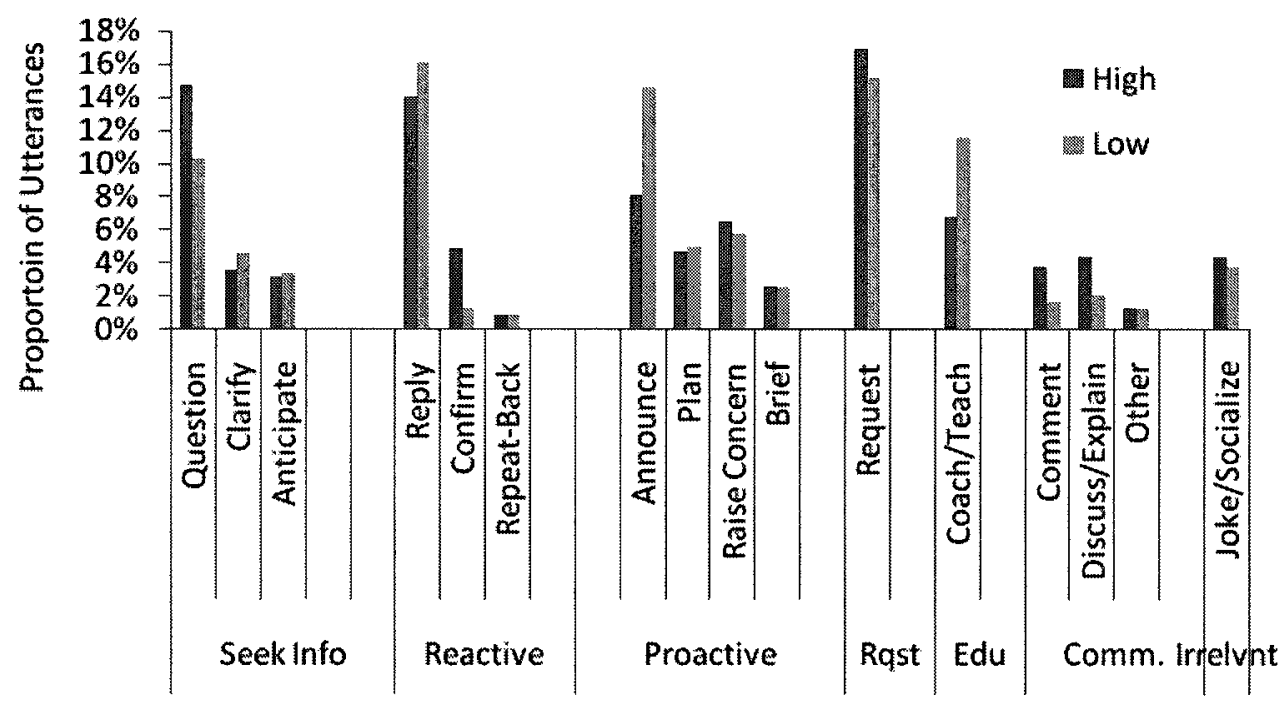

Type of Communication - Sub-Categories

Figure 7. Proportion of communication types by sub-categories for high and low complexity procedures. 
OR Team Communication, Mental Models, and Situation Awareness 54

Content of communication. The general topic of each utterance, that is, what was talked about, was coded into categories. Nine content categories were identified and are summarized in Table 2.

Table 2

Content Categories and Examples of Coded Utterances

\begin{tabular}{|c|c|c|}
\hline Content & Description & Examples \\
\hline Patient/Position & $\begin{array}{l}\text { Medical history, hemodynamic (blood } \\
\text { pressure, temperature etc), allergies, } \\
\text { position of patient, table }\end{array}$ & $\begin{array}{l}\text { "Any allergies?" } \\
\text {-"Yes, she's allergic to } \\
\text { Codeine." }\end{array}$ \\
\hline Surgical/Procedure & $\begin{array}{l}\text { Surgical approach, specific needs of } \\
\text { procedure, incision maneuvers, organ } \\
\text { manipulation }\end{array}$ & $\begin{array}{l}\text { "See that node, go towards } \\
\text { the lung." }\end{array}$ \\
\hline Drugs & $\begin{array}{l}\text { Antibiotics, epidural, other pain } \\
\text { control }\end{array}$ & $\begin{array}{l}\text { "You didn't give any Dex } \\
\text { eh?" } \\
\text {-"No, not from me." }\end{array}$ \\
\hline Staff/Scheduling & $\begin{array}{l}\text { Whereabouts of staff members, } \\
\text { knowledge of team member's names, } \\
\text { current's day's schedule, upcoming } \\
\text { case schedule }\end{array}$ & $\begin{array}{l}\text { "Is [surgeon] on his way?" } \\
\text {-"Yes, he was in a } \\
\text { meeting." }\end{array}$ \\
\hline Tools/Equipment & $\begin{array}{l}\text { Surgical tools, vital monitors, VATS } \\
\text { screens, infusion pumps }\end{array}$ & $\begin{array}{l}\text { "Do you have an arm } \\
\text { ring? } \\
\text {-Ya, right here." }\end{array}$ \\
\hline Medical Action & Direction or command & "Lights off please." \\
\hline Lung & $\begin{array}{l}\text { Airways, vents, pressure, suction, lung } \\
\text { up/down, inflation, deflation }\end{array}$ & $\begin{array}{l}\text { "Drop right lung please." } \\
\text {-"Lung down." }\end{array}$ \\
\hline Other Cases & $\begin{array}{l}\text { Next case, past case, upcoming case, } \\
\text { case of other surgeon or type of } \\
\text { surgery }\end{array}$ & $\begin{array}{l}\text { "Call for next patient, I'll } \\
\text { need a single Lumen." }\end{array}$ \\
\hline Irrelevant & Personal, sports, jokes, music & $\begin{array}{l}\text { "How come I don't hear } \\
\text { music?" }\end{array}$ \\
\hline Status Check & $\begin{array}{l}\text { General cross checking between } \\
\text { members, verify how other is doing }\end{array}$ & "Everything okay up top?" \\
\hline Time/Transition & Mention of clock time, or time left in & "How long since last \\
\hline
\end{tabular}


procedure, passing of time, indicates dose?"

transition to next phase

"Closing in 15 minutes."

Utterance content was assessed as a function of surgery complexity in order to map patterns of information sharing throughout the procedures. Figure 8 demonstrates similar proportions of utterance content among high and low complexity surgeries. The two most frequent communication topics were equipment (high $=21 \%$, low $=18 \%$ of utterances) and surgery/procedure (high $=16 \%$, low $=23 \%$ of utterances). Differences between complexity groups occurred within patient positioning (high $=14 \%$, low $=8 \%$ of utterance), and medical action (high $=10 \%$, low $=16 \%$ of utterances).

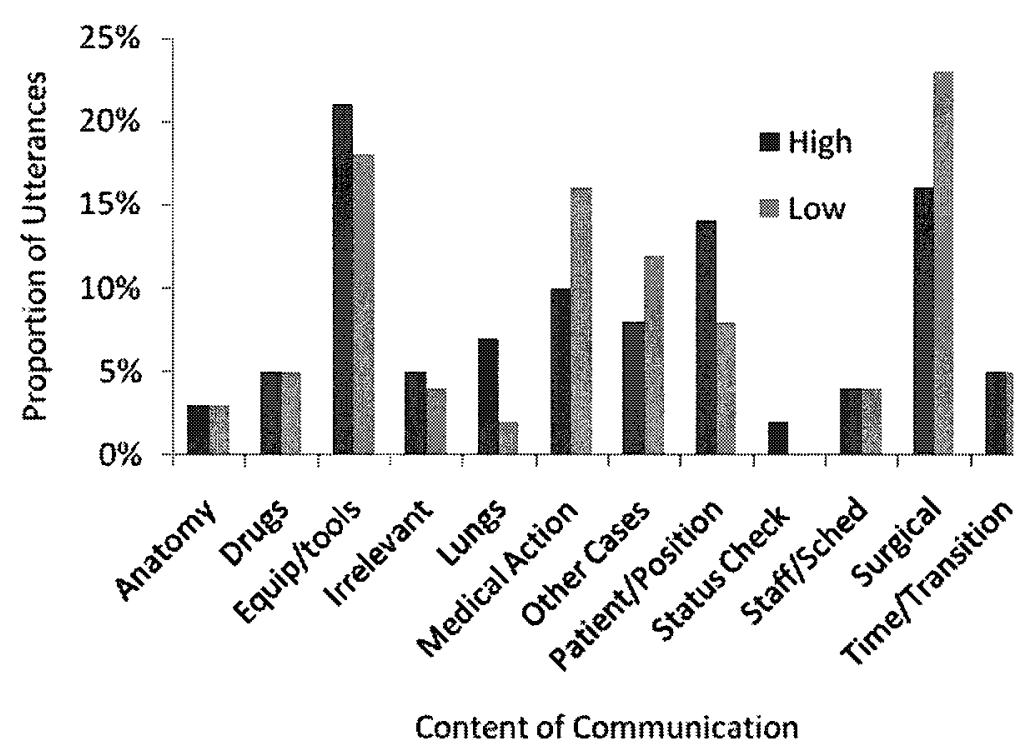

Figure 8. Distribution of communication by content category, for high and low complexity procedures.

Communication content varied as a function of phase, however, this analysis is not presented here because it is replicated in the analysis of content of TSA indicators. To avoid unnecessary overlap, the data can be found in Appendix C. However, one point of 
OR Team Communication, Mental Models, and Situation Awareness 56

interest should be noted here and that is the high proportion of communications concerning other cases in the presence of the current patient. Specifically, other cases accounted for $21 \%$ of all communications within the close in high complexity surgeries and $49 \%$ in low complexity surgeries. From all communications involving other cases, 47\% involved upcoming cases. Upcoming cases included details about the patient or case (23\%), location of patient ( $8 \%)$, tools or equipment needed (12\%), and actions requested (4\%) (e.g., mark surgical site). The rest of other case communication was split between calls for the next patient (29\%), and questions and/or problems about other cases from outside the OR accounted (24\%). Outside disruptions included phonecalls in or other staff entering the OR to ask or share information (14\%), a current team member checking on other cases from within the OR (via calling or in person); and after-effect comments from other case interruption (4\%). These results may suggest multiple layers (i.e, past, current, future) of coexisting TSA and are discussed later.

Analysis of speaker. The proportion of speaker-specific communication was analyzed relative to total communications to assess the distribution of utterances among the team. Figure 9 shows that in both high and low complexity groups, the staff surgeon (S) participated in the largest proportion of communication (49\% and $61 \%$ for high and low complexity, respectively). Circulating nurses ( $\mathrm{CN} 1$ and $\mathrm{CN} 2)$ participated in a combined percentage of $16 \%$ in high, and $21 \%$ of low complexity surgeries. Staff anesthetists (A) participated in $17 \%$ of high complexity, but only $3 \%$ of low complexity surgeries. Scrub nurses (SN), surgical fellows (SF) and anesthesia residents (AR) appeared underrepresented with low proportions of about $7 \%$ and below in both complexity groups. 
OR Team Communication, Mental Models, and Situation Awareness 57

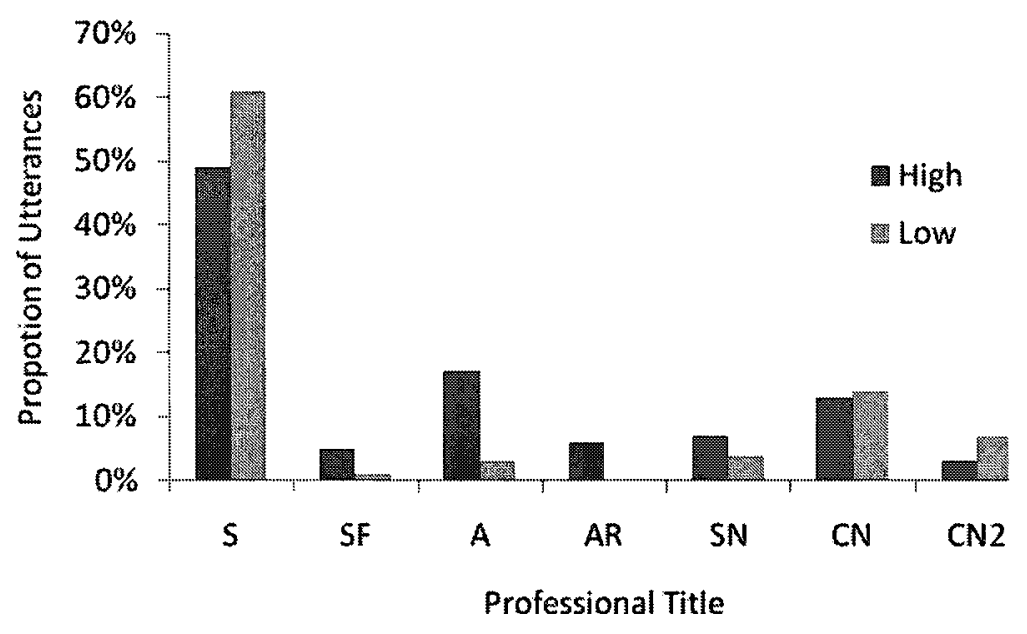

Figure 9. Proportion of communication utterance as a function of speaker for high and low complexity procedures.

Patterns of information flow. Sequential analysis (Siegel \& Castellan, 1988) mapped the flow of teamwork-related communication by assessing the probability of utterances between each discipline. Sequential analysis of communication has been used to map team cognition (Kiekle, Cooke, Foltz \& Shope, 2001), group interaction and critical thinking (Joeng, 2003), and team mental models (Carley, 1997). Using zero-order probabilities, the proportion of times that each team member engaged in conversation with any other member was compared to the total number of utterances. As the thoracic teams often contained six or more people at one time, this data was more clearly illustrated using the three main disciplines (i.e., surgery, anesthesia, nursing), instead of individual professions (i.e., resident, staff). The entire OR team was also represented as a fourth receiver of information, since a large proportion of communications were broadcasted to the team as a whole versus specific people.

The results from the sequential analysis are visualized using link diagrams, where the likelihood of interaction among disciplines (or within a given discipline) is shown 
OR Team Communication, Mental Models, and Situation Awareness 58 with arrows indicating the direction between speaker and receiver. The most likely paths of information flow are highlighted using thicker arrows, and the strength of each connection is denoted by the probability value.

Figure 10 shows that surgery team appears to be the main information hub in both high and low complexity surgeries, with most of the communication either originating from surgery or directed to them. The previous analysis of speaker demonstrated that the staff surgeon and not fellow can be considered the main source of communication. In high complexity surgeries, the most likely paths of communication involved members of surgery, specifically from surgery to anesthesia (.16), followed by surgery to nursing (.15), nursing to surgery (.12), surgery to surgery (.11). In low complexity surgeries, the most likely paths also involved surgery: surgery to surgery (.21), surgery to nursing (.21), surgery to team (.14), and nursing to surgery (.11). Nurses had similar proportions of communication within themselves (.08 and .09 for high and low respectively), while anesthesia had .09 in high and only .03 in low. In both groups, there was a very low proportion of interaction among the nursing and anesthesia teams, $(.04$ and below). The low group also had a higher proportion of communications directed to the team from surgery (.14), compared to the high group (.09). 

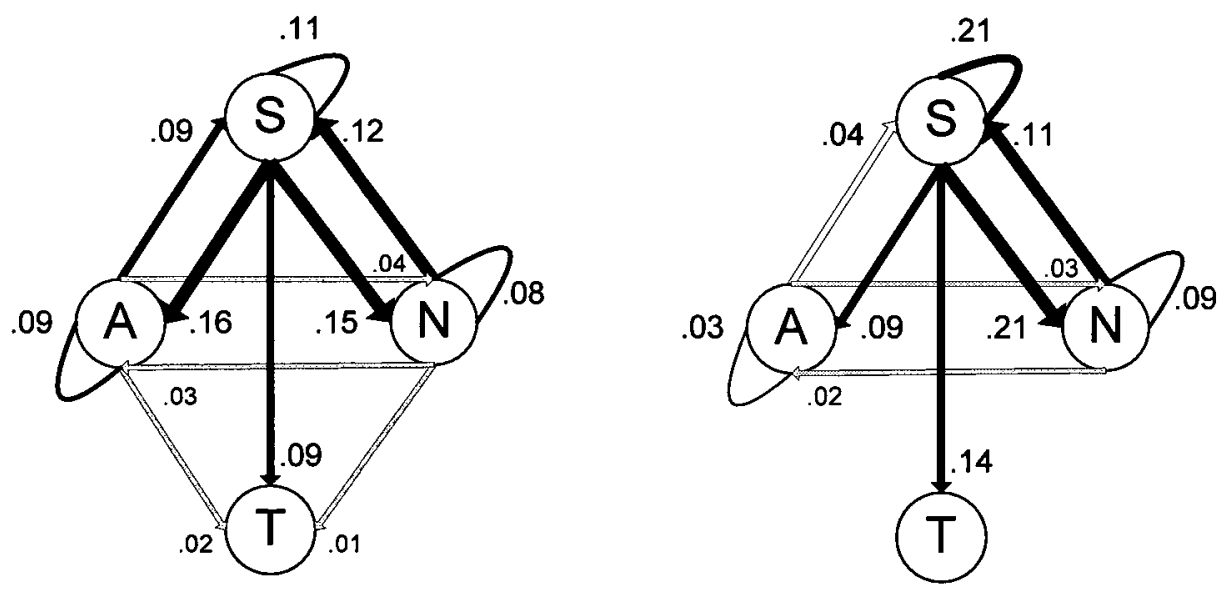

Figure 10. Sequential analysis diagram showing probabilities of information paths; left diagram - high complexity, right diagram - low complexity.

Interim summary of key findings. Thus far, this chapter has described a common structure of thoracic procedures that facilitated the comparison of different procedures. Procedures were grouped into high and low complexity levels, showing that longer, more complex cases were positively correlated with the amount of communication. For both high and low complexity groups, the surgery phase contained the largest proportion of communication. Seeking, responsive and proactive information were the most common communication purposes, and the most likely topic of communication was equipment or surgical-related. The surgeon typically sent and received the most information, and was the only member to address the team as a whole. In high complexity cases, the surgeon was equally likely to speak to the anesthesia or nursing team, while in low complexity cases, the surgeon was more likely to speak with nursing. The lowest probability of interaction in both groups was between anesthesia and nursing. 
OR Team Communication, Mental Models, and Situation Awareness 60

Coding up to this point helped build the foundation for TSA communication as the unit of analysis used to answer the research question. The next cycle of communication coding identified sequences of communication that represented TSA. This coding took into account aspects of the previously coded data by analyzing verbal utterances as meaningful sequences of dialogue within the context of a given phase.

\section{TSA Indicators}

Communication data was analyzed to find verbal exchanges whose purpose was to make the current situation, goals, and envisioned future situations clear, and mutually understood (Hazlehurst, McMullen \& Gorman, 2007). Such communications were categorized as building and maintaining TSA. A second category that emerged from the data were patterns of communications indicating a loss of TSA in the form of miscommunication, need for extended clarification, potential for information loss, and overall disjointed teamwork processes. These potential losses were defined as TSA breakdowns.

Table 3 shows an example of a sequence of utterances reflecting active TSA construction; the surgeon warns the anesthesiologist of an upcoming request, which is acknowledged. The surgeon then proceeds with the request, while also explaining the reasons for his/her actions in a highly coordinated manner. In conversation analysis (e.g., Sacks, Schegloff \& Jefferson, 1974), this is referred to as "turn-taking", and reflects active investment by both parties to share information about the current situation and each other's activities, and thus remain aware of what is going on. A TSA breakdown is represented in Table 4 by a surgeon's surprise due to the actions of the anesthesiologist 
OR Team Communication, Mental Models, and Situation Awareness 61

who has inflated the lung without warning. By not giving advance warning, a surprised surgeon has the potential to damage an inflated lung that interferes with the surgical site.

Table 3

TSA Indicator Showing the Building and Maintaining of TSA.

\begin{tabular}{lll}
\hline Speaker & Receiver & Dialogue \\
\hline S & A & Going to be asking you to puff up lung. \\
A & S & Ok. \\
S & A & Ok puff up. \\
S & A & Going to check to make sure we're not compromising. \\
S & A & Okay, drop again. \\
S & A & Drop lung. \\
\hline
\end{tabular}

Table 4

TSA Indicator Showing Breakdown in TSA

\begin{tabular}{lll}
\hline Speaker & Receiver & Dialogue \\
\hline S & A & Lung is inflating! Did you do something? \\
A & S & You're still ventilating? \\
S & A & Oh sure. \\
A & S & Is that better? \\
S & A & Yes. \\
\hline
\end{tabular}

Across the 14 observed surgeries (excluding outlier), 436 communications (29\%) were considered as TSA indicators. Figure 11 shows that within the high complexity surgeries, $15.83 \%$ of all communications were identified as reflecting TSA breakdowns, while $13.70 \%$ were identified as reflecting TSA maintenance. Within low complexity surgeries, $6.78 \%$ of all communications were considered TSA breakdowns, while $19.07 \%$ 
OR Team Communication, Mental Models, and Situation Awareness 62 were considered TSA maintenance. TSA breakdowns were more likely to occur in high complexity procedures than low. ${ }^{2}$

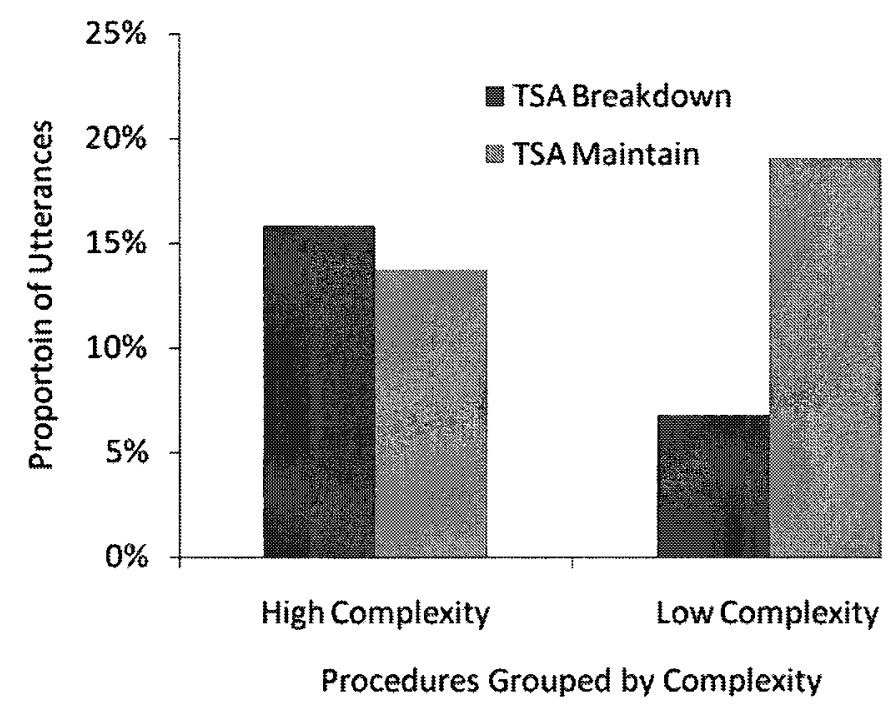

Figure 11. Proportion of total communication reflecting TSA maintenance and breakdowns within high and low complexity groups.

Utterances within TSA sequences were further analyzed as a function of phase to assess the distribution of TSA related communication within procedures. Proportions were calculated by comparing the number of utterances classified as breakdowns or maintenance, to the total number of utterances within each phase. Results show that TSA related communication was distributed differently throughout the surgery as a function of case complexity. Within high complexity surgeries, Figure 12 shows that the largest proportion of utterances reflecting TSA breakdown occurred within the surgery phase ( $18.5 \%$ of surgery communication). The second largest was during the close, accounting for $16.1 \%$ of communication, followed by patient prep (14.8\%), scope $(12.7 \%)$ and then

\footnotetext{
${ }^{2}$ Ignoring the assumption of independence violation, the data in Figure 11 is significant, $X^{2}=4.27, p<.01$.
} 
OR Team Communication, Mental Models, and Situation Awareness 63

lines $(9.7 \%)$. In contrast, low complexity cases had the highest proportion of breakdowns within the lines phase (27.8\%), followed by scope $(6.1 \%)$ and surgery $(2.5 \%)$, with no breakdowns in the other two phases. These results suggest that the team activity within certain phases may be more likely to reflect TSA loss.

Proportions of maintained TSA communication also appeared to differ by complexity. Results indicate that high complexity procedures have the highest proportions of TSA maintenance within the close (18.3\%) and the lines (17.4\%) phase, followed by scoping (14.8\%), prep (11.0\%) and then surgery (10.6\%). Low complexity procedures also show the highest proportion of maintained TSA utterances within the close $(47.10 \%)$, followed by surgery $(19.0 \%)$, lines (11.1\%), and scoping (4.1\%), and none in patient prep. These results suggest that team activity within each phase may affect the way the team maintains TSA.

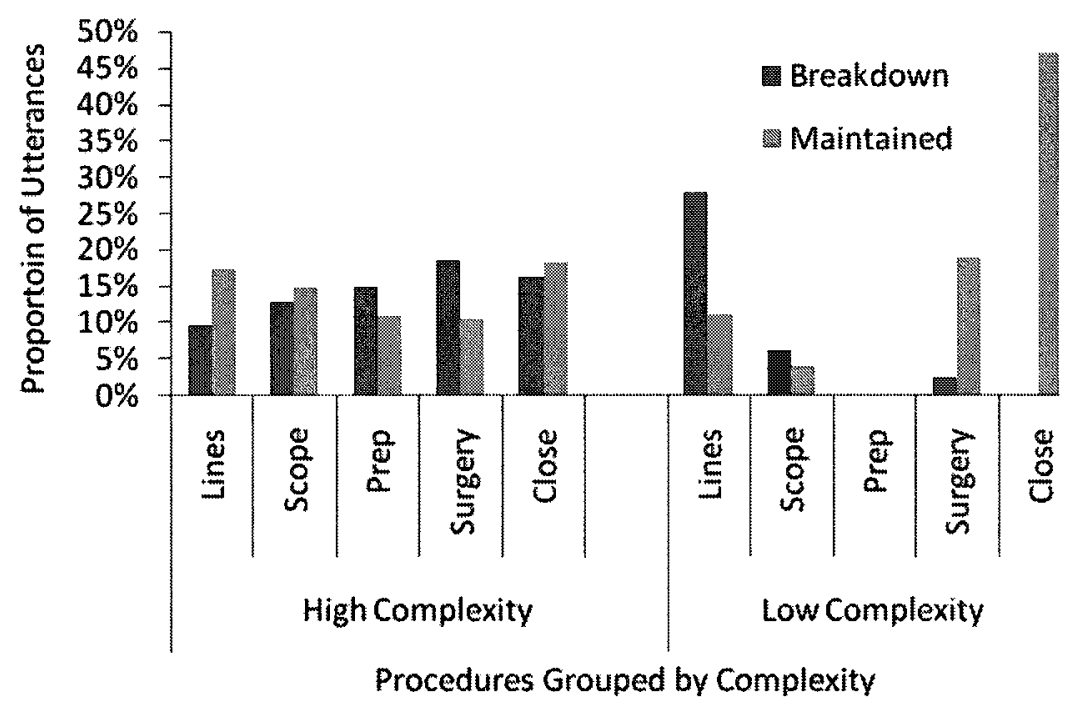

Figure 12. Proportion of utterances within total communication per phase for each type of TSA indicator, as a function of phase and case complexity. 
OR Team Communication, Mental Models, and Situation Awareness 64

An examination of communication type among TSA indicators alluded to differences between breakdowns and maintained TSA. Most notably, Figure 13 shows that within proactive communications, announcements (high $=14 \% \mathrm{vs.}$ low $=6 \%)$ and planning (high $=8 \%$ vs. low $=2 \%$ ) reflected maintained TSA more frequently than breakdowns, suggesting that proactive communications may be more characteristic of maintained TSA. However, concern-raising was associated with more TSA breakdowns ( $11 \%$ vs. $3 \%$, which fits with the definition of breakdowns as indicative of problems. These results could have generalizable implications for finding TSA indicators in other teams.

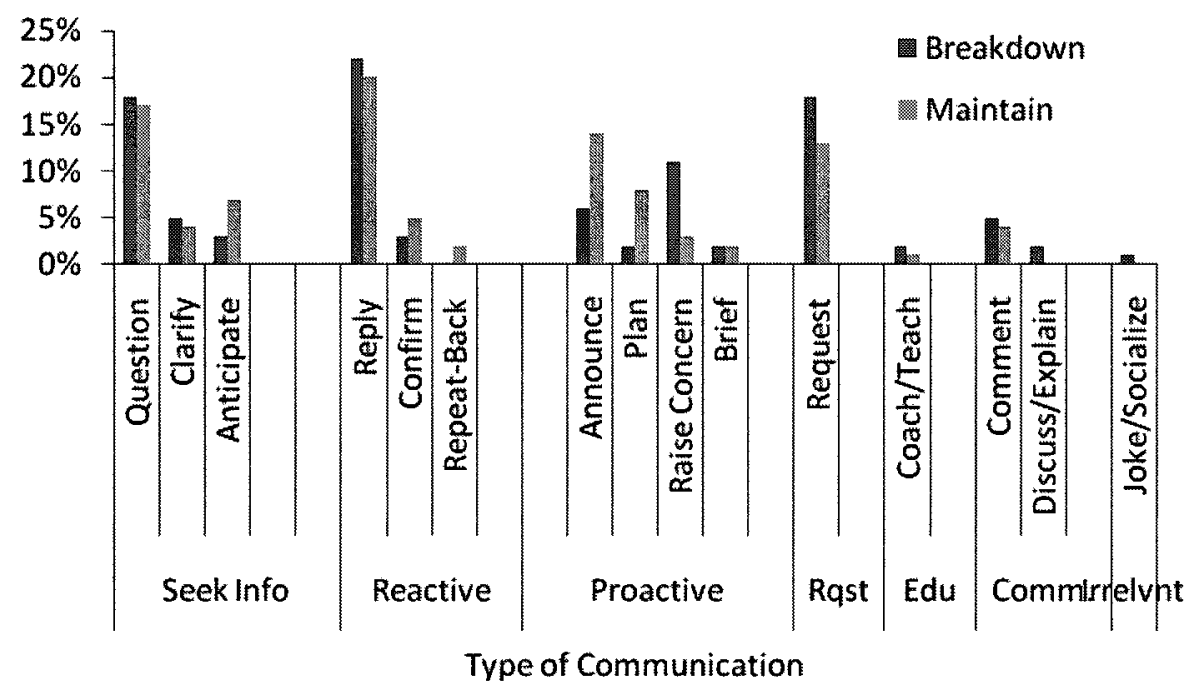

Figure 13. Communication type as a function of overall utterances within each type category.

Information flow within TSA breakdowns. Sequential analysis assessed the probability of speakers most likely to be involved in TSA communication breakdowns. Healthcare workers were grouped into sub-teams of disciplines involved (i.e., surgery, anesthesia, nursing and everyone) and the zero-order probabilities were calculated from 
OR Team Communication, Mental Models, and Situation Awareness 65

the total sample of 217 breakdown utterances. Figure 14 (left-hand diagram) shows the surgeon as the most likely to be involved in TSA breakdowns. Particularly, breakdown communication tended to travel from surgery to nursing (.24), nursing to surgery (.15), surgery to the team (.15), and surgery to anesthesia (.14). Slightly less probable paths were between anesthesia to surgery (.08), and within the surgery team (.07). All other paths were very infrequent $(<.05)$, in particular, both directions of nursing and anesthesia were approximately .01 . Note that $3.2 \%$ of the overall breakdown utterances were between a team member and someone from outside the OR (e.g., caller), and thus were included in the total amount of communications since dialogue seguences also included team members, but others were not represented in the link diagram.

There appear to be different patterns of information flow for communication reflecting maintained TSA. Figure 14 (right-hand diagram) shows that the most likely paths of information flow were from anesthesia to surgery (.29), back from surgery to anesthesia (.21), from surgeon to the team (.11), and from nursing to surgery (.09). All other dyads had very low probability of communciation (below .06). Note that a .05 probability of communication occurred among the team and 'others' but is not displayed. 

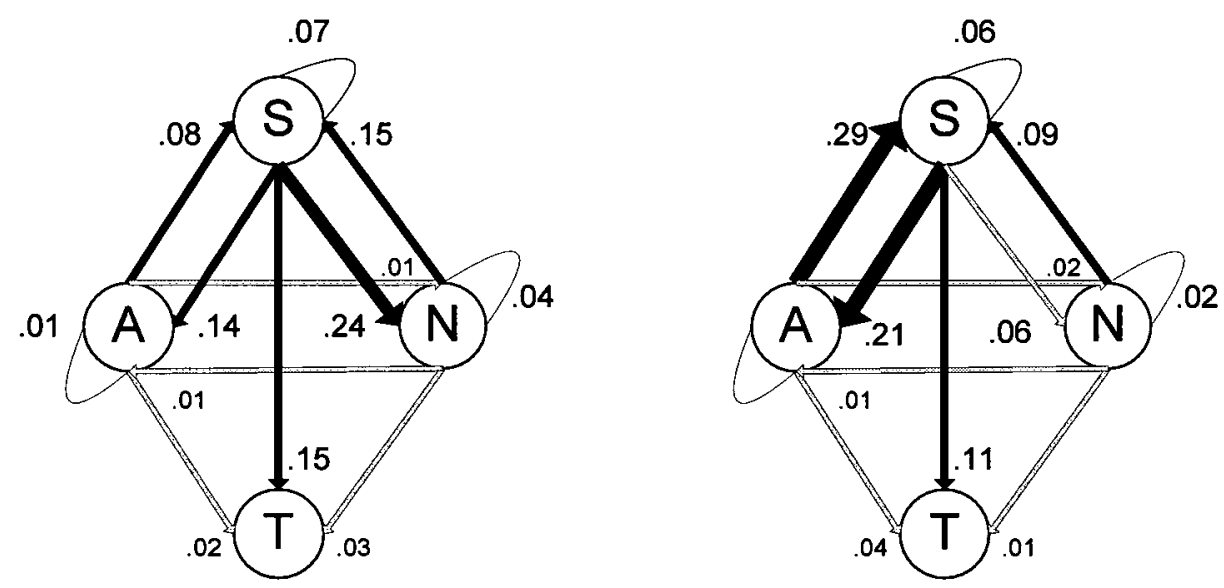

Figure 14. Link diagram illustrating probability of information flow involved in TSA indicators between members; left - TSA breakdowns, right - maintained TSA.

Surgery-specific TSA categories. The coding of communication content of TSA indicators assisted in subsequently drawing implications specific to thoracic surgery. The content categories identified within the TSA indicators reflected the lungs, equipment, patient position, schedule, and procedure. The preoperative pause (composed of patient and drug related content) was identified as an additional category of TSA indicator due to the frequent issues noted during observations and discussed later. Next, each content category is first operationally defined in terms of TSA built/maintained or breakdown, followed by an example.

Lung TSA was considered built and maintained when surgeons and anesthesiologists established joint attentiveness about the patient's airways. In the example below, TSA is first built by the surgeon warning the anesthesiologist that a request will be made, which allows time to divert attention to the surgeon's needs. The surgeon then makes the request, and explains his/her actions, creating a mutual understanding of the situation. 
OR Team Communication, Mental Models, and Situation Awareness 67

S: I'm going to be asking you to puff up the lung.

A: Okay.

S: Okay, puff up.

S: I'm going to check to make sure we're not compromising.

In contrast, lung TSA is considered to breakdown when the anesthesiologists did not inform the surgeon that the lungs were sufficiently inflated/deflated; the surgeons did not warn the anesthesiologist about their actions near the heart; the anesthesiologist does not warn Surgeon about something they do to the lungs; or there was lack of confirmation for requests. In the example below, the surgeon is surprised at the actions of the anesthesiologist who has inflated the lung without telling the surgeon.

\section{S: Lung is inflating! Did you do something?}

A: You're still ventilating?

S: Oh sure.

Position TSA was considered maintained when the surgeon and anesthesiologist successfully negotiated the position of the patient, or coordinated actions during any movement of the patient. In the example below, TSA is built by the anesthesiologist initiating the move. By asking if the surgeon is ready, it gives the surgeon time to finish his/her current task and to divert attention to where it is needed. The anesthesiologist then synchronizes the team's moves by warning them of a count, and proceeding to count to three to ensure coordination of the move.

\section{A: Tu prêt? Ready to move the patient?}

S: [nods, comes to table]

A: Prepare to move patient on 3

A: $\quad \ldots$ On $3,1-2-3$ 
OR Team Communication, Mental Models, and Situation Awareness 68

Breakdown in position TSA was identified when there was a lack of leadership, particularly when initiating the move; those necessary to move the patient were not present, or unable to be located when needed; or the actual move was off-timed, causing awkward and potentially dangerous forces to the sedated and intubated patient. In the example below, the count was established by the surgeon, who is actually unprepared for the move.
S: Okay, let's turn.
S: $\quad$ When you're ready, count it.
A: $\quad 1-2-3$
S: $\quad$ No no no! I'm not in yet!

Equipment TSA was considered maintained when a member of the team requested a piece of equipment, which is correctly acted upon. TSA was also maintained when an equipment need was anticipated, eliminating the need for a request. In the example below, the circulating nurse anticipates the needs of the anesthesiologist, instead of waiting to be asked.

CN: Anything you need?

A: No, all good.

A: Actually, might need a pressure bag.

$\mathrm{CN}: 500 ?$

A: $\quad 500, y a$.

Breakdowns in Equipment TSA were considered to occur when an extended information exchange is needed to reach common understanding of a tool; the wrong tool was brought due to a miscommunication; or the OR was not properly equipped with tools needed, or unexpected tool is requested. In the example below, TSA broke down through confusion over the exact type of stapler needed by the surgeon. The surgeon's initial stapler request 
required clarification from the nurse, and the process of clarification ends up confusing the surgeon to what was even asked in the first place.

S: We're going to need an endostapler.

$\mathrm{CN}$ : Blue or green?

$\mathrm{CN}$ : Is the first one green or blue?

SN: Blue I believe, but I'll check for you.

$\mathrm{SN}:$ Did you want a vascular?

S: Did I say blue?

$\mathrm{SN}$ : I don't know, I thought I heard blue.

S: It's not what I say, it's what I mean.

Schedule $S A$ was considered maintained when the team discussed the details or needs of upcoming cases, such as patient identity and procedure expectations (which in cases of breakdown can lead to the infamous wrong patient/wrong site/wrong procedure). In the example below, the anesthesiologist and surgeon brief about patient's health score and medication for the upcoming case, facilitating the transition from the current case to the next.

A: $\quad$ There's no anesthesia in chart out there, -so when he's ready, I'll see the man.

A: $\quad$ Patient is only $2.8 *$.

S: Is that okay for anesthesia?

A: I'll just go ahead

SF: $\quad H e$ 's not acute

SN: Do we have endozyme made up already?

$\mathrm{CN1}$ : Ya, on the floor over there.

*Rating of patient health $/ 5$, lower scores $=$ better 
Schedule TSA was considered to breakdown when a team member is confused when the current patient is not who they were expecting; that day's case order is switched without knowledge of key team member; the OR is not properly equipped for case switch. In the example below, TSA is lost when a different patient was on the table, meaning different equipment (i.e., bronchoscope) was needed.

\section{S: Oh it's this patient. They switched them around?}

S: I thought we were doing an epidural??

SF: It got moved up.

S: $\quad$ They've got to stop switching the order - we'll need a bronch...

Interruption from other cases was an extension of TSA breakdown within the scheduling category. This category described TSA issues related to interruption from cases that were not the primary responsibility of the observed team. Loss of TSA due to other cases occurred when a phone call into the OR required the surgeon or anesthesiologist to stop current activity; the surgeon needed to call out of OR during surgery to discuss or check on other case while in middle of current case; individuals from outside the OR entered in to ask questions, or update status of a different case, cause interruption in current case; or members continued to discuss the delays that just occurred still causing them to stop what they are doing. In the example below, the current case was interrupted by a call from outside the OR who needed to consult the surgeon about another critical case in another unit. The whole team stopped their activities to listen, and the entire case was delayed for at least 7 minutes (more after call ended).

$\mathrm{S}: \quad$ [Request for someone to call OR]

$\mathrm{CN}$ : Get him on the line, let's see what going on.

Caller: Blood through traech site, through tube...

S: $\quad$ This is a serious case,... 
OR Team Communication, Mental Models, and Situation Awareness 71 [7 minute delay, all team stopped to listen]

S: $\quad$...that's what this does, takes us away from patient on table

TSA concerned with the preoperative pause was considered built and maintained when it was announced in the presence and attention of the full team, contained all of the necessary information about the case (patient name, consent, procedure, antibiotics) and said with sufficient volume and clarity to be heard by the whole team. In the example below TSA was established because all members were present (noted in contextual information of data), and the necessary information was announced by the surgeon to an attentive team. The surgeon inquired about the antibiotic administration, which is confirmed clearly by the anesthesiologist.

\section{S: Did you do a pause?}

CN1: Not yet

$\mathrm{S}: \quad$ [Patient name, procedure]

S: A.B. in?

A: Yes

On the other hand, TSA was considered to breakdown if there was a person(s) or information missing during the pause; the pause is too quiet to hear, or the speaker does not completely finish pause; the speaker has difficulty getting team's attention, or the pause is announced without the team's full attention; the pause is said incorrectly. In the example below, TSA is considered to breakdown because although it was announced clearly by the nurse, the surgeon fellow was not paying attention and did not respond to the question about antibiotics. Furthermore, the surgeon enters and also begins to initiate the pause, but when the nurse indicates that is was already done (clearly in the absence of the surgeon), the information was not repeated.

CN: [Announces patient's name, allergies, asks if Antibiotics are in yet] 
OR Team Communication, Mental Models, and Situation Awareness 72

CN: Antibiotics?? [cough cough- to get SF's attention; *S not present]

$\mathrm{SF}: \quad$ [No clear response]

S: [S enters] Got everything there?

CN: $Y a$.

S: $\quad$ There's no need for Ancef (AB)

$\mathrm{SN}$ : We already did the pause.

Procedure TSA was maintained when intentions or actions about the surgical procedure itself, were clear and collectively understood. The communication was purposefully directed and had the expected reply when appropriate. In the example below, TSA is built as the surgeon and the anesthetist establish a common ground regarding the timeline of the procedure.

$\mathrm{S}$ : We've completed this section, now going to do our open.

S: What was our start time frame? 10:30?

$\mathrm{CN}$ : yes

A: $\quad 2 / 12$ hours, that's excellent!

On the other hand, breakdown in procedure TSA occurred when a team member was unclear on timeline of surgery (e.g. ended sooner than expected); team member was unaware or surprised by another's actions. In the example below, TSA is considered lost because the information about the surgeon's whereabouts was not properly disseminated to the team, whether by the surgeon or by other team members who knew this information.

A: Can we start now, or are we waiting for your people?

A: Because we don't want to have patient falling asleep for 15 minutes for no reason ( $A$ is annoyed)

$\mathrm{SF}: \quad Y a$, just waiting for $[S]$ 
OR Team Communication, Mental Models, and Situation Awareness 73

To map patterns of TSA, communication was assessed in terms of the proportion of utterances reflecting breakdowns or maintenance relative to total communications within each procedure complexity group. Results showed differences in the proportion of TSA communication within each content category as a function of high and low complexity groups. Figure illustrates differences in TSA content as a function of indicator type. Within high complexity procedures, TSA breakdowns were most apparent within communication about equipment (33.33\%), while TSA maintenance was most apparent within communication about the lungs (32.18\%). Within low complexity procedures, TSA breakdowns and maintenance were most apparent within communication about the procedure $(69.75 \%$ and $48.89 \%$ respectively). These results may suggest that the team may be more effective in maintaining TSA when communicating about the lungs, than when communicating about equipment. It is possible that these patterns reflect a higher priority on maintaining awareness of the patient than on the equipment used during the procedure. 
OR Team Communication, Mental Models, and Situation Awareness 74

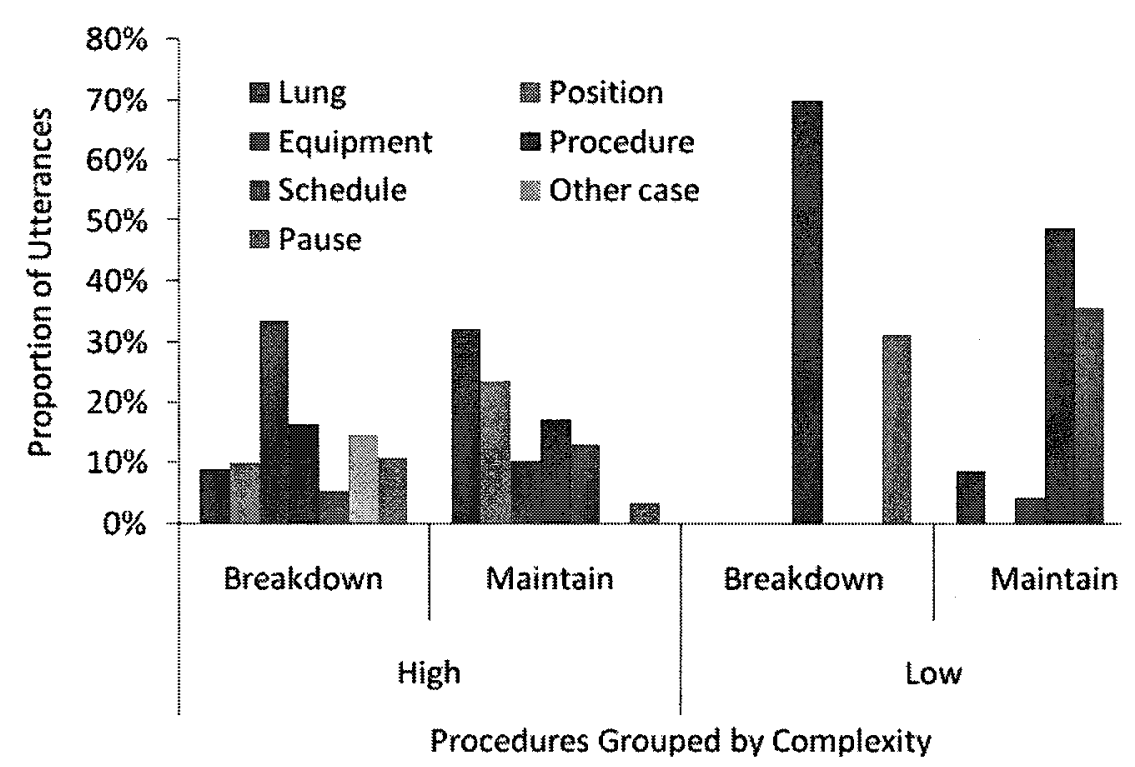

Figure 16. TSA indicators as a function of content categories.

Summary. Different proportions of TSA indicators were found within each content category. Procedure-related TSA was maintained most frequently within the procedure, whereas equipment-related TSA were most associated with breakdowns. High complexity surgeries were most likely to contain both types of indicators, but primarily showed breakdowns regarding equipment, while maintaining TSA regarding the lungs. Furthermore, breakdowns were more likely to involve the surgeon and nurse, whereas maintaining TSA was more likely to involve the surgeon and anesthesia. These results are in line with the topic of conversation, since the surgeon tends to request equipment from the nurses and discusses the lungs with anesthesia.

These iterative coding cycles helped to guide the post-observations interviews with the observed team members in the third phase of the study. Notable patterns of communication, such as surgeon-oriented information sharing and breakdown vulnerability, alerted the researcher of possible areas of interest in which to probe the 
OR Team Communication, Mental Models, and Situation Awareness 75

interviewees. The following section describes the analysis of post-observation interviews, which was the foundation of mental model construction.

\section{Team Mental Models}

In order to create a common basis for linking between mental models and TSA communications, TMMs were defined by collecting meaningful information chunks from the interview that related to the previously defined TSA categories. For example, a surgeon, resident anesthetist, and a nurse that were observed together in a given surgery were interviewed. From their interviews, knowledge related to content categories from the communication analysis (e.g., lungs, equipment, the pause etc.) was extracted to be used in the TMM. Consequently the TMMs for this particular procedure would contain knowledge from these three interviewees. This method facilitated the eventual comparison of the TMM to the actual TSA indicators.

TMMs were represented by matrices as a means to systematically organizing the data to compare knowledge. Table 5 illustrates an example matrix; the columns represent the knowledge from each team member, while rows group similar themes of information across members.

Table 5

A General Template for Team Mental Model Matrix.

\begin{tabular}{|c|c|c|c|}
\hline & \multicolumn{3}{|c|}{ OR Team Members } \\
\hline & Team Member X & Team Member Y & Team Member Z \\
\hline .0.0 & Task 1 & Task 1 & Task 1 \\
\hline$\underset{\leftarrow}{\overleftarrow{H}}$ & Task 2 & Task 2 & Task 2 \\
\hline
\end{tabular}


In addition to chunking interview data according to the content categories, information within the team mental models was also coded based on the specificity of team (i.e., individual members and/or team characteristics) and of task (i.e., physical and procedural aspects of the work environment) knowledge described in the literature review. The aim was to find overarching themes that could be used to categorize the type of information that made up the gap. Note, however, that in this analysis, team knowledge was never specific because for reasons of anonymity and participants described themselves or particular people only by their respective disciplines. As such, some of the information may actually be representing specific knowledge, even though it was categorized as related. This limitation is discussed later. Table 6 illustrates TMMs for each of the TSA content categories. The full list of TMM analyzed can be found in Appendix D. Note that the combination of team members varies depending on the surgery observed and individuals interviewed. Once the team mental models were created in relation to the TSA categories, the columns representing individual members were compared in order to identify possible gaps among knowledge of similar themed content. The following section describes the processes of identifying gaps and similarities in team mental models.

Table 6.

TMM of Each TSA Content Category by Team and Task Specificity/Relatedness Knowledge Type Team Knowledge

\begin{tabular}{llll}
\hline Lungs & S11 & A1 & A6 \\
\hline Team related/ & Patient is well- & A may ask S if they & S will confirm lungs \\
Task specific & managed from both & want lungs down, or & down with A, if A \\
& sides & S may request from & on the "ball" this
\end{tabular}


OR Team Communication, Mental Models, and Situation Awareness 77

A

will be done

already, but may

have to do it when $\mathrm{S}$

asks.

\begin{tabular}{|c|c|c|}
\hline Equipment & S11 & N14 \\
\hline $\begin{array}{l}\text { Team related/ } \\
\text { Task related }\end{array}$ & $\begin{array}{l}\text { If N's not usually } \\
\text { with team, need to } \\
\text { be more vocal, ask } \\
\text { for equipment, less } \\
\text { anticipation }\end{array}$ & $\begin{array}{l}\text { Surgeons don't know equipment as well as } \\
\text { nurses, don't always ask for what they } \\
\text { want }\end{array}$ \\
\hline Position & S12 & A9 \\
\hline $\begin{array}{l}\text { Team related/ } \\
\text { Task specific }\end{array}$ & $\begin{array}{l}\mathrm{S} \text { and A negotiate } \\
\text { the patient's position }\end{array}$ & $\begin{array}{ll}\text { Move: A in charge, } & \text { Move: when done } \\
\text { (but whoever is at } & \text { scope, and A done } \\
\text { head, may be AR), } & \text { with lines } \\
\text { does count } & \end{array}$ \\
\hline Schedule & S11 & N3 \\
\hline $\begin{array}{l}\text { Team related/ } \\
\text { Task related }\end{array}$ & $\begin{array}{l}\text { Know day before if } \\
\text { order changes, } \\
\text { unusual not to know } \\
\text { change in same day }\end{array}$ & $\begin{array}{ll}\text { AR meets pat in AM } & \text { N checks with RFA } \\
\text { pre-surgery (delayed } & \text { (yellow sheets) - } \\
\text { if } \mathrm{N} \text { bring pat in } \mathrm{b} 4 & \text { contains } \mathrm{S} \text { requests } \\
\text { AR has seen them) } & \end{array}$ \\
\hline Pause & $\mathrm{S} 2$ & N3 \\
\hline Task specific & $\begin{array}{l}\text { Pause: After scope } \\
\text { and move; }\end{array}$ & $\begin{array}{ll}\text { Pause is done before } & \text { Pause: usually } \\
\text { incision (but varies, } & \text { occurs when } \\
\text { may forget pause!) } & \text { scoping, }\end{array}$ \\
\hline Procedure & S2 & N10 \\
\hline $\begin{array}{l}\text { Team related/ } \\
\text { Task specific }\end{array}$ & \multicolumn{2}{|c|}{$\begin{array}{l}\text { Towards end, } \mathrm{S} \text { leaves tubes } \\
\text { in chest cavity, tells } \mathrm{N}, \\
\text { initiates close }\end{array}$} \\
\hline
\end{tabular}


OR Team Communication, Mental Models, and Situation Awareness 78

Gaps/similarities in team mental models. Knowledge within mental models was compared and contrasted in order to identify gaps and similarities. This thesis defines gaps in mental models as disconnected expectations or beliefs about a particular event or object in the OR team environment, that is, information within the TMM that appears opposite or conflicting to the extent that members hold different expectations about the same situation. Similarities in mental models were defined based in previous research (e.g., Cannon-Bowers \& Salas, 2001; Cannon-Bowers et al, 1993; Langan-Fox, Anglim \& Wilson, 2004; Lim \& Klein, 2006) as either identical (i.e., common, if not identical, knowledge between members), overlapping (i.e., some common knowledge between members, but necessarily fully redundant knowledge), and compatible (i.e., models may not need to have shared or similar knowledge, but that the knowledge must lead members to draw similar expectations for performance).

Table 7 is an example TMM that highlights possible gaps using underlined text, while similarities are shown in bold. Within the TMM, the three members seem to have conflicting views about the start time of the pause; the surgeon indicated that it usually begins after the scope and moving of the patient, and the anesthesiologist says it is before the incision. While these two perceptions appear compatible, (as the incision follows the scope and patient positioning), the nurse reported that the pause occurs while scoping, which conflicts with the first two models. Using this method of comparison, identified gaps and similarities within each TMM were eventually compared to TSA related communication. For efficiency purposes, gaps and similarities within TMM are presented and explained within the analysis of associations between TMM and TSA. This method was chosen because the overall goal was to compare gaps and similarities in 
TMM to the TSA indicators, and not to focus on specific gaps within TMMs exclusively. In the final analysis, links between the gaps/similarities in TMM and the TSA indicators were identified by similar content categories of TSA indicators.

Table 7

Gap/Similarity Identification in TMM Concerning the Pause.

\begin{tabular}{|l|l|l|l|}
\hline Type of knowledge & S2 & A1 & N3 \\
\hline Task Specific & $\begin{array}{l}\text { Pause: After } \\
\text { scope and move; }\end{array}$ & $\begin{array}{l}\text { Pause is done before incision } \\
\text { (but varies, may forget } \\
\text { pause!) }\end{array}$ & $\begin{array}{l}\text { Pause: usually } \\
\text { occurs when } \\
\text { scoping }\end{array}$ \\
\hline
\end{tabular}

Linking Mental Models to TSA

Links between TMM and TSA indicators were defined as a function of the TSA content categories: the pause, the lungs, procedure, equipment, and schedule. In an effort to efficiently and effectively represent the links, specific TSA utterances that best reflected either a breakdown or building and maintaining TSA were isolated from the longer TSA sequence. Then, information within TMMs that most clearly constituted the gap or similarity and corresponded to the TSA content category were isolated and included in the link. The link itself is represented by contrasting the selected TSA utterances to information from the TMM. The strength of link is defined by the specificity of the TMM knowledge in relation to the TSA indicator. Generally, specific team and task knowledge indicated stronger links than related knowledge.

Two types of links were identified: symmetrical and asymmetrical links. Symmetrical links connected a gap in the TMM to a breakdown in TSA communication, or equally, agreement in the TMM to maintained TSA communication. Asymmetrical 
OR Team Communication, Mental Models, and Situation Awareness 80

links represented a mismatch of either TMM gaps to TSA maintenance, or TMM agreement to TSA breakdown. The following tables provide detailed explanation of example links for each TSA category. The full list of links can be found in Appendix D.

Table 8 illustrates a symmetrical link between gaps in TMM and TSA breakdown within the context of the lungs. The TMM gap comes from A1, who feels that communication is only needed when something needs to be done, versus S11 who feels there should be constant updating. The link to TSA comes from the surgeon's surprise (and potentially disrupted) by the unexpected lung inflation, as there was no pre-warning by anesthesia.

Table 8

Link Between TMM Gap and TSA Breakdown Regarding Lungs

\begin{tabular}{|l|l|l|}
\hline \multicolumn{2}{|l|}{ TMM Gap } & TSA Breakdown \\
\hline S11 & $\begin{array}{l}\text { S tells A when problems, updates } \\
\text { throughout }\end{array}$ & $\begin{array}{l}\text { S: Lung is inflating. Did you do something? } \\
\text { A: You are still ventilating? } \\
\text { S: Oh sure. }\end{array}$ \\
\hline A1 & $\begin{array}{l}\text { Only communication if something } \\
\text { needs to be done, A will alert S if } \\
\text { needed }\end{array}$ & \\
(Team/Task Related)
\end{tabular}

Table 9 shows a symmetrical link between similarities in the TMM and building and maintenance of TSA. S12 and A6 have identical knowledge about keeping one another in the loop about what is going on with each other's activities, by "constantly checking in" and "checking to see how things are going". The link is demonstrated in the interaction of the surgeon asking how things are going, and then asking the anesthesiologist if there is a concern for saturation. This link is considered strong because 
OR Team Communication, Mental Models, and Situation Awareness 81

although the TMM knowledge is related, the communication is related as the mental models clearly describe the TSA related communication.

Table 9

Link between TMM agreement and TSA maintenance regarding Lungs

\begin{tabular}{|l|l|l|}
\hline \multicolumn{2}{|l|}{ TMM Agreement } & TSA Maintenance \\
\hline S12 & $\begin{array}{l}\text { Ask A how things going, if okay to } \\
\text { extubate - constant checking in }\end{array}$ & $\begin{array}{l}\text { S: How are we doing over there? } \\
\text { A: Not bad }\end{array}$ \\
& $\begin{array}{l}\text { S: Are you worried about saturation? } \\
\text { A: Ya, a bit. }\end{array}$ \\
\hline A1 & $\begin{array}{l}\text { A will check over curtain to see } \\
\text { how things going }\end{array}$ & \\
& (Team/Task Related) & \\
\hline
\end{tabular}

Table 10 shows an asymmetrical link where TSA is maintained when the surgeon initiates the turn and the anesthesiologist coordinates with the count. However, once the move is underway, the surgeon realizes that there is a problem (i.e., "I'm not in yet!). This appears to get resolved when the surgeon gives permission to go ahead; however, the team fails to notice that the patient's legs are slowly rising under the equipment table. When the surgeon notices it is already too late and the patient table hits some equipment, causing it to crash on the floor. So, while the mental models are identical in the roles and responsibilities of the move in terms of who initiates and who counts, this is not enough to prevent the momentary loss of TSA in the actual turning of the patient.

Table 10

Link Between TMM Agreement and TSA Breakdown Regarding Patient Positioning

\begin{tabular}{|l|l|l|}
\hline \multicolumn{2}{|l|}{ TMM Agreement } & TSA Breakdown \\
\hline S7 & $\begin{array}{l}\text { S in charge of the turn, but A is at } \\
\text { head, does the 1-2-3 }\end{array}$ & S: Ok let's turn \\
& & A: $1-2-3$ \\
& (Team Related/Task Specific) & S: No, no I'm not in yet!! \\
\hline
\end{tabular}




\begin{tabular}{|l|l|l|}
\hline A8 & $\begin{array}{l}\text { Move takes 2-3 steps; A rallies for } \\
\text { turn, keeps track of lines \& tubes; } \\
\text { Whoever holding head is the leader } \\
\text { (should be A) 1,2,3; A counts "on } \\
\text { my count, going to turn" } \\
\text { (Team Related/Task Specific) }\end{array}$ & $\begin{array}{l}\text { S: Ok, now you can tighten. } \\
\text { hits SN's table, equipment falls] }\end{array}$ \\
\hline
\end{tabular}

Table 11 shows a symmetrical link between similarities in the TMM of positioning the patient and TSA communication that is built and maintained. The link is considered strong because the TMM contains details specific to the content discussed within the TSA indicators. Both members appear to hold compatible knowledge that either the surgeon or the anesthesiologist should initiate the turn, and whoever is at the head leads the count to coordinate the team. These roles and responsibilities are consistent with the TSA communication, as the anesthesiologist initiates the turn by ensuring the team is ready, and then coordinates the positioning of the patient.

Table 11

\section{Link Between TMM Agreement and TSA Built and Maintained Regarding Patient}

\section{Position}

\begin{tabular}{|l|l|l|}
\hline \multicolumn{2}{|l|}{ TMM Agreement } & TSA Built and Maintained \\
\hline S7 & $\begin{array}{l}\text { S in charge of the turn, but A is at } \\
\text { head, does the 1-2-3 }\end{array}$ & $\begin{array}{l}\text { A: Tu près? Ready to move patient? } \\
\text { S: [nods, comes over] } \\
\text { A: Is everyone ready to turn? }\end{array}$ \\
& S: On 3, 1-2-3 \\
A1 & $\begin{array}{l}\text { Turn: No clear leader, but surgeon } \\
\text { should be directing, but may be A } \\
\text { (whoever is at head) - depends on S }\end{array}$ & \\
& $\begin{array}{l}\text { [patient turned on side] } \\
\text { (Team Related/Task Specific) }\end{array}$ & \\
\hline
\end{tabular}

Table 12 illustrates an asymmetrical link where the TMM was identical in terms of agreeing that the surgeon should indicate close to help anesthesia, however in this 
case, the surgeon did not warn the team. As a result, the anesthesiologist experiences a

loss in TSA when the case ends earlier than anticipated.

Table 12.

Link Between TMM Gap and TSA Breakdown Regarding the Procedure.

\begin{tabular}{|l|l|l|}
\hline \multicolumn{2}{|l|}{ TMM Agreement } & TSA Breakdown \\
\hline S2 & $\begin{array}{l}\text { Towards end, S ... initiates close } \\
\text { Time important, so A can plan } \\
\text { when to finish up }\end{array}$ & $\begin{array}{l}\text { S: Thank you } \\
\text { [Surgeon leaves] }\end{array}$ \\
A1 & $\begin{array}{l}\text { When next pat is called, A knows } \\
\text { to start pulling out and taking off } \\
\text { equipment }\end{array}$ & $\begin{array}{l}\text { SN: Ya, we're finished } \\
\text { A: can never really tell, it's only 2:15...not sure } \\
\text { what's going on }\end{array}$ \\
\hline N3 & $\begin{array}{l}\text { S may announce how much time } \\
\text { left (e.g. 20 min then done) } \\
\text { A prefers S to tell how much time } \\
\text { is left - helps to know about when } \\
\text { to wake up, don't like to be } \\
\text { surprised }\end{array}$ & \\
\hline
\end{tabular}

Table 13 shows a symmetrical link between similarities in the TMM and building TSA concerning procedure. S11 and A6 have identical knowledge about the surgeon announcing time until close. In the TSA communication, the surgeon announces the close, so team knows to start their related close activities. The link is considered strong because the TMM knowledge pertains specifically to the TSA communication.

Table 13

Link Between TMM Agreement and TSA Building and Maintaining Regarding the Procedure.

\begin{tabular}{|c|c|c|}
\hline \multicolumn{2}{|c|}{ TMM Agreement } & TSA Built and Maintained \\
\hline S11 & $\begin{array}{l}\text { S tells A when closing - time to finish; } \\
\text { Time important, so A can plan when to } \\
\text { finish up } \\
\text { (Team Related/ Task Specific) }\end{array}$ & $\begin{array}{l}\text { S: Okay, I'm going to pull back now } \\
\text { [indicating close] } \\
\text { A: Thanks. }\end{array}$ \\
\hline
\end{tabular}




\begin{tabular}{|l|l|l|}
\hline A6 & $\begin{array}{l}\text { A prefers S to tell how much time is left } \\
- \text { helps to know about when to wake up, } \\
\text { don't like to be surprised }\end{array}$ \\
(Team Related/ Task Specific)
\end{tabular} \mid

Table 14 illustrates a symmetrical link between the gaps in TMM about scheduling information and a breakdown in schedule TSA. In this case, both S7 and A9 share compatible knowledge that the case is briefed about beforehand. The nurse however, reports that schedule changes do occur, but there is a good chance that this information does not get passed along to the surgeon in time. The resulting link to TSA breakdown occurs when the surgeon enters the OR and is surprised by the unexpected case, which also created equipment delay.

Table 14

Link Between TMM Gap and TSA Breakdown Regarding Scheduling.

\begin{tabular}{|c|c|c|}
\hline \multicolumn{2}{|c|}{ TMM Gap } & TSA Breakdown \\
\hline S7 & $\begin{array}{l}\text { S will have briefed with SF night } \\
\text { before (or will do at sink during } \\
\text { scrub) } \\
\text { (Team related/ Task related) }\end{array}$ & $\begin{array}{l}\text { S: oh it's this patient. They switched them } \\
\text { around! } \\
\text { S: I thought we were doing an epidural?? } \\
\text { SF: It got moved up }\end{array}$ \\
\hline N10 & $\begin{array}{l}\text { May try to switch case order if big } \\
\text { delays, make efficient. Pass info } \\
\text { onto Surgeons, but } 50 / 50 \text { if they } \\
\text { know or not, adapt as best they can } \\
\text { (Team related/Task specific) }\end{array}$ & $\begin{array}{l}\text { we'll need a bronch - } \\
\text { S: Even the patient was told - when was it } \\
\text { changed? I left at } 6 \ldots \\
\text { S: I want a memo when they change the order } \\
\text { CN1: I'll tell [name]. }\end{array}$ \\
\hline
\end{tabular}

Table 15 shows a symmetrical link between similarities in the TMM and the building and maintaining of TSA communication regarding scheduling. Again, all three team members show compatible knowledge about discussing the upcoming patient before the actual case, and knowing the schedule ahead of time. This agreement is reflected in 
the communication when the anesthesiologist and surgeon brief about the next case during the close of the current case. As well, the nurses show awareness of the type of next procedure and take initiative to call for the next patient before being asked to do so. Due to the specificity of knowledge within the TMM linked to the TSA communication, the links are considered strong.

Table 15

Link Between TMM Agreement and TSA Building and Maintaining Regarding Scheduling.

\begin{tabular}{|c|c|c|}
\hline \multicolumn{2}{|c|}{ TMM Agreement } & TSA Built and Maintained \\
\hline S7 & $\begin{array}{l}\text { S will have briefed with SF night } \\
\text { before (or will do at sink during } \\
\text { scrub) } \\
\text { (Team related/Task related) }\end{array}$ & \multirow[t]{3}{*}{$\begin{array}{l}\text { S: Next is Bullectomy } \\
\text { CN1: I sent for the patient } \\
\text { [...] } \\
\text { A: Briefing details of next case (patient details) } \\
\text { A: You want to do bronchoscopy, double lumen? } \\
\text { S: Ya }\end{array}$} \\
\hline A9 & $\begin{array}{l}\text { A discuss with S plan of approach - } \\
\text { especially if non-routine or very sick } \\
\text { patient before operation, and ideally } \\
\text { b4 patient in room - less to discuss if } \\
\text { just routine case } \\
\text { (Team related/Task specific) }\end{array}$ & \\
\hline $\mathrm{N} 10$ & $\begin{array}{l}\text { Bookings scheduled for next day, } \\
\text { know team in advance; } \\
7: 25 \text { am meetings everyday Ns: } \\
\text { short staff, changes, contact } \\
\text { precautions, equip malfunctions } \\
\text { (Team related/Task specific) }\end{array}$ & \\
\hline
\end{tabular}

Table 16 shows a symmetrical link between gaps in the TMM dealing with equipment, and a TSA breakdown involving equipment. S11 states that communication about equipment becomes less efficient when the nurses are not as familiar with the team. However, N14 stated that surgeons may not be as familiar with the equipment as the nurses, leading to less efficient communication. The associated breakdown is seen on 
both accounts; the surgeon requests a certain type of stapler (device used to simultaneously cut and seal organ tissue), which needs clarification from the nurse to which colour (colour determines the size of staple). However, once the nurse brings the correct staples, the surgeon realizes that the size is actually too big, and requests a blue stapler instead, supporting the link. The links are considered moderate since the information from the surgeon could apply to other situations, while the nurse's knowledge is more specific to equipment communication.

Table 16

Link Between TMM Gap and TSA Breakdown Regarding Equipment.

\begin{tabular}{|l|l|l|}
\hline \multicolumn{2}{|l|}{ TMM Gap } & TSA Breakdown \\
\hline S11 & $\begin{array}{l}\text { If N's not usually with team, need to be } \\
\text { more vocal, ask for equipment, less } \\
\text { anticipation }\end{array}$ & $\begin{array}{l}\text { S: I"ll take the bronchs stapler } \\
\text { CN2: Is that green? }\end{array}$ \\
& $\begin{array}{l}\text { S: Green } \\
\text { [CN leaves OR] } \\
\text { [CN re-enters OR] }\end{array}$ \\
\cline { 1 - 1 } N14 & $\begin{array}{l}\text { Surgeons don't know equipment as well } \\
\text { as nurses, don't always ask for what } \\
\text { they want }\end{array}$ & $\begin{array}{l}\text { S:8? That's too big, we'll have to use blue } \\
\text { [CN2 Shows S equipment] }\end{array}$ \\
& $\begin{array}{l}\text { (Team related,/Task specific) } \\
\end{array}$ & \\
\hline
\end{tabular}

Table 17 shows a symmetrical link between the TMM of equipment communication and TSA communication about equipment. There appears to be compatible knowledge that good nurses have the ability to anticipate the surgeon's needs. This anticipation is reflected in the TSA dialogue, when the surgeon asks for a piece of equipment, which the nurse has already anticipated and gotten ahead of time. The link is strong since the TMM is referring to how equipment is anticipated, which is precisely the topic of conversation within the TSA communication.

Table 17 
Link Between TMM Agreement and TSA Maintained Regarding Equipment.

\begin{tabular}{|l|l|l|}
\hline & TMM Agreement & TSA Built and Maintained \\
\hline S11 & $\begin{array}{l}\text { If N's not usually with team, need to be } \\
\text { more vocal, ask for equipment, less } \\
\text { anticipation }\end{array}$ & $\begin{array}{l}\text { S: Need 1 size 16, that's all } \\
\text { CN1: Should be right there } \\
\text { (Team related/Task specific) }\end{array}$ \\
\hline N14 & $\begin{array}{l}\text { N need to be aware of everything for A, } \\
\text { S, anticipate supplies needed } \\
\text { (Team related/Task specific) }\end{array}$ & \\
\hline
\end{tabular}

Table 18 shows an asymmetrical link between gaps in the TMM about the pause and a TSA breakdown about the pause. There appears to be compatible knowledge that the team should be present, yet the surgeon is not there for the pause. While the breakdown is not necessarily captured in the TSA dialogue, the contextual information indicates that the surgeon in fact was not present for the pause. The link is strong as the TMM knowledge covers the pause specifically.

Table 18

Link Between TMM Gap and TSAB breakdown Regarding the Pause.

\begin{tabular}{|l|l|l|}
\hline \multicolumn{2}{|l|}{ TMM Agreement } & TSA Breakdown \\
\hline S11 & $\begin{array}{l}\text { Needs at least one member from } \\
\text { every team - trust - that each other } \\
\text { will speak up if problem; } \\
\text { (Team related/Task specific) }\end{array}$ & $\begin{array}{l}\text { CN1:[Patient name, allergies, procedure], } \\
\text { CN1: any a.b.?? } \\
\text { CN1: no? } \\
\text { A: no [delayed response] } \\
\text { [*S not present] }\end{array}$ \\
\cline { 1 - 1 } A6 & $\begin{array}{l}\text { Everyone must be in room, rarely } \\
\text { does not happen } \\
\text { (Team related/Task specific) }\end{array}$ & \\
\hline N3 & $\begin{array}{l}\text { Everyone should be there } \\
\text { (Team related/Task specific) }\end{array}$ & \\
\hline
\end{tabular}


Table 19 illustrates a symmetrical link between the TMM regarding the pause, and TSA maintained during the pause. Within the TMM, there is identical knowledge all three members about everyone being present, and also that it is usually the surgeon or the nurse who announces the pause. Here, the pause is executed normally; everyone is present, the proper information is said, and the antibiotic information is confirmed. The links are considered strong because the information in the TMM is specific to the communication within the TSA dialogue.

Table 19

Link Between TMM Agreement and TSA Maintained Regarding the Pause.

\begin{tabular}{|c|c|c|}
\hline \multicolumn{2}{|c|}{ TMM Agreement } & TSA Built and Maintained \\
\hline S7 & $\begin{array}{l}\text { S responsible for pause (but who is } \\
\text { supposed to say it and who says it } \\
\text { varies; } \\
\text { Everyone should be present for } \\
\text { pause } \\
\text { (Team related/Task specific) }\end{array}$ & $\begin{array}{l}\text { S: Did you do a pause? } \\
\text { CN1: not yet } \\
\text { S: Patient name, procedure, A.B. in? } \\
\text { A: yes }\end{array}$ \\
\hline A9 & $\begin{array}{l}\text { Nurse (sometimes S) states pause; } \\
\text { Everyone should be present, but still } \\
\text { loop holes even when done perfectly } \\
\text { (Team related/Task specific) }\end{array}$ & \\
\hline N10 & $\begin{array}{l}\text { CN usually does, but varies, reads } \\
\text { off consent; } \\
\text { Pause done when all people in room, } \\
\text { after scrub or positioning } \\
\text { (Team related/Task specific) }\end{array}$ & \\
\hline
\end{tabular}

Problems with the pause. The pause was of particular interest to this study due to the strong associations between TSA and pause-related TMM that could provide practical implications for patient safety. Even though it appeared to be underrepresented in the earlier analyses in terms of utterances, the problems were contained within the contextual 
OR Team Communication, Mental Models, and Situation Awareness 89 information captured by the researcher. Fourteen pauses ( 1 missed by researchers) were reviewed. Half of the pauses (7/14) were carried out without at least one key person: the staff surgeon two pauses, the surgeon fellow for three pauses, the staff anesthesiologist one pause, and the circulating nurse and surgeon fellow once missed the same pause. Ironically, from those interviewed, the general consensus (with the exception of one) was that everyone should be there for the pause, but this clearly was not the case in practice.

Link symmetry. Forty-five links were identified, including 21 with TSA breakdown and 24 with maintained TSA. The majority of the links $(87 \%)$ were defined as symmetrical (i.e. TMM agreement and TSA maintenance or TMM gaps and TSA breakdowns) compared to asymmetrical (13\%) (i.e., TMM agreement and TSA breakdowns or TMM gaps and TSA maintenance). Figure 15 shows that links with breakdown TSA contained $71 \%$ symmetrical links and $29 \%$ asymmetrical links. Links with maintained TSA were only symmetrical ${ }^{3}$.

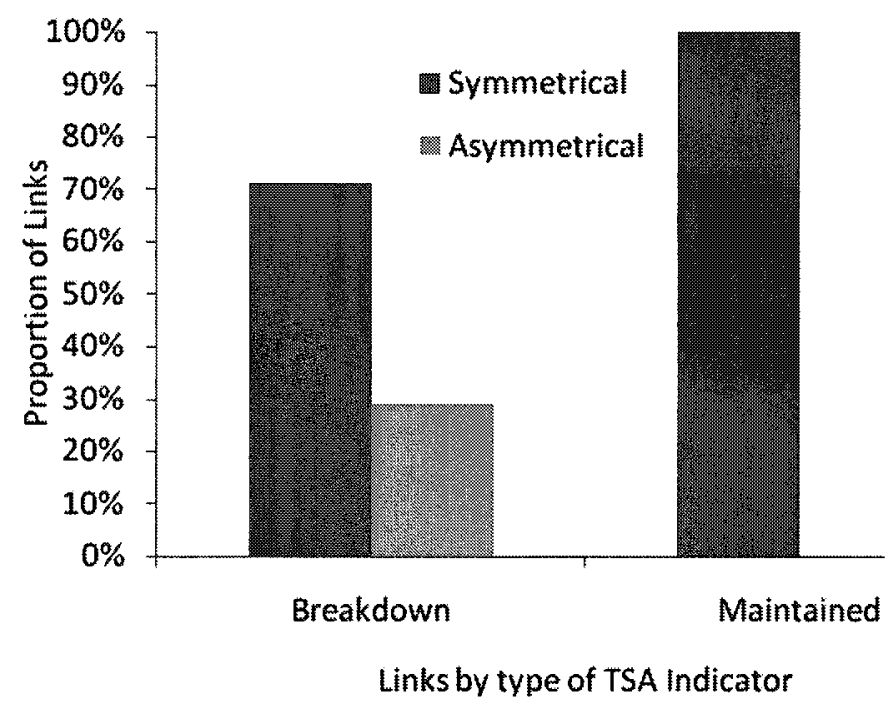

Figure 15. Links as a function of Symmetry and TSA Indicator

\footnotetext{
${ }^{3}$ Ignoring the assumption of independence violation, the data in Figure 15 is significant, $X^{2}=33.9, p<.001$.
} 
TMM-TSA links by content categories. Links were further examined as a function of TSA content. Figure 16 shows that breakdown links were primarily identified within equipment (six links), followed by the pause (five links), procedure (four links), lungs (three links), schedule (two links), and position (one link). In contrast, links from maintained TSA were primarily identified within lungs (eight links), followed by procedure and equipment (five links each), position (three links), pause (two links) and schedule (one link). Not all TSA indicators were able to be linked with TMM. Nonlinked indicators tended to have only one member's knowledge in TMM or mental model knowledge that was not relevant enough to the TSA related communication to be considered linkable.

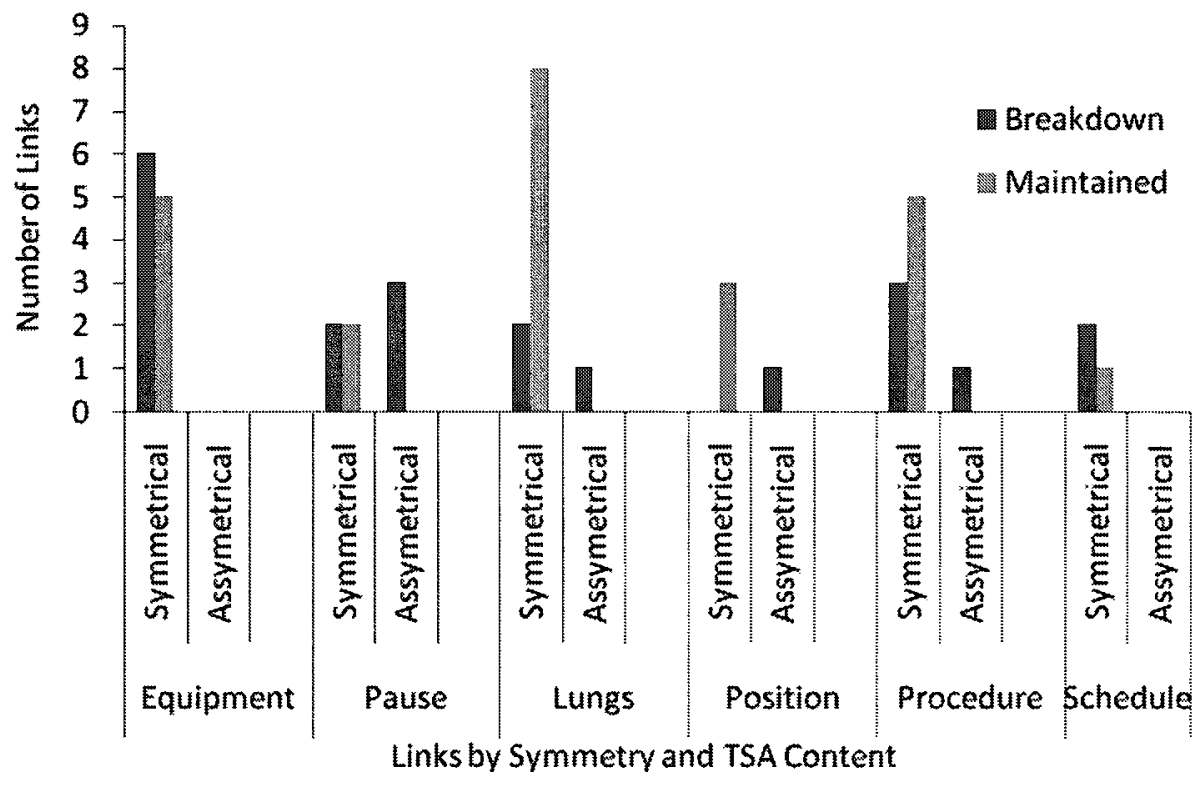

Figure 16. Number of identified links as a function of symmetry, content and TSA indicator type. 
OR Team Communication, Mental Models, and Situation Awareness 91

Interesting to note are the content categories that contain asymmetrical links were the pause, the lungs, procedure and position. These links contained similar TMM but TSA breakdowns. For example, many of the TMM about the pause agreed on full team presence and what information needs to be mentioned, however, frequently these broke down during the actual pause. It is possible that these instances of breakdowns were influenced by other factors beyond the cognitive congruency of the team, such as organizational aspects of the healthcare system. Perhaps people are missing from the pause because they are attending to other cases concurrently, as was suggested earlier with the multiple layers of TSA.

Attitudes and perceptions of teamwork. Subjective perceptions of teamwork were assessed using descriptive statistics computed from the ORMAQ (Sexton et al., 1996). The goal was to derive a general description of the teamwork perceptions and attitudes of the interviewees that could be used as additional explanations for differences in mental models about information flow and observed communication patterns.

Within ORMAQ, questions are grouped into five sub-topics concerning different aspects of teamwork: teamwork and communication (e.g., communication between A \& S teams was established and maintained), command and control (e.g., the senior surgeon should be formally in charge of the OR team during surgery), speaking up (e.g., when our team is busy, there are clear ways to ask for additional help), briefing (e.g., OR team members in leadership positions should verbalize their plans for procedures/actions and make sure that the information is understood and acknowledged), and feedback (e.g., I feel that I receive adequate feedback about my performance). Each category contains a number of questions concerning the topic, with Likert scale responses ranging from 1-5. 
Means were calculated for each of the sub-topics, and as function of each profession (i.e., surgery, nursing, and anesthesia). Scores closer to five are associated with more positive perceptions of teamwork. Results are displayed in Figure 17.

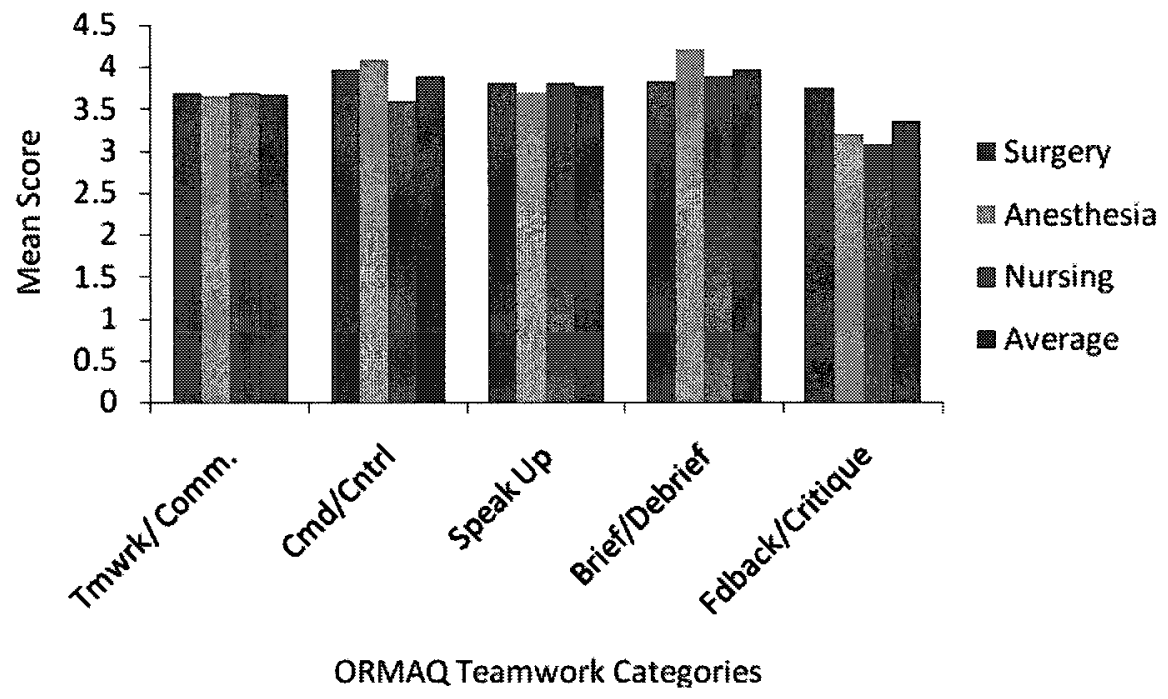

Figure 17. Mean ORMAQ scores for each category.

Overall, the results do not appear to differ by discipline or by teamwork construct. Due to the small sample size, Friedman's Test was used to test the significance between scores, but results were not significant, $X^{2}=3.27, d f=4, p=.513$, indicating no differences between mean scores of the ORMAQ categories. On a descriptive level, feedback and critique appear to have received the lowest mean ratings from all participants (3.34/5), while briefing received the highest rating with a mean score of 3.97/5. Command and control had a mean score of $3.88 / 5$, while teamwork/communication scored 3.68 and speaking up scored 3.76. On the whole, the members who participated in the survey appeared relatively satisfied with the measured aspects of teamwork. Unfortunately, the ORMAQ did not represent immediately interesting results in terms of supporting or challenging the concept of the mental models 
OR Team Communication, Mental Models, and Situation Awareness 93

inferred from the interviews, possibly due to the small sample size $(n=12)$. Perhaps individuals did not feel comfortable reporting overly negative answers, or were positively biased by answering retrospectively, or perhaps they were just in general satisfied. Results of individual questions are discussed later in terms of support for mental model and TSA comparisons.

Summary of findings. Across high and low complexity groups, the highest proportion of communication occurred within the surgical phase. The most common form of communication was seeking, responding, and providing information about equipment and the lungs. The surgeon was the hub of information sharing, and the most common paths of information flow were between surgeon and nursing, surgeon and anesthesia, and from surgeon to the team in general, while the least common path was between anesthesia and nursing. In high complexity procedures, TSA breakdowns typically involved equipment, while maintained TSA typically involved the lungs. In low complexity procedures, TSA breakdowns typically involved the procedure and the pause, while maintained TSA typically involved the schedule.

Overall, results from this study suggest that some TSA indicators can be associated with gaps/similarities in TMMs. The most likely links were symmetrical between gaps and breakdowns, or similarities and maintenance. The linking of the two constructs appeared to vary as a function of context and content of the mental models, more so than the simple classification of gap or similarity. The strongest links were those in which knowledge was specific to the content of conversation, which made up the TSA indicators. Results from these analyses have several theoretical and practical implications 
both thoracic-specific and can be generalized to other surgical teams. These are discussed next.

\section{Discussion}

\section{Overview of findings}

This study explored whether the constructs of TSA and mental models could be linked using communication analysis. The comparison of thoracic surgery team mental models to communication patterns used during teamwork utilized qualitative, ethnographic research methods including interviews, observations, field notes, and questionnaires. In line with the previous research reviewed in this thesis (e.g., Ash, Berg, \& Coiera, 2004; Ellingson, 2002; Hazlehurst, McMullen, \& Gorman, 2007; Reddy, Dourish, \& Pratt, 2001), these patterns were based on instances where multiple professions needed to collaborate. Implications of the link between mental models and TSA were used in a theoretical framework to explain the associations between variables identified in this study as well as key implications for healthcare safety and Human Factors research.

The characteristics of thoracic communication leading to TSA indicators are addressed first, followed by the mental models and the detailed analyses between them. Results and implications are discussed in relation to thoracic surgery, and generalized as a theoretical framework, concluded by limitations and suggestions for future research.

Distribution of communication. Thoracic procedures tend to have a common structure consisting of patient intubation, scoping and position patient, surgical prep, surgery, and surgical close. The concentration of communication within the surgery phase, for all procedures, may indicate a higher level of inter-dependency in terms of 
OR Team Communication, Mental Models, and Situation Awareness 95

teamwork: the surgeons who perform the surgery, the anesthetists who maintain the patient's vitals, and the nurses who assist with tools and tasks outside of the sterile environment. The other phases do not necessarily require the presence of all individuals, decreasing the number of communication agents. For example, often the surgeon would not appear until the scoping process. As such, lower proportions of communication may indicate that activities are independent, reducing the need to interact.

Communication type. A large part of the thoracic teamwork processes involved information sharing, including seeking information, responding to others, proactively offering information and requesting items or actions. However, there may have been a greater need to focus on the patient and procedure in high complexity cases. This finding is implied by less frequent education related communication. It may be more difficult to teach and operate during the most complex cases, and the patient would take priority. Furthermore, a non-structured style of speaking was implied by a lack of explicit confirmation, which seemed to depend on the personal tendencies of those involved, and not on standard practices within the OR. These open-loops may contribute to miscommunications and procedural delay, but might be reduced through increased use of read-backs. By repeating the desired request, the sender knows the message was acknowledged and clearly understood.

Communication content. The distribution of communication content delineated the main patterns of activity within high and low complexity procedures. Equipment and surgical content characterized the high complexity procedures through the coordination and overt communication needed for VATS between the staff and fellow surgeon. As such, teamwork patterns captured during these highly interdependent activities may not 
generalize to other types of surgery less associated with equipment-based procedures. Low complexity cases had less frequent lung and position based communication, attributed to the minimally-invasive activities that did not require selective lung deflation and by the infrequent need to turn.

A high frequency of communication involving other cases implies the existence of at least three different levels of TSA within a given case: the current, future, and concurrent cases. While in one case, teams needed to order the next patient, request equipment, brief about upcoming patient details, and consult about cases not under the surgeon's care. One explanation given by a team member is that the OR team conceptualizes the entire day as a surgical unit, not separate cases. These findings may have implications for the facilitation of information sharing, such as displaying details for upcoming procedures to further assist TSA and transition between cases.

Communication participants. The surgeons can be described as the hub of information sharing, in that they initiated and received most of the communications, and were the most likely to address the team as a whole. This notion is supported by an ORMAQ item, in which most members agreed that the senior surgeon should be formally in charge of the OR team during surgery. This finding is also consistent with Parush et al. (2009), who defined cardiac surgeons as the communication hub based on having the least consistent access to information sources, yet needing to know most of the information. In VATS, the surgeon focuses on a screen showing their actions, which limits the ability to attend to other sources of information. This need for information sharing has implications for future research such as the development of display technology to facilitate information sharing, and is discussed in implications. 
The lowest proportion of communication occurred between the nursing and anesthesia teams. Since anesthesia professionals are not bound by the sterile area (as are surgeons), they do not require much assistance (e.g., with tools) from the nurses, which resulted in less frequent interactions. In the absence of communication, these members appeared to rely on visual and auditory cues to build and maintain their situation awareness. During interviews, multiple participants described attending to the actions and communication of others, such as cues for the close (e.g., surgeon calling for the next patient, or requesting staplers or sutures). This notion is consistent with other research such as Shu and Furuta (2005) who suggest that TSA is achieved in part through explicit communication (e.g., direct face to face verbal exchange) and part is inferred through observed external actions of another without explicit verbal exchange (e.g., non-verbal actions). Such passive attentiveness supports communication as a non-exclusive means of maintaining awareness for those both directly and indirectly involved.

TSA indicators. TSA communication indicators reflected two TSA processes: maintenance and loss. The building and maintaining of TSA consisted of information exchange that facilitated teamwork by enabling coordination of unique perspectives on the same information through interaction (Gorman, Cooke, \& Winner, 2006). Breakdowns reflected communication efficiency and effectiveness, where information was not dispersed in a manner that fostered a mutual understanding.

Within high complexity procedures, a larger proportion from the total communication reflected TSA breakdown compared to TSA maintenance, possibly suggesting TSA vulnerability. It may be that complex procedures degrade effective communication even though it is critically needed. In high complexity surgeries, TSA 
OR Team Communication, Mental Models, and Situation Awareness 98

breakdowns occurred more frequently during surgery, while in low complexity surgeries, breakdowns occurred more frequently during the lines and intubation. Possible validation for this distribution is more clearly illustrated through consideration of the TSA content.

Different communication types characterized the TSA maintenance as compared to breakdown. Maintained TSA had a higher frequency of planning and announcements than breakdowns, which would allow teams to build mutual expectations of future events. However, concern-raising characterized breakdowns because it alerted to potential problems. This method of communication analysis to explore TSA related patterns could be generalized to other teams and contexts. The difference would be the task-specific content which would be sensitive to the teams' activities.

TSA content categories. TSA communication indicators were characterized by the following content categories: procedure, lungs, position, equipment, and schedule. The highest proportion of TSA breakdown in high complexity procedures was when talking about equipment. One possible explanation concerns the multiple descriptors of commonly used tools. Specifically, staplers used during the close can be one of three different colours that indicate the height and staple spacing. In addition, there are long and short stapler length depending on if the procedure is open or VATS. Partially specified tools (e.g., just colour) created delays if the wrong equipment is retrieved. As such, the level of request specificity needed could be competing with the surgeon's primary focus on a complex task. From a human factors perspective, results could imply a need to develop a standardized tool-specific language which could improve communication efficiency by decreasing miscommunications and lengthy clarifications. 
The finding that TSA breakdowns in the low complexity group were greatest for procedure may be explained by a lower priority placed on pre-briefing, therefore affecting information dissemination. From interviews, when procedures are considered straightforward (i.e., low complexity), staff surgeons and anesthesists do not always call ahead or brief with team members in advance, but instead leave the residents and fellows in charge. If this information is not circulated to the other team members, it could explain confusion at this point in time. This finding highlights the importance of team briefing to maintain awareness of an evolving schedule.

The finding that lung and position TSA were well maintained (and did not often break down) within high complexity surgeries could indicate a more effective coordination for highly interdependent tasks in thoracic surgery. This coordination process was reflected in the continuous communication turn-taking between surgery and anesthesia, who each have their primary concerns about the patient but are equally affected by the actions of the other team. To turn a sedated patient requires the coordinated efforts of several team members, sometimes over a series of smaller moves to get the patient into the final position. During the turn, surgery and anesthesia each expressed their needs and concerns -anesthesia about proper ventilation and surgeon about access to the surgical site - and a satisfactory comprise is reached.

One important trend in many cases of breakdowns in TSA is that they did not persist. When a problem surfaced, team members did not simply give up and abandon the procedure, but generally engaged in recovery communication aimed at re-building TSA. In an example of equipment TSA breakdown, teams typically went through the detailed process of listing the descriptors of the required tool, such as name, colour, length, and 
staple size, until shared understanding was reached. Similarly, if an anesthesiologist inflated the lungs too early and surprised the surgeon, the surgeon dictated the desired actions to be able to continue with the procedure.

In view of this, perhaps TSA breakdowns can be considered as varying degrees of TSA degradation as opposed to a "total and final loss". Within the dynamic team context, once TSA is established, it can constantly shift and evolve depending on team membership and purpose of interaction. Degraded TSA, then, may be the temporary shift of TSA from sufficient to less than satisfactory, where mental model gaps are not successfully bridged by communication. When degradation occurs, the team quickly works to regain TSA, because if they did not, the procedure cannot continue and escalate into a potential adverse event. Neither maintained nor degraded TSA is a permanent and discreet team state, but rather represent dynamic shifts along a TSA continuum.

In summary, the analysis of TSA indicators by type and content of communication suggested that thoracic teams tend to be better at maintaining TSA in some contexts than others. It appears that TSA concerning interdependent activities may be easier to maintain, possibly because team members possess more similar mental models about activities that are more relevant to them, compared to general team activity.

Team mental models. TMMs were modeled in order to characterize the perceptions and knowledge of individuals about the procedure and the OR teamwork. Thoracic TMMs contained knowledge that was concurrently similar and compatible between members. This definition is consistent with previous literature in that there is probably not a single mental model that must be shared among team members, but that there are most likely multiple mental models co-existing among team members at a given 
OR Team Communication, Mental Models, and Situation Awareness 101

point in time, especially when carrying out complex tasks (e.g. Cannon-Bowers \& Salas, 2001; Cannon-Bowers et al, 1993; Langan-Fox, Anglim \& Wilson, 2004; Lim \& Klein, 2006).

Knowledge within TMM was coded as team specific, team related, task specific or task related. Most of the information within the TMM was identified as team related and task specific. Team information was typically related because, for anonymity purposes, participants only addressed themselves and others in terms of their respective discipline, and not by name. For this reason, there was no information coded as team specific (i.e., referring to a particular team configuration). However, it should be noted that participants likely had specific people or teams in mind when describing team knowledge. As such, future research should consider having participants define whether they are referring to specific people (without identifying them) or the general discipline in order to make this distinction clearer in the analysis.

Task information was generally more specific because thoracic procedures could be described in a step-by-step fashion without concern of anonymity. That said, task related information was still described, particularly in relation to the quality of communication. Most participants mentioned communication such as cross-checking and updating in terms of overall quality, frequency, and openness between members throughout the case. This type of knowledge could apply to a variety of specific tasks, and was coded as team related, task specific.

Specific information in the TMM facilitated the identification of gaps and similarities. This finding has implications for future research concerning the extraction of mental model knowledge in time-constrained situations. Familiarity with the knowledge 
enables extraction of information that is more focused and related to the research question. In this study, initial interviews were more self-directed by the participant, who described the procedures in their own style and pace. As such, the type of information extracted was less specific and applicable to specific observations. However, through experience from the observations, the extraction process focused onto the finer details of the variables of interest. More specific mental knowledge eventually facilitated the identification of links between TSA and TMM.

Linking TSA and TMM. Gaps and similarities in TMMs were linked to patterns of communication reflecting TSA. Generally, gaps in the TMM were associated with momentary breakdown in TSA, while similarities were associated with the building and maintenance of TSA. This result is consistent with previous literature that suggests that similar mental models can facilitate effective communication and teamwork (e.g., O'Conner \& Johnson, 2006) because verbal communication is more meaningful when the words used have a known and common context or framework (Lewis, 2002). However, in a few cases, TMMs were considered similar, yet a corresponding TSA loss was observed. This may be attributed to some general level TMM knowledge that was compared to very specific details documented during observations. In these cases, the mental model knowledge may have not have been specific enough to capture the TSA that was reflected in the communications.

Implications of Study

Theoretical implications. The various links between TMM and TSA can be viewed as reflecting basic teamwork processes. The descriptive categories of the links 
OR Team Communication, Mental Models, and Situation Awareness 103

(e.g., lungs, procedure, scheduling, pause, etc.) can be abstracted into two recurring high level teamwork factors:

1. Interdependence/Coordination characterized situations where the actions or information needs of one person influenced the actions or information needs of another. Such almost symbiotic relations characterized TSA indicators within the context of lungs and patient positioning. These were affected by mental models that differed in terms of team roles and responsibilities, such as leadership. Coordinated practices can endure if communication can compensate for dissimilar mental models, making the effectiveness of communication a cornerstone of effective teamwork.

2. Communication effectiveness affected team's ability to send or receive information to build mutual understanding. This teamwork factor characterized problems with equipment requests, surgical maneuvers, and procedural timelines. When communication effectiveness is compromised, the disruption of passive awareness for those indirectly involved ultimately deteriorates the overall TSA.

Interdependence and communication effectiveness seem to be complimentary factors of teamwork grounded in mental models. Shared mental models can make communication and coordination more efficient by requiring less communication between individuals for the same result (Langan-Fox et. al., 2004). Interdependence typifies teamwork, and interaction and information sharing foster coordination of interdependent activities. Communication is needed to coordinate interdependent activities and also fuels passive awareness of all other team members indirectly involved, thus perpetuating the cyclical relationship. These three conceptual categories describe 
teamwork processes that characterize thoracic surgery, but could also apply to other heterogeneous teams.

A point to note about TSA indicators is that they were not observed between members whose activities were not interdependent. This idea would account for the lack of TSA related communication between nurses and anesthesia. However, it does not mean that they lacked awareness of each other's activities. Two members could have interdependent activities at one point in time, but then completely independent activities at another. TSA indicators in communication facilitate the identification of interdependencies that are context specific, which would more realistically describe team behaviour over time, instead of generalizing communications patterns to all contexts and all members. Conceptual categories extend these indicators to more general patterns of teamwork that could equally explain TSA communication in other domains.

Implications to Patient Safety. The teamwork disruptions represented here as TSA breakdowns did not result in patient mortality, however, such 'minor' events (that alone were not expected to have serious consequences for the patient) can impact the surgical team's ability to compensate for a major life-threatening event (Carthey, de Leval \& Reason, 2001). Surgical error is deeply embedded in the effectiveness of teamwork, and teamwork related disruptions may be the best independent predictors of surgical error (Wiegmann, Elbardissi, Dearani, Daly, \& Sundt 3rd, 2007). While individually, these disruptions seem inconsequential, there is still the potential of negative patient outcomes if not effectively addressed.

An implication of this study to patient safety is that teams with more similar TMM may be less likely to commit error. The greater proportion of link symmetry 
OR Team Communication, Mental Models, and Situation Awareness 105

suggested that breakdowns in TSA were more likely to be linked with gaps in TMM, while TSA was maintained when TMM were similar. Support for this idea has been shown in cardiac surgery, where primary surgical teams (i.e., frequently operated with the same surgeon) had a lower incidence of total surgical flow disruptions, surgical error, and teamwork failures (Wiegmann et al, 2007). Surgeon-technical team (fellows, residents and scrub nurses) failures primarily consisted of coordination, communication, and team familiarity events such as the handing off of a wrong surgical instrument when requested properly (ElBardissi, Wiegmann, Henrickson, Wadhera, Sundt $3^{\text {rd }}$, 2008). The increased team cohesiveness and familiarity of these teams may be attributed to more similar TMM developed through experience of working together.

In comparison, the finding here that gaps in team mental models are associated with breakdowns in TSA may suggest less effective teamwork and potential threats to patient safety. As such, there may be a need to train mental model similarity among teams. Such training has been attempted using Crew Resource Management (CRM) training, where teams of people who work together are actually trained together in the basic teamwork behaviours (e.g., Gaba, Howard, Kevin, Fish, Smith, \& Sowb, 2001; Grogan, Stiles, France, et al., 2004). CRM training can involve aspects of cross-training, where individuals from different disciplines take on other's roles in order to increase their understanding of the teams' responsibilities outside of their own, thus enhancing their team mental model.

Another implication of this research is that events which disrupt the natural progression of an operation may be ameliorated by the use of standardized language. Many instances of TSA breakdown could have been directly prevented by a modification 
OR Team Communication, Mental Models, and Situation Awareness 106

of the communication style between team members. Often, communication failures were the result of lack of message confirmation, or a failure to fully understand the meaning of the message delivered. By implementing a standardized communication pattern where the speaker's message is repeated by the recipient (i.e., read-back.), the communicator creates a closed-loop communication model where both parties are acutely aware of the status of the message. Standardized language has long been used in high-risk industries to prevent the occurrence of communication mishaps; this study further emphasizes its applicability to the operating room setting.

A novel finding of this research was that TMM similarity could also be linked to TSA breakdowns, most notably for missing team members and antibiotic administration during the pause. Such findings highlight potential challenges of the WHO pre-operative checklist that will need to be addressed. For example, one checklist item is supposed to 'guarantee' that antibiotics were given 60 minutes prior to making any incision to prevent surgical site infections. However, it seems that other factors before the patient even enters the OR, such as whether they were requested ahead of time, may affect timely administration. One member noted that there was a " $50 / 50$ chance $A B$ are in before the pause...if not, it's the least of my worries... I will give at pause - or right after incision." For a 60 minutes administration to be possible, it might more sense to have a checklist before the patient enters the OR.

Adjustments to current pre-operative briefing may reduce the TSA breakdowns that spawned from the pause, however, it is essential that team members feel a sense of responsibility as well as empowerment to speak up if they perceive a problem. One solution may be to structure the briefing such that each team member be responsible for 
addressing aspects of patient care that are under his/her direct control (ElBardissi, Wiegmann, Henrickson, Wadhera, Sundt $3^{\text {rd }}, 2008$ ). For example, the surgeon describes critical operative steps and antibiotic needs, the anesthesiologist describes patient positioning and airway concerns, and the nurse describes planned equipment use and patient information. The administration of discipline-specific preoperative briefing identifying critical patient/procedure/equipment information may be more important than creating an ideal comprehensive one, such as the checklist created by the WHO. Interventions encouraging all members of the surgical team to take active involvement in patient care may help to ensure full team attendance and avoid future error from lack of communication.

Finally, the elicitation of mental models and TSA related communication supports the design of future technologies, such as team displays intended to facilitate information sharing. TSA related communications reveal multifaceted factors crucial for teamwork, including what information is shared when, and by whom. The implication in terms of display design is that not all information would need to be displayed at all times. This finding was also supported from interviews with cardiac team members, who identified different information as being needed by different team members at different points in time. Knowing the degree which team members need to know the same information will influence how technologies such as team displays are designed.

\section{Study Limitations}

This study included several limitations. The small sub-specialty of thoracic surgery (i.e., four staff surgeons) meant that many healthcare workers were observed repeatedly. Therefore, assumptions needed to perform quantitative data analysis (i.e., 
OR Team Communication, Mental Models, and Situation Awareness 108

independence of sampling) were violated. Given that an actual hospital sample was used, it was not possible to assign team members or patients to cases. Future studies could benefit from focusing on at least a single type of procedure, which may allow differences to be attributed to specific teams. Furthermore, mental model elicitation could target explicit task details, instead of thoracic procedures in general.

The need to obtain patient consent two hours prior to OR time prevented full-day case observation. Follow-up discussions with a staff surgeon concluded that future observations would be facilitated by waiving patient consent due to the unobtrusive nature of the study. This way, the entire day's activities could be observed as a cohesive unit (versus snapshots), which is a more realistic representation of the teams' routine. Specific teams then would be observed repeatedly, and communication could be compared as a function of procedure type.

Team members' limited availability impeded the measurement of numerous variables of interest. The interviews, for instance, were only conducted with half of the observed sample and the resulting TMM did not represent all team members. Future research should consider the limited availability of healthcare professionals, possibly by conducting group interviews during working hours, instead of relying personal time.

Finally, classification of breakdowns and maintained TSA was not validated by SMEs. While the categories were operationally defined based on previous research and from emerging themes in the data, it is possible that OR team members may not judge TSA indicators in the same manner as were specified here. Future research should consider some form of validation from team members within each profession. One 
suggestion would be to have SMEs rate the researcher's defined TSA indicators on a scale of severity, or to have an SME assist with the initial coding.

Despite limitations, similarities with other studies can strengthen the transferability of findings. Specifically, in both thoracic and cardiac procedures, the surgeon was identified as being the information hub (Parush et al., 2009). The surgeon demonstrated the greatest need for information by sending and receiving the most communications, and was also identified as needing to know the most information. Furthermore, the most critical communications, as marked by TSA indicators, occurred during the more critical phases of surgery (most invasive for the patient). Suspected communications breakdowns in cardiac and thoracic procedures were associated with open-loops, which had potential for information loss. Although this data may not transfer to all healthcare contexts, similarities among communication data between thoracic and cardiac provide more substantial implications, which can then be tested in other contexts in the future. Generalization across several surgical procedures is the first step towards extending findings to other domains of healthcare.

\section{Implications for Future Research}

The finding that patterns of communication may characterize TSA processes and can serve as an indirect measure of mental model congruence supports the advancement of research on mental model similarity and performance theories. Most published research in this area is based on the notion that those with more similar mental models will perform better as a team because they are better able to build and maintain TSA. Findings from this study are consistent with such research, but also suggest that other factors beyond the control of the OR team can influence TSA. This notion comes from 
OR Team Communication, Mental Models, and Situation Awareness 110 the finding that TMM sometimes coincided with TSA breakdown, typically when someone was distracted or physically not present. Such findings demonstrate the importance of communication analysis in terms of assessing the fine detail of the situation, and not just quantifying error.

This research offers a novel way to investigate the connection between mental models and TSA through team communication. Specifically, communication analysis can be used to map and understand team activity through information flow. Knowledge of these teamwork processes can then be elicited through interviews and represented as TMM. Subsequently, by comparing patterns of information sharing to teamwork represented as mental models, it is possible to assess the types of team interactions that may be affected by cognitive versus environmental processes. For example, when gaps in the TMM linked to TSA breakdowns, it would appear that dissimilar knowledge can disrupt work flow. However, when TMM knowledge was similar and TSA breakdowns persisted, it seemed that factors beyond the control OR team may have attributed to the issue.

Similar research in this area (e.g., Elbardissi et al., 2008; Parush et al., 2009) has focused on cardiac surgery teams (which rely heavily on drug-related communication between the surgeon and the perfusionist), while to date no TSA research has addressed thoracic surgery. The distinctiveness of thoracic surgery stems from the adoption of the VATS for most procedures, making it more dependent on technology and coordination than other types of manual procedures (e.g., orthopedics). The risk of VATS is that if something goes wrong, the surgical team needs to quickly open the surgical site to operate manually. Meanwhile, the patient's chest is likely filling with blood, risking 
OR Team Communication, Mental Models, and Situation Awareness 111

further complications. Therefore, the study of specific types of surgeries is key for identifying unique facets of team interaction that would not be transferable from other research. Ultimately, exploring TSA and mental models as theoretical underpinnings of team communication will promote further understanding of the fundamental relationship between team mental models, communication and team situation awareness. 
OR Team Communication, Mental Models, and Situation Awareness 112

References

Alvarez, G. \& Coiera, E. (2005). Interruptive communication patterns in the intensive care unit ward round. International Journal of Medical Informatics, 74(10), 791 796.

Arora, V., Johnson, J., Lovinger, D., Humphrey, H. J. \& Meltzer, D. O. (2005).

Communication failures in patient sign-out and suggestions for improvement: a critical incident analysis. Quality and Safety in Health Care, 14, 401-407.

Ash, J., Berg, M. \& Coiera, E. (2004). Some unintended consequences of information technology in health care: the nature of patient care information system-related errors. Journal of American Medical Informatics Assoc, 11, 104-112.

Awad, S., Fagan, S., Bellows, C., Albo, D., Green-Rashad, B,. De La Garza, M., \& Berger D. (2005). Bridging the communication gap in the operating room with medical team training. The American Journal of Surgery, 190 (5), 770-774.

Baber, C., Jenkins, D., Salmon, P., \& Walker, G. (2006). Human Factors Methods: A Practical Guide for Engineering And Design. Hampshire, England: Ashgate Publishing.

Baggs, J. G., \& Schmitt, M. H. (1988). Collaboration between nurses and physicians. Journal of Nursing Scholarship, 20, 145-149.

Baker, C. C., Johnson, J. H., Malone, M. T., \& Malone, T. B. (1979). Human factors engineering for Navy weapons systems. Alexandria, VA: Essex Corporation.

Baker, G. R., Norton, P.G., Flintoft, V., Blais, R., Brown, A., Cox, J., Etchells, E., Ghali , W.A., Hebert, P., Majumdar, S.R., O'Beirne, M., Palacios-Derflingher, L., Reid, R.J., Sheps, S., and Tamblyn, R. (2004). The canadian adverse events study: The 
OR Team Communication, Mental Models, and Situation Awareness 113 incidence of adverse events among hospital patients in Canada. CMAJ, 170(11), 1678-86.

Ball, L. J. \& Ormerod T.C. (2000). Putting ethnography to work: The case for a cognitive ethnography of design. International Journal of Human Computer Studies, 53, 147-168.

Bardam, J. (2000). Temporal coordination: On time coordination of collective activities at a surgical department. Computer Supported Cooperation Work, 9, 157-187.

Beyea, S. C., (2004). Improving verbal communication in clinical care. AORN Journal. Retrieved Oct 1, 2008 from: http://findarticles.com/p/articles/mi_m0FSL/is_5_79/ai_n6074289.

Blakar, R.M. (1985). Towards a theory of communication in terms of precondition: A conceptual framework and some empirical explorations. In H. Giles and R.N. St Clair (Eds.), Recent advances in language, communication and social psychology. London: Lawrence. Erlbaum.

Canadian Patient Safety Institute (2008). Safer Healthcare Now! Retrieved Nov 2, 2008 from: http://www.patientsafetyinstitute.ca/events/SHN.html.

Cannon-Bowers, J. A., Salas, E., \& Converse, S. A. (1993). Shared mental models in expert team decision making. In N. J. Castellan, Jr. (Ed.), Current issues in individual and group decision making. Hillsdale, N J: Erlbaum, 221-246.

Cannon-Bowers, J.A. \& Salas, E. (2001). Reflections on shared cognition. Journal of Organizational Behaviour, 22, 195-202.

Cannon-Bowers, J.A., Tannenbaum, S.I., Salas, E. \& Volpe, C.E. (1995). Defining team competencies: Implications for training requirements and strategies. In R. Guzzo 
OR Team Communication, Mental Models, and Situation Awareness 114 and E. Salas (Eds.), Team effectiveness and decision making in organizations (pp. 333-380). San Fransisco: Jossey Bass.

Carley, K.M. (1997). Extracting team mental models through textual analysis. Journal of Organizational Behavior, 18, 533-558.

Carthey, J., de Leval, M.R. \& Reason, J.T. (2001). The human factor in cardiac surgery: errors and near misses in a high technology medical domain. Annals of Thoracic Surgery, 72, 300-305.

Catchpole, K., Elliott, M., Goldman, A., Leval, D., Macdonald, C., Marc, R., Mcewan, A., Mcquillan, A., \& Pigott, N. (2007). Patient handover from surgery to intensive care: using Formula 1 pit-stop and aviation models to improve safety and quality. Paediatric Anaesthesia, 17(5), 470-478.

Caprice, C., Gustafson, M., Roth, E., Sheridan, T., Gandhi, T., Dwyer, K., Zinner, M., \& Dierks, M. (2006). A prospective study of patient safety in the operating room. Journal of Surgery, 139(2), 159-173.

Clark, H. H. \& Brennan, S. E. (1991). Grounding in communication. In L. B. Resnick, J. Levine and S. D. Teasley (Eds.), Perspectives on socially shared cognition (pp. 17-149). Washington, DC: American Psychological Association.

Cooke, N.J., Kiekel, P.A., \& Helm E. (2001). Measuring team knowledge during skill acquisition of a complex task. International Journal of Cognitive Ergonomics: Special Selection on Knowledge Acquisition, 5, 297-315.

Cooke, N.J., Kiekel, P.A., Salas, E., Stout, Bowers , C., \& Cannon-Bowers, J (2003). Measuring team knowledge: a window to the cognitive underpinnings of team performance. Group Dynamics: Theory, Research, and Practice, 7(3), 179-199. 
Cooke, N.J., Salas, E., Cannon-Bowers, J.A., \& Stout, R. (2000). Measuring team knowledge. Human Factors, 42, 151-173.

Creswell, J. W. (2007). Qualitative inquiry and research design: Choosing among five approaches (2nd ed.). Sage Publications: Thousand Oaks, California.

Edmondson, A.C. (2003). Speaking up in the operating room: How team leaders promote learning in interdisciplinary action teams. Journal of Management Studies, 40(6), $1419-1452$.

Edwards, A., \& Wilson, J.R. (2004). Implementing virtual teams: A guide to organizational and human factors. Aldershot, UK: Gower.

ElBardissi A.W., Wiegmann D.A., Henrickson S., Wadhera R., Sundt $3^{\text {rd }}$ T.M. (2008). Identifying methods to improve heart surgery: an operative approach and strategy for implementation on an organizational level. European Journal of Cardiothoracic Surgery, 34 (5), 1027-1033.

Ellingson, L.L. (2002), Communication, collaboration, and teamwork among health care professionals. Communication Research Trends 21(3), 1-21.

Encinosa, W.E., \& Hellinger, F.J. (2008). The Impact of medical errors on ninety-day costs and outcomes: An examination of surgical patients published online: $25 \mathrm{July}$ Health Services Research, Retrieved Sept 30 from: http://www3.interscience.wiley.com/cgi-bin/fulltext/120855828/HTMLSTART.

Endsley, M. R., (1995a). Measurement of situation awareness in dynamic systems. Human Factors, 37(1), 65-84. 
OR Team Communication, Mental Models, and Situation Awareness 116

Endsley, M. R., (1995b). Toward a theory of situation awareness in dynamic systems. Human Factors, 37(1), 132-164.

Endsley, M. R., (2000). Direct measurement of situation awareness: Validity and use of SAGAT. In D.J. Garland (Ed.), Situation awareness analysis and measurement (pp. 147-173). Mahwah, NJ: Lawrence Erlbaum Associates.

Endsley, M.R. \& Bolstad, C.A. (1994). Individual differences in pilot situation awareness. International Journal of Aviation Psychology, 4(3), 241-264.

Endsley, M. R., \& Jones, W. M. (2001). A model of inter- and intrateam situation awareness: Implications for design, training and measurement. In M. McNeese, E. Salas \& M. Endsley (Eds.), New trends in cooperative activities: Understanding system dynamics in complex environments. Santa Monica, CA: Human Factors and Ergonomics Society.

Espinosa, J. A., Kraut, R. E., Slaughter, S. A., Lerch, J. F., Herbsleb, J. D., \& Mockus, A. (2002). Shared mental models, familiarity, and coordination: a multi-method study of distributed software teams. Proceedings of the Twenty-third International Conference on Information Systems, 425-433.

Evans, A.W., Harper, M.E. \& Jentsch, F. (2004). I know what you're thinking: Eliciting mental models about familiar teammates. In A. J. Cañas, J. D. Novak, F. M. González, (Eds.) Proc. of the First Int. Conference on Concept Mapping: Concept Maps: Theory, Methodology, Technology (pp. 1-6). Pamplona, Spain, University of Central Florida. 
OR Team Communication, Mental Models, and Situation Awareness 117

Flin, R., Yule, S., McKenzie, L., Paterson-Brown, \& Maran, N. (2006). Attitudes to teamwork and safety in the operating theatre. Journal of the Royal Colleges of Surgeons of Edinburg \& Ireland 4(3), 145-151.

Fracker, M. (1991). Measures of situation awareness: Review and future directions (Rep. No.ALTR-1991-0128). Wright Patterson Air Force Base, Ohio: Armstrong Laboratories, Crew Systems Directorate.

Frankel, A., Gardner, R., Maynard, L., Kelly, A. (2007). Using the communication and teamwork skills (CATS) assessment to measure health care team performance. Joint Commission Journal of Quality Patient Safety, 33(9), 549-558.

Furuta, K. \& Shu, Y. (2004). Team situation awareness and its assessment. The Seminar of JSPS-KOSEF Core University Program on Energy Science \& Technology Subtask CR04-2-2 “Advancement on Operation \& Maintenance for Nuclear Power Plant" November 1-2, 2004, Tohoku University, Sendai, Japan.

Gaba, D.M., Howard, S.K., Kevin, K.J., Fish. J., Smith . B.E., \& Sowb, Y.A. (2001). Experience Simulation-Based Training in Anesthesia Crisis Resource Management (ACRM): A decade of experience. Simulation Gaming, 32, 175-193.

Garbis C., \& Artman, H. (2004). Team situation awareness as communicative practices. In S. Banbury, \& S. Tremblay (Eds.), A cognitive approach to situation awareness: theory and application (pp. 275-296). Burlington, USA: Ashgate Publishing Company.

Glaser, G.B. (1978). Theoretical Sensitivity. Sociology Press, Mill Valley: CA.

Gorman, J. C., Cooke, N. J., Pedersen, H. P., Connor, O. O., \& Dejoode, J. A. (2005). Coordinated awareness of situation by teams (CAST): Measuring team situation 
OR Team Communication, Mental Models, and Situation Awareness 118 awareness of a communication glitch. Proceedings of the Human Factors and Ergonomics Society 49th Annual Meeting (pp. 274-277). Santa Monica, CA: HFES.

Gorman, J.C., Cooke, N.J., \& Winner, J.L. (2006). Measuring team situation awareness in decentralized command and control systems. Ergonomics, 49, 1312-1325.

Greenberg, C.C., Regenbogen, S. E., Studdert, D. M., Lipsitz, S. R., Roger,s S. O., Zinner, M. J. \& Gawande, A. A. (2007). Patterns of communication breakdowns resulting in injury to surgical patients. $J$ Am Coll Surg, 204(4), 533-40.

Grogan, E.L., Stiles, R.A., France, D.J., Speroff, T., Morris, J.A., Nixon, J.B., Gaffney, F.A., Seddon, R, \& Pinson, C.W. (2004). The impact of aviation-based teamwork training on the attitudes of health-care professionals, J Am Coll Surg, 199, 843848.

Guerlain, S., Adams, R., Turrentine, T. S., Guo, H., Collins, S. R. \& Calland, F. (2005). Assessing team performance in the operating room: development and use of a "black box" recorder and other tools for the intraoperative environment. Journal of American College of Surgery, 200(1), 29-37.

Gutwin, C. \& Greenberg, S. (2004). The Importance of awareness for team cognition in distributed collaboration. In E. Salas and S. M. Fiore (Eds.) Team Cognition: Understanding the factors that drive process and performance (pp. 177-201). Washington: APA Press.

Gutwin, C. \& Greenberg, S. (1996). Workspace awareness for groupware. In M. Tauber (Ed.), Companion Proceedings of CHI'96: Human Factors in Computing Systems (pp. 208-209). New York: ACM Press. 
OR Team Communication, Mental Models, and Situation Awareness 119

Hammersly, M. \& Atkinson, P. (1995). Ethnography: principles in practice $\left(2^{\text {nd }}\right.$ ed.). Routledge: London.

Harris, K. T., Treanor, C. M. \& Salisbury, M. L. (2006). Improving patient safety with team coordination: challenges and strategies of implementation. Journal of Obstetric, Gynecologic, \& Neonatal Nursing, 35(4), 557-566.

Hazlehurst, B., McMullen, C. K. \& Gorman, P. N. (2007). Distributed cognition in the heart room: How situation awareness arises from coordinated communications during cardiac surgery. Journal of Biomedical Informatics, 40, 539-551.

Helmreich, R. \& Davies, J. M. (1996). Human factors in the operating room: interpersonal determinants of safety, efficiency and morale. Baillière's Clinical Anaesthesiology 10(2), 277-295.

Henderson, S., Mills, M., Hobbs, A., Bleakley, A., Boyden, J. \& Walsh, L. (2007). Surgical team self-review: Enhancing organizational learning in the royal cornwall hospital trust. In M. Cook, J. Noyes \& Y. Masakowski (Eds.). Decision Making in Complex Environments (pp. 259-267). Burlington: Ashgate Publishing Company.

Henneman, A., Lee, J., \& Cohen, J. (1995). Collaboration; a concept analysis. Journal of Advanced Nursing, 21, 103-109.

Hollan, J., Hutchins, E. \& Kirsh, D. (2000). Distributed cognition: Toward a new foundation for human-computer interaction research. ACM Transactions on Computer-Human Interaction, 7(2), 174-196.

Hood, M. (1985). Techniques in general thoracic surgery. Michigan: Saunders. Janis, I. L. (1972). Victims of groupthink. Boston: Houghton Mifflin Company. 
OR Team Communication, Mental Models, and Situation Awareness 120

Jeong, A.C. (2003). The sequential analysis of group interaction and critical thinking in online threaded discussions. The American Journal of Distance Education, 17(1), $25-43$

The Joint Commission (2009). Sentinel events. Retrieved August 21, 2009 from: http://www.jointcommission.org/ SentinelEvents/Statistics/ jcaho.

The Joint Commission (2008) The accreditation of healthcare organizations (JCAHO). Retrieved Sept 252008 from: http://cms.h2e-online.org/ee/regsandstandards.

Kaber, D. B. \& Endsley, M. R. (1998) Team situation awareness for process control safety and performance. Process Safety Progress, 17(1), 43-48.

Klimoski R. \& Mohammed, S. (1994). Team mental model: construct or metaphor? Journal of Management, 20, 403-437.

Kohn L. T., Corrigan J. M. \& Donaldson, M. S. (2000). To err is human: Building a safer health system. Washington, DC: National Academy Press.

Kraiger, K, \& Wenzel L. H. (1997). A framework for understanding and measuring shared mental models of team performance and team effectiveness. In E. Salas, M.T. Brannick, \& C. Prince (Eds.), Team performance assessment and measurement: Theory, methods, and applications (63-84). Hillsdale, NJ: Erlbaum.

Kiekel, P. A., Cooke, N.J., Foltz, P. W., \& Shope, S. M. (2001). Automating measurement of team cognition through analysis of communication data. In M. J. Smith, G. Salvendy, D. Hams, \& R. J. Koubek (Eds.), Usability evaluation and interface design, (pp. 1382-1386). Mahwah, NJ: Erlbaum. 
OR Team Communication, Mental Models, and Situation Awareness 121

Langan-Fox, J., Anglim, J. \& Wilson, J. R. (2004). Mental models, team mental models and performance: Process, development, and future directions. Human Factors and Ergonomics in Manufacturing, 14(4), 331-352.

Langan-Fox, J., Code, S. \& Langfield-Smith, K. (2000). Team mental model techniques, methods, and analytic approaches. Human Factors, 42, 242-271.

Leape, L. L \& Berwick, D. M. (2005). Five years after to err is human: What have we learned? JAMA, 293, 2384-2390.

Leonard, M., Graham, S. \& Bonacum, D. (2004). The human factor: the critical importance of effective teamwork and communication in providing safe care. Qual Saf Health Care, 13, 85-90.

Lim, B \& Klein, K. (2006). Team mental models and team performance: A field study of the effects of team mental model similarity and accuracy. Journal of Organizational Behaviour, 27, 403-418.

Lingard, L., Espin, S., Whyte, S., Regeh, G., Baker, G. R., Reznick, R., Bohnen, J., Orser, B., Doran, D. \& Grober, E. (2004). Communication failures in the operating room: an observational classification of recurrent types and effects. Qual Saf Health Care, 13, 330-334.

Lingard, L., Garwood, S. \& Poenaru, D. (2004). Tensions influencing operating room team function: does institutional context make a difference? Medical Education; $38,691-699$.

Luft, J. \& Ingham, H. (1955). The Johari window: A graphic model of interpersonal awareness. Proceedings of the western training laboratory in group development. Los Angeles: UCLA. 
OR Team Communication, Mental Models, and Situation Awareness 122

Makary, M, Sexton, B., Freischlag, J., Holzmueller, C., Millman, A., Rowen, L. \& Pronovost, P. (2006). Operating room teamwork among physicians and nurses: Teamwork in the eye of the beholder. J Am Coll Surg, 202, 746-752.

Mathieu, J. E., Heffner, T. S., Goodwin, G. F., Cannon-Bowers, J.A. \& Salas, E. (2004). Scaling the quality of teammates' mental models: Equifinality and normative comparisons. Journal of Organizational Behavior, 26(1), $37-56$.

McGowan, A., \& Banbury, S. (2004). Evaluating interruption-based techniques using embedded measures of driver anticipation. In S. Banbury and S. Tremblay (Eds.), A Cognitive approach to situation awareness (pp. 176-192). Aldershot, UK: Ashgate.

Mickan, S. M., \& Rodger, S. A. (2005). Effective health care teams: A model of six characteristics developed from shared perceptions. Journal of Interprofessional Care, 19(4), 358-370.

Mohammed, S. \& Dumville, B.C. (2001). Team mental models in a team knowledge framework: expanding theory and measurement across disciplinary boundaries. Journal of Organizational Behavior, 22, 89-106.

O'Conner, D. L., \& Johnson, T. E. (2006). Understanding team cognition in performance improvement teams: A meta-analysis of change in shared mental models. In A.J. Cañas \& J.D. Novak (Eds.). Concept Maps: Theory, Methodology, Technology, Proceedings of the Second Int. Conference on Concept Mapping. San José, Costa Rica. 
Orasanu, J. (1994) Shared problem models and flight crew performance. In: Johnston, N., McDonald, N., Fuller, R. (Eds.), Aviation psychology in practice (pp. 255-285). Aldershot, UK: Ashgate.

Mogford, R. H. (1997). Mental models and situation awareness in air traffic control. International Journal of Aviation Psychology, 7(4), 331-341.

Moray, N. (1990). A lattice theory approach to the structure of mental models. Philosophical

Transactions of the Royal Society of London, Series B, 327(1241), 577-583.

Moss, J., Xiao, Y. (2004). Improving operating room coordination: communication pattern assessment. Journal of Nursing Administration, 34(2), 93-100.

Paris, C. R., Salas, E., and Cannon-Bowers, J. A (2000). Teamwork in multi-person systems: a review and analysis. Ergonomics, 43(8), 1052-1075.

Parush, A., Momtahan, K., Foster-Hunt, T., Kramer, C., Holm, C., and Nathan, H. (2008). Critical information flow analysis in the cardiac operating room. In the Proceedings of the International System Safety Conference. Vancouver, BC, Canada.

Parush, A., Momtahan, K., Kramer, C., Foster-Hunt, T., Sohmer, B., Nathan, H. (2009). Communication Indicators for Team Situation Awareness in the Cardiac OR: Implications for augmentative technology. Submitted for publication.

Patel, V., Cytryn, K., Shortliffe, E. \& Safran, C. (2000). Research Basic to Medical Education: The Collaborative Health Care Team: The Role of Individual and Group Expertise. Teaching and Learning in Medicine, 12(3), 117 - 132. 
OR Team Communication, Mental Models, and Situation Awareness 124

Pew, R. W. (2000). The state of situation awareness measurement: Heading toward the next century. In M. R. Endsley, \& D. J. Garland (Eds.), Situation Awareness Analysis and Measurement (pp.33-47). Mahwah, NJ: Lawrence Erlbaum Associates Inc.

Pomerantz, A. \& Fehr, B.J. (1997). Conversation Analysis: An Approach to the Study of Social Action as Sense Making Practices. In van Dijk, T. A. (Ed) Discourse as Social Interaction. London: Sage Publications, 64-91.

Rassmussen, J. (1979). On the structure of knowledge: A morphology of mental models in a man-machine system context (Report No. RISWM-2192). Roskilde, Denmark: Risa National Laboratory.

Rasmussen, J. (1986). Information processing and human-nachine interaction: An approach

To cognitive engineering, Chapter 10, Amsterdam: Elsevier.

Reason, J. (1995). Understanding adverse events: Human factors. Qual. Health Care $4(2): 80-89$

Reddy, M., Dourish, P., \& Pratt, W. (2001). Coordinating heterogeneous work: Information and representation in medical Care. Proceedings of European Conference on Computer Supported Cooperative Work (pp. 239-258). September 16-20, Bonn, Germany.

Reddy, M., Pratt, W., Dourish, P., \&, Shabot, M.M. (2003). Sociotechnical requirements analysis for clinical systems. Methods Inf Med, 42, 437-44. 
OR Team Communication, Mental Models, and Situation Awareness 125

Reddy, M. C., \& Spence, P.R. (2008). Collaborative information seeking: A field study of a multidisciplinary patient care system. Information Processing and Management 44, 244-255.

Rentsch J. R. \& Hall R. J. (1994). Members of great teams think alike: A model of team effectiveness and schema similarity among team members. In M.M. Beyerlein \& D.A. Johnson (Eds.), Advances in interdisciplinary studies of work teams, vol.1. Series on Self-managed Work Teams (pp. 223-262). Greenwich, CT: JAI Press.

Rentsch, J. R. \& Klimoski, R .J. (2001). Why do 'great minds' think alike?: Antecedents of team member schema agreement. Journal of Organizational Behavior, 22, 107 120.

Rouse, W. B. \& Morris, M. M. (1986). On looking into the black box: Prospects and limits in the search for mental models. Psychological Bulletin, 100, 349-363.

Sacks, H., Schegloff, E. A., \& Jefferson, G. (1974). A simplest systematics for the organization of turn-taking for conversation. Language, 50, 696-735.

Sasse, M. A. (1991). How to t(r)ap user's mental models. In M.J. Tauber \& D. Ackerman (Eds.), Mental models and human-computer interaction, 2 (pp. 59-79). Amsterdam: Elsevier.

Salas, E., Dickinson, T. L, Converse, S. \& Tannenbaum, S. I., (1992). Toward an understanding of team performance and training. In R. W. Swezey \& E. Salas (Eds.), Teams: Their training and performance (pp. 3-29). Norwood, NJ: Ablex,.

Salmon, P. M., Stanton, N. A., Jenkins, D. P., Walker, G. H., Young, M. S. \& Aujla, A. (2007). What really is going on? Review, critique and extension of situation 
OR Team Communication, Mental Models, and Situation Awareness 126 awareness theory. In D. Harris (Ed.), Engin. Psychol. and Cog. Ergonomics (45)62 (pp. 407-416). Springer, Berlin: Heidelberg.

Sarter, N. B. \& Woods, D. D. (1991). Situation awareness: A critical but ill-defined phenomenon. International Journal of Aviation Psychology, 1(1), 45 - 57.

Schramm W. (1954). How communication works. In the process and effects of mass communication. University of Illinois Press.

Sevdalis, N., Healey, A. \& Vincent, C. (2007). Distracting communications in the operating theatre. Journal of Evaluation in Clinical Practice, 13, 390-394.

Sexton, B., Helmreich, R., Glenn, D., Wilhelm, J., \& Merrit, A. (2000). Operating Room Management Attitudes Questionnaire (ORMAQ). The University of Texas at Austin Human Factors Research Project (Technical Report 00-2).

Siegal, S. \& Castellan, N.J. (Eds). (1988). Nonparametric statistics for the behavioral sciences (2nd ed.). United States: McGraw-Hill.

Shields, T. (2004). General Thoracic Surgery. Lippincott Williams \& Wilkins. pp. 524

Shu,Y., \& Furata K. (2002). Team situation awareness as a basis of team intention inference: Definition and framework. SICE 2002 Aug 5-7 Osaka.

Shu,Y., \& Furata K. (2005). An inference method of team situation awareness based on mutual awareness. Cognition, Technology and Work, 7(4), 272-287.

Sinreich, D., Gopher, D., Ben-Barak, S., Marmor, Y. \& Lahat, R. (2005). Mental models as a pratical tool in the engineer's toolbox. International Journal of Production Research, 43(14), 2977-2996.

Smith, K., Hancock, P.A. (1995). Situation awareness is adaptive, externally directed consciousness. Human Factors 37(1), 137-148. 
OR Team Communication, Mental Models, and Situation Awareness 127

Stanton, N.A., Salmon, P.M., Walker, G.H., Baber, C., \& Jenkins, D.P. (2005). Human factors methods: A practical guide for engineering and design. Burlington, USA: Ashgate Publishing Company.

Stanton, N. A., Stewart, R., Harris, D., Houghton, R. J., Baber, C., McMaster, R., Salmon, P., Hoyle, G., Walker, G. H., Young, M. S., Linsell, M., Dymott, R. \& Green, D. A. (2006). Distributed situation awareness in dynamic systems: Theoretical development and application of an ergonomics methodology. Ergonomics, 49(12-13), 1288-1311.

Stelfox, H. T., Palmisani, S., Scurlock, C., Orav, E. J. \& Bates, D.W. (2006). The "to err is human" report and the patient safety literature. Quality and Safety in Health Care, 15, 174-178.

Stout, R., Cannon-Bowers, J.A., \& Salas, E. (1996). The role of shared mental models in developing team situation awareness: Implications for training. Training Research Journal, 2, 85-116.

Taylor, R. M. (1989). Situational awareness rating technique (SART): The development of a tool for aircrew systems design. Proceedings of the AGARD AMP Symposium on Situational Awareness in Aerospace Operations, CP478. Seuilly-sur Seine: NATO AGARD.

Undre, S., Sevdalis, N., Healey, A. N., Darzi, A. \& Vincent, C. A. (2006). Teamwork in the operating theatre: Cohesion or confusion? Journal of Evaluation in Clinical Practice, 12(2), 182-189. 
Undre, S., Sevdalis, N., Healey, A. N., Darzi, A. \& Vincent, C.A. (2007). Observational teamwork assessment for surgery (OTAS): Refinement and application in urological surgery. World Journal of Surgery, 31, 1373-1381.

Walley, S.P., \& Shepherd, A. (1992). The task analysis process. In B. Kirwan, \& L.K. Ainsworth (Eds.), A guide to task analysis. Washington, DC: Taylor \& Francis, Inc.

Wallin, C., Meurling, L., Hedman, L., Hedega, J. \& Fellander-Tsai, L. (2007). Targetfocused medical emergency team training using a human patient simulator: Effects on behavior and attitude. Medical education, 41, 173-180.

Wegner, D. M. (1986). Transactive memory: A contemporary analysis of the group mind. In B. Mullen \& G. R. Goethals (Eds.), Theories of group behavior (pp. 185-205). New York: Springer-Verlag.

Wiegmann, D.A., Elbardissi, A.W., Dearani, J.A., Daly, R.C., \& Sundt $3^{\text {rd }}$, T.M. (2007). Disruptions in surgical flow and their relationship to surgical errors: an exploratory investigation. Surgery, 142, 658-665.

Weil, S., Foster, P., Freeman, J., Carley, K., Diesner, J., Franz, T., Cooke, N., Shope, S., \& Gorman, J. (n.d.). Converging approaches to automated communications-based assessment of team situation awareness. 2-48.

West, M. A. \& Field, R. (1995). Teamwork in primary health care: Perspectives from organizational psychology. Journal of Interprofessional Care, 9(2), 117-122. The World Health Organization (2008). Safe Surgery Saves lives. Retrieved Sept 16, 2008 from: 
OR Team Communication, Mental Models, and Situation Awareness 129

http://www.who.int/patientsafety/safesurgery/knowledge_base/bibliography9/en/i ndex.html. 
Appendix A

Questionnaire and Demographics

\section{Operating Room Management Attitudes Questionnaire (ORMAQ)}

Please Rate Teamwork with team members using the following scale:

\begin{tabular}{|c|l|l|l|c|}
\hline A & \multicolumn{1}{|c|}{ B } & \multicolumn{1}{c|}{ C } & D & E \\
\hline Very Low & Low & Adequate & High & Very High \\
\hline
\end{tabular}

1. Surgical Attendings

5. Anesthesia Attendings

9. Perfusionists

2. Surgical Residents

6. Anesthesia Residents

10.Anesthesia/Perfusionist

3. Surgical OR Nurses

7. CRNAs

11.Nursing Assistants

4. Surgical Scrub Techs

8. CRNA Students

12. Department Leadership

Operating Room Teamwork during your Last Surgical Case:

\begin{tabular}{|c|l|l|l|c|}
\hline A & \multicolumn{1}{|c|}{ B } & \multicolumn{1}{|c|}{ C } & D & E \\
\hline Very Low & Low & Adequate & High & Very High \\
\hline
\end{tabular}

1. A team concept \& environment for open communications was established and maintained.

2. Workload and task distribution were clearly communicated and acknowledged by team members.

3. Communication between anesthesia and surgical teams was established and maintained (changes in the course of events were communicated as appropriate).

4. The team worked in a timely manner that avoided complications.

5. The use of social conversation, humor, teaching, music, etc., was appropriate to the specific situation (briefly explain your rating below): 
OR Team Communication, Mental Models, and Situation Awareness 131

6. Did you receive a preoperative briefing? ( Yes / No )

7. If yes, did it address team coordination and planning for potential problems? ( Yes / No )

8. Were you aware of any errors during the last operation? ( Yes / No )

9. Did you receive a postoperative debriefing? ( Yes / No )

10. If yes, did it debrief any errors you may have seen? ( Yes / No / Not Applicable)

11. Did you observe any conflict (e.g., unresolved disagreement, open disagreement over strategy, mismatched personalities, etc)? ( Yes / No )

If yes, was it managed effectively? ( Yes / No ) Explain:

Rate the following statements using the scale below:

\begin{tabular}{|l|l|l|l|l|}
\hline A & \multicolumn{1}{|c|}{ B } & C & \multicolumn{1}{c|}{ D } & E \\
\hline $\begin{array}{l}\text { Disagree } \\
\text { Strongly }\end{array}$ & $\begin{array}{l}\text { Disagree } \\
\text { Slightly }\end{array}$ & Neutral & Agree Slightly & Agree Strongly \\
\hline
\end{tabular}

Teamwork and Communication (12 Items)

12. I I I try to be a person with whom others will enjoy working.

13. __ OR team members share responsibility for prioritizing activities in high workload situations.

14. As long as the surgery is successful, I don't care what others think of me. 
OR Team Communication, Mental Models, and Situation Awareness 132

15. I enjoy working as part of a team.

15. ___ I am ashamed when I make a mistake in front of other team members.

17. OR team members from other specialties do not interfere with my work.

18. It in insulting to wait unnecessarily for other members of the OR team.

19. In my opinion, the surgeon and the anesthetist maintain open channels of communication throughout the procedure.

20. During any given operation, I know the first and last names of every OR team member.

21. I I have the support I need from other team members to care for our patients.

22. This hospital encourages teamwork and cooperation among its OR team members.

23. The concept of an OR team does not work in our hospital.

\section{Command Roles and Responsibilities (9 items)}

24. ___ Senior staff should encourage questions from junior medical and nonmedical staff during operations.

25. Junior OR team members should not question the decisions made by senior team members.

26. The senior surgeon should be formally in charge of the OR team during surgery. 
OR Team Communication, Mental Models, and Situation Awareness 133

27. The doctor's responsibilities include co-ordination between his or her team and other support areas.

28. Successful OR management is primarily a function of the doctor's medical and technical proficiency.

29. Team members should not question the decisions or actions of senior staff.

30. There are no circumstances where a junior team member should assume control of patient management.

31. __ Decision making in our OR's should include more input from team members than it does now.

32. __ Surgeons and Anesthetists in this hospital know and understand each other's respective responsibilities.

\section{Speak Up (5 items)}

33. It is better to agree with other OR team members than to voice a different opinion.

34. I I l let other team members know when my workload is becoming (or about to become) excessive.

35. ___ The culture in our OR's makes it easy to ask questions when there is something I don't understand.

36. ___ The culture of our department makes it difficult to speak up if I perceive a problem with patient management.

37. When our team is too busy, there are clear ways to ask for additional help. 
OR Team Communication, Mental Models, and Situation Awareness 134

\section{Briefings and Debriefings (3 items)}

38. A regular debriefing of procedures and decisions after an operation is an important part of teamwork.

39. A pre-operating session team briefing is important for safety and effective teamwork.

40. ___ OR Team members in leadership positions should verbalize their plans for procedures/actions and make sure that the information is understood and acknowledged.

\section{Feedback and Critique (4 items)}

41. The only people qualified to give me feedback are others of my own specialty.

42. It bothers me when OR team members from other specialties critique my performance.

43. I I f f _ _ _ eel that I receive appropriate feedback about my performance.

44. __ Disagreements in the OR are appropriately resolved, i.e., it is not "who" is right, but what is best for the patient.

\section{COMMENTS}

What are your top three recommendations for improving patient safety in the operating room with respect to teamwork? 
OR Team Communication, Mental Models, and Situation Awareness 135

Demographic Questionnaire

\section{Please answer the following questions:}

1. What is your current professional title (e.g., resident surgeon)?

2. How long have you had this title (e.g., years, months)?

3. How long have you worked at the General Hospital (e.g., years, months)?

4. How long have you specialized in Thoracic surgery?

5. Which team members do you tend to work with most often? (e.g., nurses)

6. Gender: Male Female

7. Age: $20-30 \quad 31-40 \quad 41-50$ Above 50

8. Ethnicity:

9. Native Language: English French Other

10. Please rate the complexity of the following surgeries using the following scale: 1 (simple) to 5 (complex)

Esophagoscopy
Mediastinoscopy
Bronchoscopy
Lobectomy/Thoracotomy

Esophagectomy Bullectomy/Pleurectomy Chest Lavage 
OR Team Communication, Mental Models, and Situation Awareness 136

Appendix B

Observed Thoracic Procedures

\section{Low Complexity Procedures}

Both an Esophagoscopy and a Bronchoscopy involve the examination of the inside of the esophagus or the lower airways for obstructions such as a tumor, using a flexible fiberoptic scope that transmits video images. Alone, each procedure is considered non-surgical, but is often used in conjunction with other invasive surgical procedures in order to examine the surgical site before incision. A Mediastinoscopy is slightly more invasive, and is most commonly used to detect or stage cancer. The procedure involves a small incision in the chest or neck, which allows the physician to directly see the organs inside, and to collect tissue samples (often lymph nodes) for laboratory study.

\section{High Complexity Procedures}

On the other end of the surgical spectrum, Lobectomy/Thoracotomies requires cutting through one or more major muscles of the chest wall to access and remove some portion of the pulmonary lobe. During VATS lobectomy, surgeons operate using elongated, narrow tools that enter the body through minor incisions (sometimes called 'ports') in the thorax. The parts being operated on are not directly visible by the naked eye but are captured by a fiberoptic thoracoscope. During an Esophagectomy the principal objective is to remove the esophagus, in order to remove cancerous tumors from the body. In most cases, the stomach is transplanted into the neck, taking the place originally occupied by the esophagus. In some cases, the removed esophagus is replaced by another hollow structure, such as the patient's colon. During a Bullectomy, enlarged bullae (air sacs in the lungs) are removed allowing the healthy air sacs in the lungs to 
expand and make breathing easier. The accompanying Pleurectomy is a surgical procedure to remove part of the pleura, the lining surrounding the chest cavity which cushions the lungs during respiration.

\section{Outlier Procedure}

A pulmonary, or chest Lavage is the "intentional drowning" or therapeutic whole-lung rinse, which involves pumping approximately 15 to 18 litres of Saline fluid into and back out of a patient's lungs (one Litre at a time) in order to clean them out, as a literal translation. This procedure is very rarely done at the Ottawa Hospital (i.e., once every two years). For this reason, the lavage was considered an outlier, was only considered in the analyses for purposes of comparison and is specifically indicated.

Five Phases of Thoracic Surgery

1. The first phase, lines and intubation, starts when the patient is brought into the OR, hooked up to all the necessary intravenous lines and hemodynamic monitors, sedated, and intubated for the ventilating machine. Here the nurses also do a manual count of all of their tools, and anesthesia administers the required medication to the patient.

2. The second phase, scope and patient position, involves the combined effort of surgery and anesthesia in the use of a camera scope inserted into the esophagus to check the placement of the Lumen tubes (used to selectively inflate and deflate the lungs during surgery) and to inspect the surgical site before incision. The patient then needs to be moved into the proper position (also referred to as the 'turn') depending on the type of procedure (e.g., lateral- on their side with one arm extended outwards). The turn is a multi-person effort, often requiring help 
OR Team Communication, Mental Models, and Situation Awareness 138

from other staff, as the patient is fully sedated and intubated. The team must use coordinated but mindful force, as not to dislodge the carefully place lumen tubes, risking a tear in the esophagus.

3. The third phase, patient prep (term used in the OR, short for preparation), is characterized by the administration of the sterilizing solution to the surgical site to prevent infection. Following prep, the patient is draped with sterile sheets, leaving only the surgical site exposed. Those involved in the surgery must also scrub at the sinks outside the OR to sterilize themselves, followed fully gowning in sterile robes and gloves. Once the team is ready to operate, protocol is that they go through their final checklist - called the pre-operative pause- where the patient's name, procedure, surgical site, administration of antibiotics (A.B.) and patient's consent is read aloud by one member to the team.

4. The fourth phase is the surgery itself, marked by the initial incision or skin cauterization, and carries over during the main procedure. While the specific surgical activities varied depending on the type of procedure, the phase of surgery encompasses this most invasive portion.

5. The fifth and final phase is the surgical close, marking the transition from one case to the next. This may involve requesting sutures or staplers to close the wound, inserting tubes in the chest for drainage, and calling for the next patient. At this point, the nurses also do the post-operative count to ensure no tools are left behind, and the patient is transferred into the care of the post-op nursing team. 


\section{Appendix C}

Distribution of Communication Content as a Function of Phase

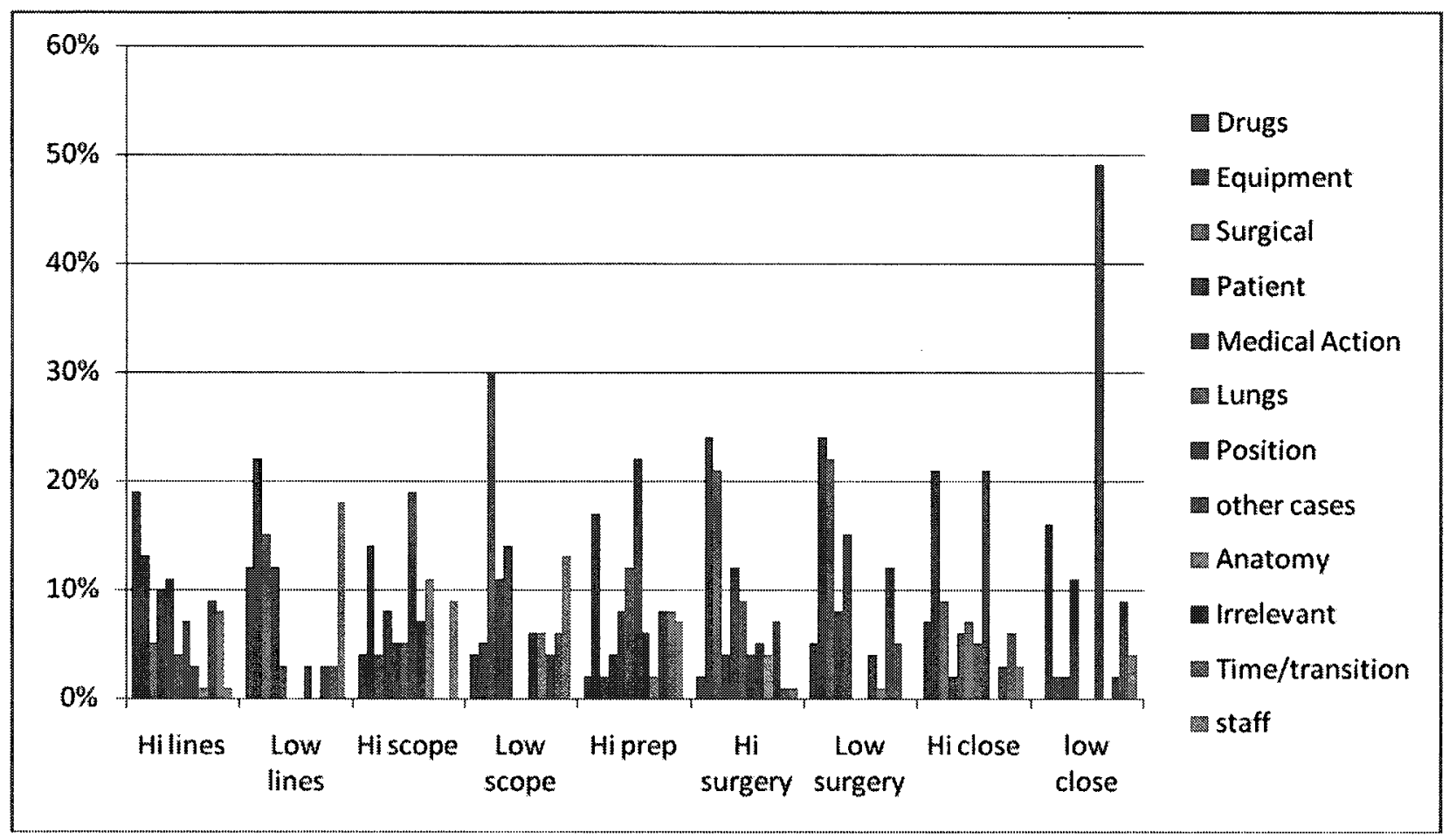




\section{Appendix D}

TMM-TSA Links

\section{Lungs: TSA Breakdowns}

\begin{tabular}{|c|c|c|}
\hline \multicolumn{2}{|c|}{ TMM Gap } & TSA Breakdown \\
\hline S11 & $\begin{array}{l}\text { S tells } A \text { when problems, updates } \\
\text { throughout } \\
\text { (Team/Task Related) }\end{array}$ & $\begin{array}{l}\text { S: Lung is inflating. Did you do something? } \\
\text { A: You are still ventilating? } \\
\text { S: Oh sure. }\end{array}$ \\
\hline $\mathrm{Al}$ & $\begin{array}{l}\text { Only communication if something } \\
\text { needs to be done, A will alert } S \text { if } \\
\text { needed } \\
\text { (Team/Task Related) }\end{array}$ & \\
\hline
\end{tabular}

\begin{tabular}{|l|l|l|}
\hline \multicolumn{2}{|l|}{ TMM Agreement } & TSA Breakdown \\
\hline S11 & $\begin{array}{l}\text { SF talk with A for special request, add } \\
\text { to RFA }\end{array}$ & $\begin{array}{l}\text { A: He wants it on the right, right? } \\
\text { CN: uhhhhh } \\
\text { A: I mean left, left }\end{array}$ \\
\hline A5 & $\begin{array}{l}\text { In OR, A will call S to ask about what } \\
\text { they what, eg, type of tube }\end{array}$ & \\
\hline N14 & $\begin{array}{l}\text { RFAs: S fills out when S booked (may } \\
\text { be weeks before), emerg has same day } \\
\text { request }\end{array}$ & \\
\hline
\end{tabular}

\begin{tabular}{|l|l|l|}
\hline \multicolumn{2}{|l|}{ TMM Gap } & TSA Breakdown \\
\hline S11 & $\begin{array}{l}\text { S tells A when problems, updates } \\
\text { throughout }\end{array}$ & $\begin{array}{l}\text { A: See all of a sudden, heart rate going up?! } \\
\text { S: [I'm] Stimulating [the heart] } \\
\text { A: Wake her up? } \\
\text { S: Ya }\end{array}$ \\
\hline A5 & $\begin{array}{l}\text { S don't always tell soon enough if } \\
\text { problem, depends on surgeon }\end{array}$ & \\
\hline
\end{tabular}

\section{Lungs: TSA Built/maintained}

\begin{tabular}{|l|l|l|}
\hline \multicolumn{2}{|l|}{ TMM Agreement } & TSA Maintained \\
\hline S12 & $\begin{array}{l}\text { 8am call into OR to give info necessary } \\
\text { for first case (e.g. Double lumen) }\end{array}$ & $\begin{array}{l}\text { A: Are we doing both? [check if S wants single or } \\
\text { double lumens] }\end{array}$ \\
\hline
\end{tabular}




\begin{tabular}{|l|l|l|}
\hline A9 & $\begin{array}{l}\text { A discuss with S plan of approach - } \\
\text { especially if non-routine or very sick } \\
\text { patient }\end{array}$ & $\begin{array}{l}\text { CN: No, he changed, just right } \\
\text { A: Okay, so just right lung then? } \\
\text { CN: Yes } \\
\text { A: Just wanted to make sure we're all on the same } \\
\text { page here }\end{array}$ \\
\hline N14 & $\begin{array}{l}\text { N checks with RFA (yellow sheets) - } \\
\text { contains S requests }\end{array}$ & \\
\hline
\end{tabular}

\begin{tabular}{|c|c|c|}
\hline \multicolumn{2}{|c|}{ TMM Agreement } & TSA Maintained \\
\hline S11 & $\begin{array}{l}\text { S tells A when problems, updates } \\
\text { throughout } \\
\text { Specialty of thoracic dictates lots of } \\
\text { communication - ortho not as much, } \\
\text { less talk with A } \\
\text { Time important, so A can plan when to } \\
\text { finish up } \\
\text { "Managing the patient together" }\end{array}$ & $\begin{array}{l}\text { S:He's coughing, but that's good } \\
\text { S: about another minute } \\
\text { A: He's coughing you said? } \\
\text { S: Ya, he's coughing }\end{array}$ \\
\hline A6 & $\begin{array}{l}\text { S should let A know how things going } \\
\mathrm{S} \text { alerts } \mathrm{A} \text { if doing something that will } \\
\text { affect hemodynamics (e.g., pressing on } \\
\text { heart) }\end{array}$ & \\
\hline
\end{tabular}

\begin{tabular}{|l|l|l|}
\hline \multicolumn{2}{|l|}{ TMM Agreement } & TSA Maintained \\
\hline A8 & S tells A to drop lungs & $\begin{array}{l}\text { S: How's she doing on one lung? } \\
\text { A: Good }\end{array}$ \\
\hline N10 & $\begin{array}{l}\text { Thoracic needs communication, } \\
\text { outcome of surgery is more intense, } \\
\text { stressful, life threatening }\end{array}$ & $\begin{array}{l}\text { S: Pushing on the heart a bit } \\
\text { S: Pushing on the heart a bit }\end{array}$ \\
& & $\begin{array}{l}\text { S: Going to be asking you to puff up lung } \\
\text { A: ok }\end{array}$ \\
& & $\begin{array}{l}\text { S: ok puff up } \\
\text { A: Going to check to make sure we're not } \\
\text { compromising }\end{array}$ \\
& & S: Okay, drop again \\
& & \\
& &
\end{tabular}

\begin{tabular}{|l|l|l|}
\hline \multicolumn{2}{|l|}{ TMM Agreement } & TSA Maintained \\
\hline S11 & Patient is well-managed from both & S: Can we start? Lungs down? \\
& $\begin{array}{l}\text { sides } \\
\end{array}$ & A: ya \\
& $\begin{array}{l}\text { S tells A when problems, updates } \\
\text { throughout }\end{array}$ & S: Any problems up top? \\
& $\begin{array}{l}\text { Specialty of thoracic dictates lots of } \\
\text { communication }\end{array}$ & A: no problems \\
\hline
\end{tabular}




\begin{tabular}{|l|l|l|}
\hline A1 & $\begin{array}{l}\text { A may ask S if they wants lungs down, } \\
\text { or S may request from A } \\
\text { A \& S ask each other if they are happy } \\
\text { with things }\end{array}$ \\
\hline A6 & $\begin{array}{l}\text { S asks team " Can I start?" - S asking A } \\
\text { if patient is reacting to anything.. } \\
\text { Doesn't always happen, usually just } \\
\text { more experienced Ss do this }\end{array}$ & $\begin{array}{l}\text { S will confirm lungs down with A, if A } \\
\text { on the "ball" this will be done already, } \\
\text { but may have to do it when S asks. } \\
\text { A will check over curtain to see how } \\
\text { things are going }\end{array}$ \\
\hline
\end{tabular}

\begin{tabular}{|l|l|l|}
\hline \multicolumn{2}{|l|}{ TMM Agreement } & TSA Maintenance \\
\hline S12 & $\begin{array}{l}\text { Ask A how things going, if okay to } \\
\text { extubate - constant checking in }\end{array}$ & $\begin{array}{l}\text { S: How are we doing over there? } \\
\text { A: Not bad } \\
\text { S: Are you worried about saturation? } \\
\text { A: Ya, a bit. }\end{array}$ \\
\hline A1 & $\begin{array}{l}\text { A will check over curtain to see how } \\
\text { things going }\end{array}$ & \\
\hline
\end{tabular}

\section{Positioning: TSA Breakdowns}

\begin{tabular}{|c|c|c|}
\hline \multicolumn{2}{|c|}{ TMM Agreement } & TSA Breakdown \\
\hline S7 & $\begin{array}{l}\text { S in charge of the turn, but } A \text { is at } \\
\text { head, does the } 1-2-3\end{array}$ & $\begin{array}{l}\text { S: Ok let's turn } \\
\text { A: } 1-2-3 \\
\text { S: No, no I'm not in yet!! } \\
\text { S: Ok, now you can tighten. }\end{array}$ \\
\hline A8 & $\begin{array}{l}\text { Move takes } 2-3 \text { steps; A rallies for } \\
\text { turn, keeps track of lines \& tubes; } \\
\text { Whoever holding head is the leader } \\
\text { (should be A) } 1,2,3 \text {; A counts "on } \\
\text { my count, going to turn" }\end{array}$ & $\begin{array}{l}\text { S: Move the thing, move the }- \text { [BANG, patient hits } \\
\text { SN's table, equipment falls] }\end{array}$ \\
\hline
\end{tabular}

\section{Positioning: TSA Built/maintained}

\begin{tabular}{|l|l|l|}
\hline \multicolumn{2}{|l|}{ TMM Agreement } & TSA Built and Maintained \\
\hline S7 & $\begin{array}{l}\text { S in charge of the turn, but A is at } \\
\text { head, does the } 1-2-3\end{array}$ & $\begin{array}{l}\text { A: Tu près? Ready to move patient? } \\
\text { S: [nods, comes over] } \\
\text { A: Is everyone ready to turn? }\end{array}$ \\
\hline
\end{tabular}




\begin{tabular}{|l|l|l|}
\hline & (Team related/Task Specific) & $\begin{array}{l}\text { S: On 3, 1-2-3 } \\
\text { [patient turned on side] }\end{array}$ \\
\hline A1 & $\begin{array}{l}\text { Turn: No clear leader, but surgeon } \\
\text { should be directing, but may be A } \\
\text { (whoever is at head) - depends on S }\end{array}$ & \\
\hline
\end{tabular}

\begin{tabular}{|l|l|l|}
\hline \multicolumn{2}{|l|}{ TMM Agreement } & TSA Built and Maintained \\
\hline S12 & $\begin{array}{l}\text { S and A negotiate the patient's } \\
\text { position }\end{array}$ & $\begin{array}{l}\text { CN1: S wants arms tucked cuz he's wider } \\
\text { AR: Are you going to take pillows? } \\
\text { A: I"ll hold head, you take pillow (moving patient) }\end{array}$ \\
\hline A6 & $\begin{array}{l}\text { Move pat after scoping } \\
\text { Nurse calls for PCA(s) to help, }\end{array}$ & S: He's right against foot rest? \\
& Nurse initiates turn & CN1: ya \\
& & A: Need some fluffies? \\
\hline N3 & Move: when done scope, and A done & A: Let's get a pillow under the knees \\
& with lines; & S: Is that okay? \\
& CN pages attendant & S: Yes fine, he'll be in reverse tralelenberg for most \\
& & A: of case, so as long as it doesn't buckle knees \\
\hline
\end{tabular}

\begin{tabular}{|l|l|l|}
\hline \multicolumn{2}{|l|}{ TMM Agreement } & TSA Built and Maintained \\
\hline S7 & $\begin{array}{l}\text { S in charge of the turn, but A is at } \\
\text { head, does the 1-2-3 count }\end{array}$ & $\begin{array}{l}\text { S: Can you just wait till we position him, then you } \\
\text { can do whatever you are doing? } \\
\text { A:Tu pret? ready to move patient? }\end{array}$ \\
\hline A1 & $\begin{array}{l}\text { Turn: No clear leader, but surgeon } \\
\text { should be directing, but may be A } \\
\text { (whoever is at head) - depends on S }\end{array}$ & $\begin{array}{l}\text { S: nods, comes over } \\
\text { A: prepare to move patient on 3 } \\
\text { A:Is everyone ready to turn? }\end{array}$ \\
\hline A6 & $\begin{array}{l}\text { S may initiate if in hurry - ask ready } \\
\text { A: on 3, 1-2-3 (patient on side) } \\
\text { Whoever holding head is the leader } \\
\text { (should be A) 1,2,3 }\end{array}$ & \\
\hline
\end{tabular}

\section{Procedure: TSA Breakdowns}

\begin{tabular}{|l|l|l|}
\hline TMM Gap & TSA Breakdown \\
\hline S11 & $\begin{array}{l}\text { SF is in OR ahead of staff, } \\
\text { confirms with team }\end{array}$ & $\begin{array}{l}\text { A: Can we start now, or are we waiting for your } \\
\text { people? } \\
\text { A: Cuz we don't want to have patient falling } \\
\text { asleep for 15 minutes for no reason (A is annoyed) } \\
\text { SF: Ya, just waiting for [S] }\end{array}$ \\
\hline A5 & $\begin{array}{l}\text { S may announce how much time } \\
\text { left (e.g. 20 min then done) } \\
\begin{array}{l}\text { When S enters, A and S discuss } \\
\text { face to face }\end{array}\end{array}$ & \\
\hline
\end{tabular}




\begin{tabular}{|l|l|l|}
\hline N14 & $\begin{array}{l}\text { Constant communication } \\
\text { regardless of surgery, always tense }\end{array}$ & \\
\hline
\end{tabular}

\begin{tabular}{|l|l|l|}
\hline \multicolumn{2}{|l|}{ TMM Gap } & TSA Breakdown \\
\hline S7 & $\begin{array}{l}\text { *Does NOT like constant chatter } \\
\text { of team - that is why turns on } \\
\text { music; } \\
\text { Talks to SF throughout, instructs } \\
\text { what to do/coaches }\end{array}$ & $\begin{array}{l}\text { S: this is not set up correctly } \\
\text { S: Okay, so we're okay with prep? } \\
\text { no response (S looks around) } \\
\text { S: One of you? (Ns talking, not paying } \\
\text { attention) }\end{array}$ \\
\hline S11 & $\begin{array}{l}\text { VATS - less tactile, can't work } \\
\text { from all directions - requires more } \\
\text { Communication } \\
\text { VATS vs Open: comm w/ A very } \\
\text { important, chest tube, need A help } \\
\text { with bronc during surgery - need } \\
\text { to see something they are working } \\
\text { on } \\
\text { Not big deal, not much } \\
\text { communication between staff \& } \\
\text { fellow, both know procedure }\end{array}$ & $\begin{array}{l}\text { S: Take near lung, no, I know where the lung } \\
\text { S: Take out your cherry dissector } \\
\text { S: Take out your cherry dissector } \\
\text { S: Take out your cherry dissector!! }\end{array}$ \\
\hline A6 & $\begin{array}{l}\text { Thoracic is example of "well oiled } \\
\text { machine" } \\
\text { everyone has to have good } \\
\text { communication, dealing so close to } \\
\text { heart/lungs }\end{array}$ & \\
\hline
\end{tabular}

\begin{tabular}{|l|l|l|}
\hline \multicolumn{2}{|l|}{ TMM Agreement } & TSA Breakdown \\
\hline S2 & $\begin{array}{l}\text { Towards end, S ... initiates close } \\
\text { communication and coordination } \\
\text { with A }\end{array}$ & $\begin{array}{l}\text { S: Thank you } \\
\text { [Surgeon leaves] }\end{array}$ \\
& $\begin{array}{l}\text { S tells team he is going to find PA } \\
\text { family and leaves. }\end{array}$ & $\begin{array}{l}\text { SN: Ya, we're finished } \\
\text { A: can never really tell, it's only 2:15...not sure } \\
\text { what's going on }\end{array}$ \\
& $\begin{array}{l}\text { Time important, so A can plan } \\
\text { when to finish up }\end{array}$ & \\
\hline A1 & $\begin{array}{l}\text { When next pat is called, A knows } \\
\text { to start pulling out and taking off } \\
\text { equipment } \\
\text { De-brief: S checks with A if okay } \\
\text { to leave, but not extensive unless } \\
\text { specific } \\
\text { A may anticipate time to close }\end{array}$ & \\
\hline
\end{tabular}




\begin{tabular}{|l|l|l|}
\hline N3 & $\begin{array}{l}\text { S may announce how much time } \\
\text { left (e.g. 20 min then done) }\end{array}$ & \\
& *More experienced S will know & \\
& how long they will take and let \\
others know & \\
A prefers S to tell how much time & is left - helps to know about when \\
& $\begin{array}{l}\text { to wake up, don't like to be } \\
\text { surprised }\end{array}$ & \\
\hline
\end{tabular}

\section{Procedure TSA: Built/maintained}

\begin{tabular}{|c|c|c|}
\hline \multicolumn{2}{|c|}{ TMM Agreement } & TSA Maintained \\
\hline S11 & $\begin{array}{l}\text { S tells A when closing - time to } \\
\text { finish } \\
\text { Time important, so A can plan } \\
\text { when to finish up }\end{array}$ & $\begin{array}{l}\text { S: Okay, time to go } \\
\text { S: art line? } \\
\text { A: Ya, then good to go } \\
\text { S: How long? 5-10 minutes? }\end{array}$ \\
\hline Al & $\begin{array}{l}\text { When next pat is called, A knows } \\
\text { to start pulling out and taking off } \\
\text { equipment } \\
\text { A may anticipate time to close }\end{array}$ & $\begin{array}{l}\text { A: Ask Dr. (AR) } \\
\text { AR: } 50 \text { sec } \\
\text { S: Okay I"ll be back } \\
\ldots \ldots \ldots \ldots \ldots \ldots \ldots \ldots \ldots \ldots \ldots\end{array}$ \\
\hline $\mathrm{N} 3$ & $\begin{array}{l}\text { Knows close when specimen come } \\
\text { out (lobectomy) }\end{array}$ & S: I'll be finished in $15 \mathrm{~min}$ \\
\hline
\end{tabular}

\begin{tabular}{|c|c|c|}
\hline \multicolumn{2}{|c|}{ TMM Agreement } & TSA Maintained \\
\hline S7 & $\begin{array}{l}\text { Talks to SF throughout, instructs } \\
\text { what to do/coaches } \\
\text { Will indicate time to close (e.g. } \\
\text { Closing in 10-15) }\end{array}$ & \multirow{3}{*}{$\begin{array}{l}\text { S: Let's get some epinepherine } \\
\text { S: You know we're using epi and saline right? } \\
\text { A: yep } \\
\text { S: Need to do another wash. send to psychology } \\
\text { CN: Checking if any more biopsy's? } \\
\text { S: We're finished with biopsy } \\
\text { A: Just a wash now left? } \\
\text { S: Yes, just wash } \\
\text { S: Looks good, clean out other side then call it a } \\
\text { day } \\
\text { S: Okay we're done. }\end{array}$} \\
\hline S11 & $\begin{array}{l}\text { Time important, so A can plan } \\
\text { when to finish up } \\
\text { SF own communication depends } \\
\text { on diff S. } \\
\text { Not much communication between } \\
\text { staff \& fellow, both know } \\
\text { procedure }\end{array}$ & \\
\hline A6 & $\begin{array}{l}\text { Everyone has to have good } \\
\text { communication, dealing so close to } \\
\text { heart/lungs } \\
\text { Thoracic is example of "well oiled } \\
\text { machine" } \\
\text { S may announce how much time } \\
\text { left (e.g. } 20 \text { min then done) } \\
\text { More experienced S will know } \\
\text { how long they will take and let }\end{array}$ & \\
\hline
\end{tabular}




\begin{tabular}{|l|l|l|}
\hline & others know & \\
\hline
\end{tabular}

\begin{tabular}{|l|l|l|}
\hline \multicolumn{2}{|l|}{ TMM Agreement } & TSA Maintained \\
\hline S2 & $\begin{array}{l}\text { Towards end, S leaves tubes in } \\
\text { chest cavity, tells N, initiates close } \\
\text { communication and coordination } \\
\text { with A }\end{array}$ & $\begin{array}{l}\text { S: This should be last part now (stapling) } \\
\text { S: One more please }\end{array}$ \\
\hline N10 & $\begin{array}{l}\text { Good S usually tell the time that } \\
\text { they will be closing in } \\
\text { You can't predict everything, CNs } \\
\text { need to leave OR a lot! }\end{array}$ & \\
\hline
\end{tabular}

\begin{tabular}{|l|l|l|}
\hline \multicolumn{2}{|l|}{ TMM Agreement } & TSA Maintained \\
\hline S11 & $\begin{array}{l}\text { S tells A when closing - time to finish; } \\
\text { Time important, so A can plan when to } \\
\text { finish up }\end{array}$ & $\begin{array}{l}\text { S: Okay, I'm going to pull back now } \\
\text { [indicating close] } \\
\text { A: Thanks. }\end{array}$ \\
\hline A6 & $\begin{array}{l}\text { A prefers S to tell how much time is left } \\
\text { - helps to know about when to wake up, } \\
\text { don't like to be surprised } \\
\text { (Team Related/ Task Specific) }\end{array}$ & \\
\hline
\end{tabular}

\section{Schedule SA: Breakdown}

\begin{tabular}{|c|c|c|}
\hline \multicolumn{2}{|c|}{ TMM Gap } & \multirow{3}{*}{$\begin{array}{l}\text { TSA Breakdown } \\
\text { S: oh it's this patient. They switched them around! } \\
\text { S: I thought we were doing an epidural?? } \\
\text { SF: It got moved up } \\
\text { S: They've got to stop switching the order - we'll } \\
\text { need a bronch - } \\
\text { S: Even the patient was told - when was it } \\
\text { changed? I left at } 6 . . \\
\text { S: I want a memo when they change the order } \\
\text { CN1: I'll tell [name]. }\end{array}$} \\
\hline S7 & $\begin{array}{l}\text { S will have briefed with SF night } \\
\text { before (or will do at sink during } \\
\text { scrub) } \\
\text { (Team related/ Task related) }\end{array}$ & \\
\hline $\mathrm{N} 1$ & $\begin{array}{l}\text { May try to switch case order if big } \\
\text { delays, make efficient. Pass info } \\
\text { onto Surgeons, but } 50 / 50 \text { if they } \\
\text { know or not, adapt as best they can } \\
\text { (Team related/Task specific) }\end{array}$ & \\
\hline
\end{tabular}




\begin{tabular}{|l|l|l|}
\hline S11 & $\begin{array}{l}\text { Schedule changes - meet Fridays to } \\
\text { discuss OR cases for next 2 weeks; } \\
\text { finalize changes }\end{array}$ & $\begin{array}{l}\text { S: They changed, I thought we were doing a } \\
\text { bullectomy! } \\
\text { A: Ya, two days in a row } \\
\text { who is not scheduled where patient in OR } \\
\text { [Brief about case] } \\
\text { Know day before if order changes, } \\
\text { unusual not to know change in same } \\
\text { day - but no system in place if that } \\
\text { does happen }\end{array}$ \\
\hline A1 & $\begin{array}{l}\text { Consent is signed and pat marked } \\
\text { before PA in OR }\end{array}$ & \\
\hline
\end{tabular}

\section{Schedule: TSA Built/maintained}

\begin{tabular}{|l|l|l|}
\hline \multicolumn{2}{|l|}{ TMM Agreement } & TSA Maintained \\
\hline S7 & $\begin{array}{l}\text { S will have briefed with SF night } \\
\text { before (or will do at sink during } \\
\text { scrub) }\end{array}$ & $\begin{array}{l}\text { S: Next is Bullectomy } \\
\text { CN1: I sent for the patient } \\
\text { [... }\end{array}$ \\
A: Briefing details of next case (patient details) \\
A: You want to do bronchoscopy, double lumen?
\end{tabular}

\section{Equipment: TSA Breakdowns}

\begin{tabular}{|l|l|l|}
\hline \multicolumn{2}{|l|}{ TMM Gap } & TSA Breakdown \\
\hline S11 & $\begin{array}{l}\text { If N's not usually with team, need to be } \\
\text { more vocal, ask for equipment, less } \\
\text { anticipation }\end{array}$ & $\begin{array}{l}\text { S: I"ll take the bronchs stapler } \\
\text { CN2: Is that green? } \\
\text { S: Green } \\
\text { [CN leaves OR] }\end{array}$ \\
\cline { 1 - 1 } N14 & $\begin{array}{l}\text { Surgeons don't know equipment as well } \\
\text { as nurses, don't always ask for what } \\
\text { they want }\end{array}$ & $\begin{array}{l}\text { S: } 4.8 ? \text { That's too big, we'll have to use blue } \\
\text { [CN2 Shows S equipment] }\end{array}$ \\
\hline
\end{tabular}




\begin{tabular}{|c|c|c|}
\hline \multicolumn{2}{|c|}{ TMM Gap } & TSA Breakdown \\
\hline S12 & $\begin{array}{l}\text { Complexity of case is a function of } \\
\text { ability to communicate effectively } \\
\text { Often starts, but does not complete } \\
\text { sentences (vats) }\end{array}$ & $\begin{array}{l}\text { S: we're going to need an endostapler } \\
\text { CN1: blue or green? } \\
\text { S: Is first one green or blue? } \\
\text { SN: blue I believe, but I'll check for you }\end{array}$ \\
\hline N3 & $\begin{array}{l}\text { Nurses always listening, not just } \\
\text { "staring" at team; } \\
\text { Anticipate tools needed, S might ask } \\
\text { SN, who asks CN, but CN has already } \\
\text { gotten it }\end{array}$ & $\begin{array}{l}\text { CN: Did you want a vascular? } \\
\text { S: Did I say blue? } \\
\text { SN:I don't know, I thought i heard blue } \\
\text { S: It's not what I say, it's what I mean (joke) } \\
\text { [looks back at us, wink] } \\
\qquad \ldots \ldots \ldots \ldots \ldots \ldots \ldots \ldots \ldots \ldots \ldots \ldots \\
\text { S: Can you pull out a bit? } \\
\text { AR: Is that good? } \\
\text { S: About } 5 \mathrm{~cm} \text { more } \\
\text { S: reload - wrong staple given } \\
\text { SN: I though this looked short, was in wrong } \\
\text { spot! } \\
\text { [CN leaves to get staples] }\end{array}$ \\
\hline
\end{tabular}

\begin{tabular}{|c|c|c|}
\hline \multicolumn{2}{|c|}{ TMM Gap } & TSA Breakdown \\
\hline S7 & S enter, checks own tools, pat's x-ray & $\begin{array}{l}\text { S:We'll need a vascular stapler please } \\
\text { CN: a GIA? }\end{array}$ \\
\hline N10 & $\begin{array}{l}\text { S don't always say what they mean - } \\
\text { don't' know equipment as well as nurses } \\
\text { "That's not what I wanted... Well it's } \\
\text { what you asked for...It's not what I say, } \\
\text { It's what I mean"... }\end{array}$ & $\begin{array}{l}\text { CN: ya the GLA, endogia } \\
\text { S: ya, the } 30 \\
\text { CN: short of long one? } \\
\text { S: ya that's good } \\
\ldots \ldots \ldots \ldots \ldots \ldots \ldots \ldots \ldots \ldots \ldots \ldots \ldots \ldots \ldots \ldots \ldots \ldots \\
\text { S: patient moving } \\
\text { S: "rock and ready please!" } \\
\text { S: Bronc stapler please } \\
\text { CN: ya } \\
\text { S: Still moving a bit } \\
\text { CN: what size tool? } 30,60 ? \ldots \\
\text { S: [distracted. no clear reply] }\end{array}$ \\
\hline
\end{tabular}

\begin{tabular}{|l|l|l|}
\hline \multicolumn{2}{|l|}{ TMM Gap } & TSA Breakdown \\
\hline S11 & SF own communication depends on diff & S: Okay, stapler now \\
& S. some tell everything, some just talk & S: green, no blue \\
& when needed & S: 60, blue \\
\hline N3 & Nurses always listening, not just & CN: I have a 14 \\
& "staring" at team & CN: Want re-loads on that? \\
& Anticipate tools needed, S might ask & S: Can we use green? \\
& SN, who asks CN, but CN has already & S: That's it, fire (when and where to staple) \\
& gotten it & \\
\hline
\end{tabular}




\section{Equipment TSA: Built/maintained}

\begin{tabular}{|l|l|l|}
\hline \multicolumn{2}{|l|}{ TMM Agreement } & TSA Maintained \\
\hline S11 & $\begin{array}{l}\text { If N's not usually with team, need to be } \\
\text { more vocal, ask for equipment, less } \\
\text { anticipation }\end{array}$ & $\begin{array}{l}\text { A: You guys need any blood or anything? } \\
\text { S:We've got lots, thanks } \\
\text { A: [asked to be informed about any issues]I } \\
\text { don't want to be hiding away back here" }\end{array}$ \\
\hline A5 & $\begin{array}{l}\text { A keeps ears open to maintain SA } \\
\text { (subtle hits of what is going on) } \\
\text { A listens to S's conversation: eg; asking } \\
\text { for unusual instruments }\end{array}$ & $\begin{array}{l}\text { Be aware of everything, A, S, supplies, } \\
\text { needed, anticipate } \\
\text { Use pref cards - but can't know } \\
\text { everything in advance }\end{array}$ \\
\hline
\end{tabular}

\begin{tabular}{|l|l|l|}
\hline \multicolumn{2}{|l|}{ TMM Agreement } & TSA Maintenance \\
\hline S7 & $\begin{array}{l}\text { S enter, checks own tools, pat's X-ray } \\
\text { Checks if own scope ready S will have } \\
\text { briefed with SF night before (or will do } \\
\text { at sink during scrub) }\end{array}$ & $\begin{array}{l}\text { S: Can we put foley in ounce you're tumen } \\
\text { (*intubated with lumen tube) } \\
\text { AR: Yes } \\
\text { S: You're not putting in central line are you? } \\
\text { A: No }\end{array}$ \\
\hline S11 & $\begin{array}{l}\text { A may pre-brief with A team/nurses b4 } \\
\text { pat in room, but not always } \\
\text { Consent is signed and pat marked } \\
\text { before PA in OR } \\
\text { Nurse inserts catheter }\end{array}$ & $\begin{array}{l}\text { S enters about now } \\
\text { N asks permission to insert Folley }\end{array}$ \\
\hline A6 & \\
\hline
\end{tabular}

\begin{tabular}{|c|c|c|}
\hline \multicolumn{2}{|c|}{ TMM Agreement } & TSA Maintenance \\
\hline $\mathrm{S} 2$ & $\begin{array}{l}\text { Towards end, } S \text { leaves tubes in chest } \\
\text { cavity, tells } \mathrm{N} \text {, initiates close } \\
\mathrm{S} \text { asks } \mathrm{N} \text { for two } 20 \text { inch tubes, also } \\
\text { signals close }\end{array}$ & $\begin{array}{l}\mathrm{CN} \text { : Anything you need? } \\
\text { A: No all good } \\
\text { A: Actually, might need a pressure bag }\end{array}$ \\
\hline N10 & $\begin{array}{l}\text { SA: Like babysitting = divided } \\
\text { attention } \\
\text { Auditory is primary, but communication } \\
\text { important, S needs to tell what they } \\
\text { need }\end{array}$ & $\begin{array}{l}\text { CN1: } 500 ? \\
\text { A: } 500, \text { ya. } \\
\ldots \ldots \ldots \ldots \ldots \ldots \ldots \ldots \ldots \ldots \ldots \ldots \ldots \ldots \ldots \ldots \ldots \ldots \ldots \ldots \ldots \\
\text { S: } 16 \mathrm{~mm} \text {, articulating green cartridge }\end{array}$ \\
\hline
\end{tabular}

\begin{tabular}{|l|l|l|}
\hline \multicolumn{2}{|l|}{ TMM Agreement } & TSA Maintained \\
\hline S11 & $\begin{array}{l}\text { If N's not usually with team, need to be } \\
\text { more vocal, ask for equipment, less } \\
\text { anticipation }\end{array}$ & $\begin{array}{l}\text { S: Need 1 size 16, that's all } \\
\text { CN1: Should be right there }\end{array}$ \\
\hline
\end{tabular}




\begin{tabular}{|l|l|l|}
\hline N14 & $\begin{array}{l}\text { N need to be aware of everything for A, } \\
\text { S, anticipate supplies needed }\end{array}$ & \\
\hline
\end{tabular}

\section{Pause: TSA Breakdowns}

\begin{tabular}{|l|l|l|}
\hline \multicolumn{2}{|l|}{ TMM Agreement } & TSA Breakdown \\
\hline S11 & $\begin{array}{l}\text { Needs at least one member from } \\
\text { every team - trust - that each other } \\
\text { will speak up if problem; }\end{array}$ & $\begin{array}{l}\text { CN1:[Patient name, allergies, procedure], } \\
\text { CN1: any a.b.?? } \\
\text { CN1: no? } \\
\text { A: no [delayed response] } \\
\text { [*S not present] }\end{array}$ \\
\hline A6 & $\begin{array}{l}\text { Everyone must be in room, rarely } \\
\text { does not happen }\end{array}$ & \\
\hline N3 & $\begin{array}{l}\text { Everyone should be there } \\
\end{array}$ & \\
\hline
\end{tabular}

\begin{tabular}{|l|l|l|}
\hline \multicolumn{2}{|l|}{ TMM Gap } & TSA Breakdown \\
\hline S2 & Pause: After scope and move; & CN:[Patient name, allergies, procedure] \\
A1 & $\begin{array}{l}\text { Pause is done before incision (but } \\
\text { varies, may forget pause!) }\end{array}$ & *SF not present \\
N3 & $\begin{array}{l}\text { Pause: usually occurs when scoping, } \\
\text { everyone should be there }\end{array}$ & \\
\hline
\end{tabular}

\begin{tabular}{|l|l|l|}
\hline \multicolumn{2}{|l|}{ TMM Agreement } & TSA Breakdown \\
\hline A5 & $\begin{array}{l}\text { *AB should be in 60 min prior, but } \\
\text { rarely happens. } \\
\text { No rule about saying "AB in", but } \\
\text { should be said. }\end{array}$ & $\begin{array}{l}\text { CN: [patient name. no allergies. No } \\
\text { Antibiotics. procedure name] }\end{array}$ \\
\hline N14 & $\begin{array}{l}\text { No time to admin ab in day care } \\
\text { admin - quick assessment, vitals, } \\
\text { gowns } \\
\text { AB policy, prior to incision, usually } \\
\text { A good, but not always }\end{array}$ & \\
\hline
\end{tabular}




\begin{tabular}{|c|c|c|}
\hline S11 & $\begin{array}{l}\text { *No certain person assigned to do } \\
\text { pause - can create delays when no } \\
\text { one steps up. Unsure who would } \\
\text { speak up; } \\
\text { May start pause late, e.g., already } \\
\text { scoping, S enters and asks if pause } \\
\text { done, nope; } \\
\text { Needs at least one member from } \\
\text { every team - trust - that each other } \\
\text { will speak up if problem; }\end{array}$ & \multirow[t]{3}{*}{$\begin{array}{l}\text { CN: pre-op pause. [name, procedure, allergies, } \\
\text { Antibiotics] } \\
\text { CN: A.B.?? (cough cough to get SF attention) } \\
\text { A: did not give clear response } \\
\text { S: Got everything there? } \\
\text { CN: ya } \\
\text { S; are you going to turn? } \\
\text { A: I guess we could } \\
\text { S: There's no need for Ansef (Antibiotic?) } \\
\text { SN: We already did the pause }\end{array}$} \\
\hline A5 & $\begin{array}{l}\text { After A scopes, } S \text { comes and scopes } \\
\text { again to check tube position; } \\
\text { CN announces pause: procedure, } \\
\text { side, } \mathrm{AB} \text { - everyone should be there } \\
\text { Pause may remind } \mathrm{A} \text { to but } \mathrm{AB} \text { in, } \\
\text { but if clear on chart will do before }\end{array}$ & \\
\hline N14 & $\begin{array}{l}\text { Pause: policy is that N does it, but } \\
\text { in thoracic, } \mathrm{S} \text { tends to lead show; } \\
\text { S excellent at doing pause. If they } \\
\text { don't hear pause before scrub, } \mathrm{S} \\
\text { will initiate it; } \\
\text { Pause should be repeated if new } \\
\text { person enters the room - role of } \mathrm{CN} \\
\text { to do this }\end{array}$ & \\
\hline
\end{tabular}

\begin{tabular}{|c|c|c|}
\hline \multicolumn{2}{|c|}{ TMM Agreement } & TSA Breakdown \\
\hline S11 & $\begin{array}{l}\text { Needs at least one member from } \\
\text { every team - trust - that each other } \\
\text { will speak up if problem; } \\
\text { If SF misses pause, will not ask } \\
\text { anyone to do it again for him, if he } \\
\text { knows it's been done, assumes } \\
\text { everything ok }\end{array}$ & \multirow{3}{*}{$\begin{array}{l}\begin{array}{l}\text { CN: pre op pause- name. surgery } \\
\quad \text { [complains about pause info] }\end{array} \\
\text { *SF not present } \\
\quad \ldots \ldots \ldots \ldots \ldots \ldots \ldots \ldots \ldots \ldots \ldots \ldots \ldots \ldots \ldots \\
\text { S: [Procedure name]; No need for antibiotics } \\
\text { S: [Ask the name of the patient } \\
\text { *A not present }\end{array}$} \\
\hline A6 & $\begin{array}{l}\text { Everyone must be in room, rarely } \\
\text { does not happen }\end{array}$ & \\
\hline N3 & Everyone should be there & \\
\hline
\end{tabular}

\section{Pause: TSA Built/maintained}

\begin{tabular}{|l|l|l|}
\hline \multicolumn{2}{|l|}{ TMM Agreement } & TSA Built and Maintained \\
\hline S7 & $\begin{array}{l}\text { S responsible for pause (but who is } \\
\text { supposed to say it and who says it } \\
\text { varies; }\end{array}$ & $\begin{array}{l}\text { CN1: nou do a pause? } \\
\text { S: Patient name, procedure, A.B. in? }\end{array}$ \\
\hline
\end{tabular}


OR Team Communication, Mental Models, and Situation Awareness 152

\begin{tabular}{|l|l|l|}
\hline A9 & $\begin{array}{l}\text { Everyone should be present for } \\
\text { pause }\end{array}$ & $\begin{array}{l}\text { A: yes } \\
\text { Everyone should be present, but } \\
\text { still loop holes even when done } \\
\text { perfectly }\end{array}$ \\
\hline N10 & $\begin{array}{l}\text { CN usually does, but varies, reads } \\
\text { off consent; } \\
\text { Pause done when all people in } \\
\text { room, after scrub or positioning }\end{array}$ & \\
\hline
\end{tabular}

\begin{tabular}{|c|c|c|}
\hline \multicolumn{2}{|c|}{ TMM Agreement } & TSA Built and Maintained \\
\hline S7 & $\begin{array}{l}\text { Pat name, procedure, } \mathrm{AB} \text { and } \\
\text { specific needs. Allergies not } \\
\text { officially part of pause, but nurses } \\
\text { usually say them } \\
\mathrm{S} \text { responsible for pause (but who is } \\
\text { supposed to say it and who says it } \\
\text { varies, } \\
\text { *Everyone should be present for } \\
\text { pause - S gets very mad if SF not } \\
\text { present (Team related/Task } \\
\text { specific) }\end{array}$ & $\begin{array}{l}\text { S: Patient name, procedure, A.B. In? } \\
\text { A: yes (re: } A B \text { ) }\end{array}$ \\
\hline A8 & $\begin{array}{l}\text { Pause: said by nurse } \\
\text { Those involved in Surgery should } \\
\text { be present for pause }\end{array}$ & \\
\hline N10 & $\begin{array}{l}\text { CN usually does, but varies, reads } \\
\text { off consent; } \\
\text { Pause done when all people in } \\
\text { room, after scrub or positioning }\end{array}$ & \\
\hline
\end{tabular}


Appendix E

\section{PARTICIPANT INFORMATION SHEET AND CONSENT}

Do multiple, large displays in the $\mathrm{OR}$ reduce error caused by communication interruptions?

INVESTIGATOR:

6026

INVESTIGATOR:

16035

CO-INVESTIGATOR: CO-INVESTIGATOR: CO-INVESTIGATOR:

:

Please read this Participant Information Sheet and Consent Form carefully and ask as many questions as you like before deciding whether to participate.
Avi Parush, PhD

Kathryn Momtahan, RN, PhD

Robert Elliott, MD, FRCPC

Pam Bush, RN, BScN

Ben Sohmer, MD, FRCPC
613-520-2600 ext

613-798-5555 ext

\section{INTRODUCTION}

The overall objective of this study is to design and test display concepts that can help reduce OR task interruptions due to the frequent need for information exchange. Specifically, the goals of the proposed study are to: 1) Map the information that is shared and/or exchanged among the OR team members and its consequences. This will be done by a review of the literature on communication patterns in the OR, and a task and communication episodes analysis based on observations and interviews; 2 ) design information displays that will be placed in various locations in the OR for the shared and member-specific critical information; and 3) test these display concepts in a research and training simulator in terms of changes in communication patterns and changes in adverse mishaps and human errors. The long-term objective is to influence medical device manufacturers, OR designers and administrators, and medical educators and policy makers to consider redesign and re-allocation of critical information in the OR. You are being asked to participate in the simulation exercise designed to test the new prototype information display.

\section{PROCEDURE}

The research approach in testing the new display concepts will be primarily based on realistic testing scenarios and the capture of all behaviours and actions and communications. You will be given an OR role to play (e.g., surgeon, anaesthesiologist, nurse, etc.) and will be introduced into the test scenarios in the Skills and Simulation Centre. While the scenario is in progress, all the activity will be audio and video recorded. You will also be asked to provide feedback on the design of the new display relative to the current displays available. The simulation exercise and feedback on the display design will take approximately 1.5 hours. 


\section{RISKS and DISCOMFORTS of PARTICIPATION}

There are no anticipated risks or discomforts involved in this study.

\section{Do multiple, large displays in the operating room reduce errors caused by communication interruptions?}

\section{BENEFITS OF PARTICIPATION}

There are no direct benefits of this study to you. However, we are hoping that the information we get will lead to improved display designs in the OR.

\section{COMPENSATION/RENUMERATION}

There is no monetary compensation to being in the study.

\section{CONFIDENTIALITY}

All records will be kept confidential. You will not be identified in any publications by name or initials. All data sheets and video and audio recordings will have your number only on them and they will be kept in a locked office. Once the analysis is complete, any audio and video recordings will be stored and disposed of after 15 years. Since the recordings are in the form of digital files, the files will simply be deleted in the same way that all computer files are deleted.

\section{TERMINATION OF THE STUDY}

Your participation is voluntary, and you may elect to refuse to participate or to discontinue participation at any time.

\section{ETHICS}

This study has been approved by the Hospital Research Ethics Board. The Board considers the ethical aspects of all research projects using human participants. If you wish, you may talk to the Chair, Human Research Ethics Board at 613-798-5555, extension 14902.

This study has also been approved by the Human Research Ethics Committee at Carleton University. If you wish, you may contact Dr. Janet Mantler (Chair, Carleton University Ethics Committee for Psychological Research; 613-520-2600, ext. 4173; janet_mantler@carleton.ca)

\section{PARTICIPATION}

\section{Participation in research is completely voluntary.}


You are free to choose whether to participate in this study or not. If you choose to participate, you may choose to withdraw your consent at any time. This will not impact your present or future employment at this hospital.

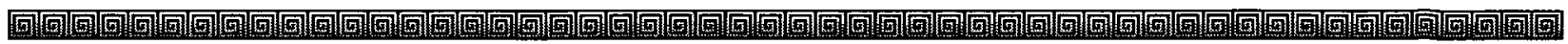

Do multiple, large displays in the operating room reduce errors caused by communication interruptions?

CONSENT TO PARTICIPATE IN RESEARCH

I understand that I am being asked to participate in a research study involving a simulation exercise in order to develop information displays to help with staff communications. I have read and understood this 3-page Participant Information Sheet and Consent Form. All of my questions at this time have been answered to my satisfaction. If I have any further questions about this study, I understand that I may contact the Principal Investigators Kathryn Momtahan, $\mathrm{RN}, \mathrm{PhD}$ at 613-798-5555, $\mathrm{x}$ 16035 or Avi Parush, PhD at Carleton University at 613-520 2600 ext. 6026.

I will receive a signed copy of this Consent Form and the attached Participant Information Sheet.

I voluntarily agree to participate in this study.

Participant's Name:

Participant's Signature: Date:

Name of Investigator/Delegate:

Signature of Investigator/Delegate:

Date:

* Name of hospital has been removed for confidentiality purposes. 